\title{
IMPACT OF SUTHERLANDIA FRUTESCENS ON HEPATIC STEATOSIS IN HIGH-FAT FED RATS
}

\author{
A Dissertation \\ presented to \\ the Faculty of the Graduate School \\ at the University of Missouri-Columbia \\ In Partial Fulfillment \\ of the Requirements for the Degree \\ Doctor of Philosophy \\ by \\ NHU Y NGUYEN \\ Dr. William R. Folk, Dissertation Supervisor \\ JULY 2018
}


The undersigned, appointed by the dean of the Graduate School, have examined the dissertation entitled

\section{IMPACT OF SUTHERLANDIA FRUTESCENS ON HEPATIC STEATOSIS IN HIGH-FAT FED RATS}

presented by Nhu Y Nguyen, a candidate for the degree of Doctor of Philosophy, and hereby certify that, in their opinion, it is worthy of acceptance.

Dr. William R. Folk, Dissertation Supervisor

Dr. Victoria J. Vieira-Potter

Dr. Laura C. Schulz

Dr. Dennis B. Lubahn

Dr. Matthew J. Will 


\section{ACKNOWLEDGEMENTS}

This doctoral dissertation is successfully completed with the tremendous help from the key people in my life.

First, I am greatly thankful to Dr. William R. Folk, my dissertation adviser, for his guidance and support for completion of my dissertation. It is an honor to work with him and learn to become an independent researcher under his mentorship.

Second, I wish to express my sincere appreciation to my committee members Drs. Victoria J. Vieira-Potter, Laura C. Schulz, Dennis B. Lubahn, and Matthew J. Will for their advice, consultation, and inspiration through my Ph.D. journey. Specifically, I have learned a great deal about leadership from Drs. Dennis Lubahn and Matthew Will, who are excellent leaders and mediators. Drs. Vieira-Potter and Schulz are the two gracious ladies and outstanding scientists that serve as my role models.

I want to thank the Vietnam Education Foundation - an independent U.S. Federal Government agency created by the U.S. Congress - for offering me a two-year fellowship as well as for giving me an opportunity to pursue my graduate studies at the University of Missouri.

Furthermore, I would like to thank Dr. Kevin L. Fritsche and members of his laboratory, as well as Ms. Sherrie Neff for their advice and assistance in the 
handling and sample collection of the rats. I want to thank Drs. Alexander Jurkevich and Dae Young Kim for assistance in performing analysis of liver histology, and Dr. Charles E. Wiedmeyer for analysis of plasma parameters. I also appreciate Drs. George E. Rottinghaus and Korey J. Brownstein for chemical analysis of bioactive compounds in Sutherlandia frutescens extracts. Furthermore, Dr. Kenneth E. Case (Regents Professor Emeritus of Industrial Engineering and Management at Oklahoma State University) and Ms. Lada Micheas are highly appreciated for their assistance and consultation in statistical analysis. Dr. Grace Y. Sun and her staff are thanked for helping with the ELISA plate reader.

My gratitude also goes to my mentees including Ethan Myers, Madeline Niemann, Connor Fraser, Tiffany Carsten, and other members in Dr. Folk's Lab for their help, cooperation, and friendship.

I sincerely thank the faculty and staff of the Genetics Area Program, Department of Biochemistry, School of Medicine, Division of Animal Sciences, and the International Center for their assistance in paperwork processing and logistics.

Moreover, I would love to extend my heartfelt appreciation to my spiritual friends and associates including, but not limited to, Hien D. Nguyen, Mai X. Ta, Ms. Chuc Hien, Ms. Phap Khai, Ms. Lan Nguyen \& her people, Linda, Gabi, Marsha, Carla, Brian, Armine, Donald, Dianne, Ellie, Na Nguyen, Jerry Nelson, Meta \& Melvin George, Hannah Linnenbringer, Richard Hull, Willi Provancha, F. 
E. (Red) \& Dorcas Leighton, and Merri Chapman for helping me during the journey to awakening, awareness, mindfulness, and enlightenment.

I am grateful to my masters and teachers, senior and junior colleagues for their patience, encouragement, and precious advice in helping me become a better person and scientist every single day. Sir. Samuel Xuan Nguyen, Dr. Kenneth \& Mrs. Lynn Case, Dr. Thuy Le, Dr. Lynne McNamara, Dr. Joseph Polacco, Dr. Jerry Nelson, Dr. Sarah Dunstan, Dr. Peter Horby, Dr. R. Scott Rector, and Dr. Elizabeth Parks are a special mention.

My life is beautifully colored and graciously blessed by the presence of my adorable and loveable angels. Indeed, I am the happy "auntie" of my little "friends" including Frances (my little "boss"), Savanna, Kaelyn, Rex, Cambel, Sebastian, Alexander, Olivia, Kynan, Acacia, Tintin, and Edward.

Lastly and most importantly, I am deeply indebted to my beloved family, especially my parents, who love me unconditionally and support me through thick and thin. Their love and support throughout my life is a source of valuable inspiration and great encouragement that helps me accomplish many life goals including this doctoral degree. 


\section{TABLE OF CONTENTS}

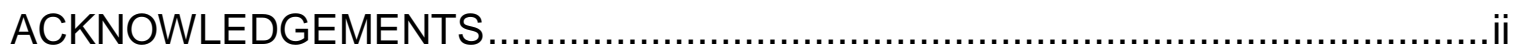

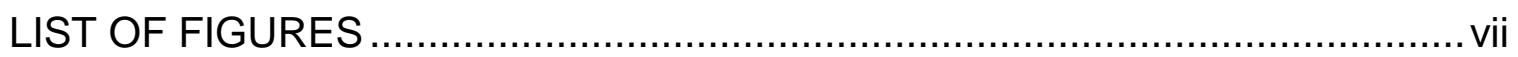

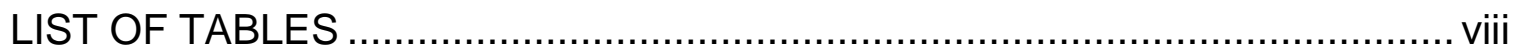

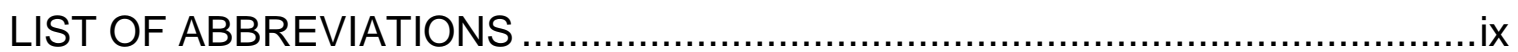

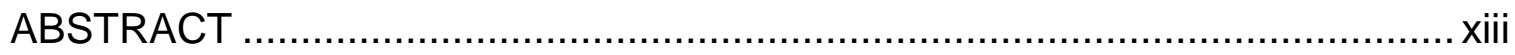

Chapter

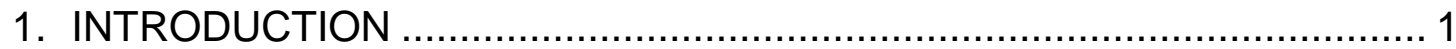

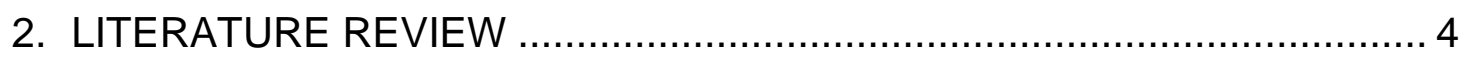

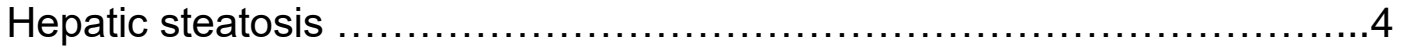

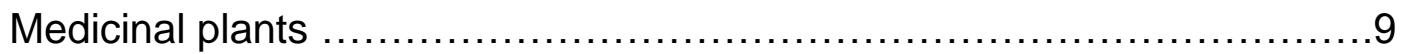

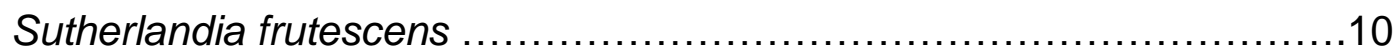

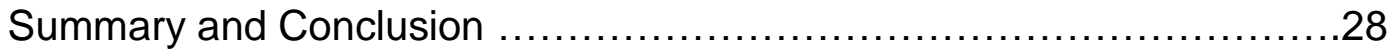

3. SUTHERLANDIA FRUTESCENS CONSUMPTION MITIGATES HEPATIC STEATOSIS BY INCREASING EXPRESSION OF FATTY ACID OXIDATION-RELATED GENES IN MALE WISTAR RATS FED A HIGH-

FAT DIET

Abstract 30

Introduction 32

Materials and Methods 33

Results 40

Discussion and Conclusion .56 
4. QUANTIFICATION OF SUTHERLANDIOSIDES BY INDIRECT

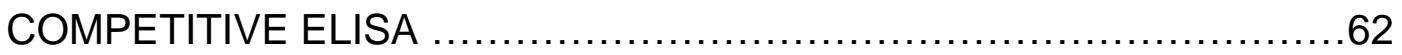

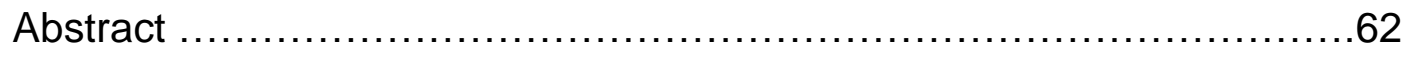

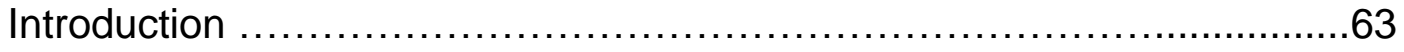

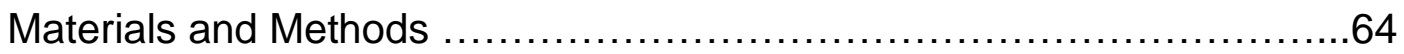

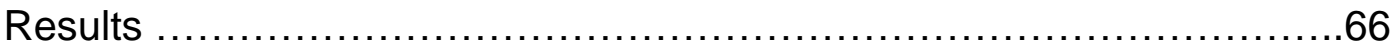

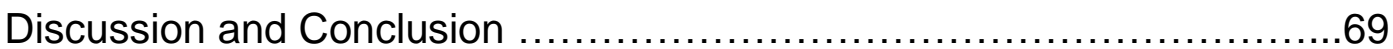

5. CONCLUSIONS AND FUTURE DIRECTIONS ...........................71

APPENDIX

3-1. DETERMINATION OF SUTHERLANDIOSIDE B FROM S. FRUTESCENS PLANT OR FROM S. FRUTESCENS AQUEOUS EXTRACTS ............... 75

3-2. VALIDATION OF TASTE AVERSION OF S. FRUTESCENS................ 79

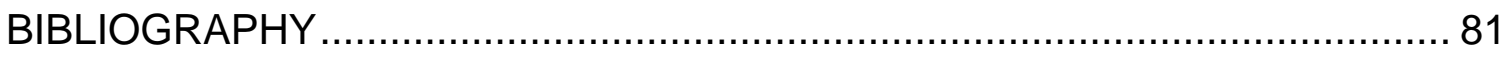

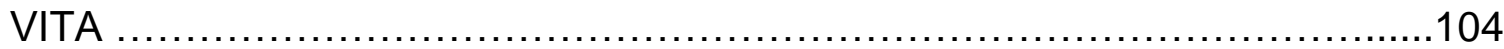




\section{LIST OF FIGURES}

\section{FIGURE}

2.1. Progression of non-alcoholic fatty liver disease (NAFLD) ........................6

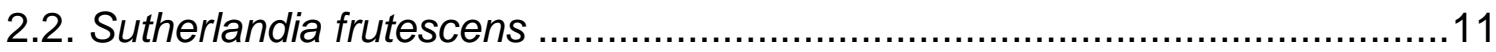

2.3. Chemical structures of A) D-pinitol, B) L-canavanine, and C) GABA .........13

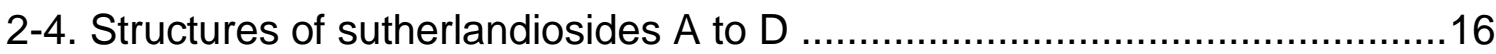

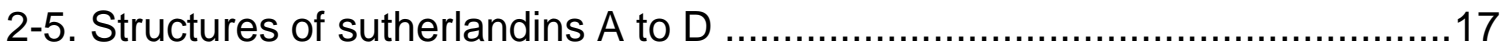

3-1. Effects of Sutherlandia on body weight $(A)$ and fasting liver weight $(B)$ of

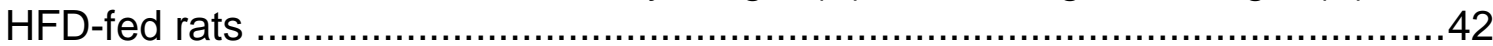

3-2. Effects of Sutherlandia on fasting plasma glucose (A), insulin (B), triglycerides (C), and free fatty acids (D) of HFD-fed rats

3-3. Inhibition of hepatic steatosis by Sutherlandia treatments in HFD-fed rats

3-4. Effects of Sutherlandia treatments on morphology of lipid droplets

3-5. Effects of Sutherlandia treatments on size and number of lipid droplets in livers of HFD-fed rats

3-6. Effects of Sutherlandia on mRNA expression of genes involved in hepatic lipid metabolism

3-7. Effects of Sutherlandia on mRNA expression of inflammatory genes .........56

4-1. Illustration of indirect competitive sutherlandioside ELISA …....................65

4-2. Standard curve development of sutherlandioside ELISA .........................66

\section{APPENDIX FIGURE}

3-1. Chromatograms of purified sutherlandiosides $B$ and $C$ from $S$. frutescens (Big Tree Nutraceutical) (A), sutherlandioside B in Sutherlandia tea (B), and sutherlandiosides B, C, and D in Pinosundia tea detected by the LC-ELSD (C) 


\section{LIST OF TABLES}

\section{TABLE}

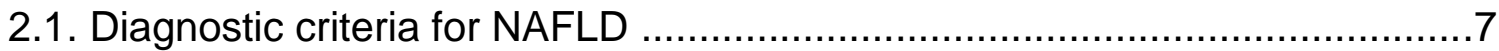

3-1. Sequences of primers used for rt-q PCR assays ..............................39

4-1. Quantitation of sutherlandiosides in rat plasma samples by indirect

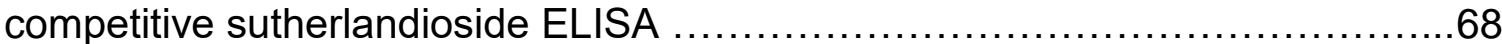




\section{LIST OF ABBREVIATIONS}

ACOX-1 Acyl-coenzyme A oxidase-1

AIDS Acquired immunodeficiency syndrome

ALT Alanine aminotransferase

ANOVA Analysis of variance

AP-1 Activator protein-1

AST Aspartate aminotransferase

BMI Body mass index

CD Cluster of differentiation

ChREBP Carbohydrate-responsive element-binding protein

COX-2 Cyclooxygenase-2

Ct Threshold cycle

CYP Cytochrome P450

cDNA Complementary DNA

DNA Deoxyribonucleic acid

ELISA Enzyme-linked immunosorbent assay

EDTA Ethylenediaminetetraacetic acid

ELSD Evaporative light scattering detectors

ERK Extracellular signal-regulated protein kinase

FAS Fatty acid synthase

FFA Free fatty acids

g Gram 


$\begin{array}{ll}\text { GABA } & \text { Y-Aminobutyric acid } \\ \text { h } & \text { Hour } \\ \text { HCC } & \text { Hepatocellular carcinoma } \\ \text { HFD } & \text { High-fat diet } \\ \text { HIV } & \text { Human immunodeficiency virus } \\ \text { HPLC } & \text { High-performance liquid chromatography } \\ \text { HSCCC } & \text { High-speed counter-current chromatography } \\ \text { IC } & \text { Inhibitory concentration } \\ \text { IFN-y } & \text { Interferon gamma } \\ \text { IL-1 } 3 & \text { Interleukin-1 beta } \\ \text { IL-4 } & \text { Interleukin-4 } \\ \text { IL-6 } & \text { Interleukin-6 } \\ \text { IgG } & \text { Immunoglobulin G } \\ \text { LC } & \text { Liquid chromatography } \\ \text { LFD } & \text { Low-fat diet } \\ \text { LPS } & \text { Lipopolysaccharide } \\ \text { MCP-1 } & \text { Monocyte chemotactic protein-1 } \\ \text { mg } & \text { Milligram } \\ \text { MS } & \text { Milliliter } \\ \text { MtSK } & \text { Millimeter } \\ \text { Mesikimate kinase enzyme of Mycobacterium tuberculosis }\end{array}$




\begin{tabular}{|c|c|}
\hline NAFLD & Nonalcoholic fatty liver disease \\
\hline $\mathrm{NASH}$ & Non-alcoholic steatohepatitis \\
\hline NF-kB & Nuclear factor kappa-light-chain-enhancer of activated B cells \\
\hline NMDA & N-methyl-D-aspartic acid \\
\hline $\mathrm{n}$ & Number of animals \\
\hline $\mathrm{ng}$ & Nanogram \\
\hline NO & Nitric oxide \\
\hline OVA & Ovalbumin \\
\hline $\mathrm{oz}$ & ounce \\
\hline PBS & Phosphate buffered saline \\
\hline $\mathrm{pg}$ & Picogram \\
\hline Pino & Pinosundia \\
\hline PPAR- $\alpha$ & Peroxisome proliferator activated receptor-alpha \\
\hline RNA & Ribonucleic acid \\
\hline rRNA & Ribosomal RNA \\
\hline ROS & Reactive oxygen species \\
\hline rt-q PCRs & Quantitative reverse transcription polymerase chain reactions \\
\hline SEM & Standard error of mean \\
\hline SREBP-1C & Sterol regulatory element-binding protein- $1 \mathrm{C}$ \\
\hline Su & Sutherlandia \\
\hline SuB & Sutherlandioside B \\
\hline STAT1 & Signal transducer and activator of transcription 1 \\
\hline TG & Triglycerides \\
\hline
\end{tabular}


TLC Thin layer chromatography

TLR Toll-like receptor

TMB 3,3',5,5'-Tetramethylbenzidine

TNF- $\alpha \quad$ Tumor necrosis factor- $\alpha$

TPA 12-O-tetra-decanoylphorbol-13-acetate

T2DM Type 2 diabetes mellitus

UV Ultra violet

VLDL Very low density lipoproteins

w/w Weight/weight

ug Microgram

$\mu \mathrm{L} \quad$ Microliter

$\mu \mathrm{m} \quad$ Micrometer

${ }^{\circ} \mathrm{C} \quad$ Degree centigrade

$3 \beta$-HSD2 $3 \beta$-hydroxysteroid dehydrogenase type 2 


\title{
IMPACT OF SUTHERLANDIA FRUTESCENS ON HEPATIC STEATOSIS IN HIGH-FAT FED RATS
}

\author{
NHU NGUYEN \\ DR. WILLIAM FOLK, DISSERTATION ADVISER
}

\section{ABSTRACT}

Hepatic steatosis is closely associated with development of obesity and type II diabetes mellitus. Western medicine for these metabolic conditions is less accessible to many developing countries because of cost, availability and need for clinical monitoring. These impediments might be addressed by development of evidence-based phytotherapies, especially those that are currently used and for which evidence of safety and efficacy can be provided.

Sutherlandia frutescens (L.) R.Br. (Sutherlandia) is a southern African medicinal plant that is widely used for a number of diseases and health conditions, including obesity and type II diabetes mellitus. Several bioactive compounds have been identified in S. frutescens, including L-canavanine, Dpinitol, and gamma-aminobutyric acid, as well as novel components such as the sutherlandiosides A-D (a group of cycloartane triterpenoids) and sutherlandins AD (a group of flavonoids). Limited evidence from cell culture and animal studies suggests Sutherlandia alters glucose homeostasis and lipid metabolism; however, the molecular mechanisms remain to be established. This research 
was conducted to examine the hypothesis that Sutherlandia consumption mitigates hepatic steatosis of rats subjected to a high-fat diet by increasing fatty acid oxidation and/or decreasing de novo lipid synthesis in the liver.

The Wistar male rats (12 animals/group) received either a standard low-fat diet (LFD) or a high-fat diet (HFD) ad libitum. The high-fat fed rats were treated for 12 weeks with or without Sutherlandia extracts in drinking water or dried Sutherlandia incorporated into feed. The results showed that both Sutherlandia treatments significantly reduced triglycerides and diminished the size of lipid droplets in the livers of HFD-fed rats, which indicates that less lipid was present in the liver cells of these rats. Furthermore, these treatments significantly upregulated fatty acid oxidation-associated genes including the transcription factor peroxisome proliferator-activated receptor $\alpha$ (PPAR- $\alpha)$ and its target genes including acyl-coenzyme A oxidase-1 (ACOX-1) and cytochrome P450, family 4, subfamily A, polypeptide 14 (CYP4A14), but did not considerably alter hepatic transcriptional expression of de novo lipid synthesis-related genes such as sterol regulatory element-binding protein-1C (SREBP-1C), carbohydrate-responsive element-binding protein (ChREBP), and fatty acid synthase (FAS).

Sutherlandiosides are unique compounds that have been recently characterized in S. frutescens. An indirect competitive enzyme-linked immunosorbent assay (ELISA) was developed in collaboration with the Department of Chemistry of Natural Compounds, Institute of Chemical Technology Prague, Czech Republic with the aim of determining the concentrations of these unique, bioactive compounds in plasma samples of the 
rats consuming Sutherlandia. A standard curve using purified sutherlandiosides from the Sutherlandia plant material was successfully established. Quantification of sutherlandiosides in plasma, however, was unsuccessful due to very low levels of sutherlandiosides present in plasma and limited availability of the totally purified sutherlandioside B standard.

Overall, this study provides a better understanding of the beneficial effects of Sutherlandia on hepatic steatosis by showing that consumption of this plant extract reduced HFD-induced accumulation of hepatic triglycerides by a mechanism that may involve increased fatty acid oxidation. This medicinal plant, therefore, may be a promising phytotherapy for hepatic conditions involving excess triglyceride accumulation. 


\section{CHAPTER ONE}

\section{INTRODUCTION}

Nonalcoholic fatty liver disease (NAFLD) is common in both developed and developing countries (1-4). NAFLD is characterized by a wide range of pathological alterations in the liver, ranging from simple steatosis to nonalcoholic steatohepatitis, fibrosis, cirrhosis and hepatocellular carcinoma (5-7). It is also strongly associated with metabolic diseases including insulin resistance, type 2 diabetes mellitus, hypertension, and dyslipidemia (5, 8-10).

Hepatic steatosis (fatty liver), an early and reversible stage of NAFLD (11), is clinically defined when accumulation of intrahepatic triglycerides exceeds $5 \%$ of the total liver weight $(12,13)$. Development of steatosis occurs when the rate of fatty acid uptake and synthesis exceeds the rate of fatty acid oxidation and secretion (14).

Herbal remedies are increasingly employed for ameliorating metabolic diseases (15-17). Among these phytotherapies, a southern African medicinal plant Sutherlandia frutescens (L.) R.Br (Sutherlandia), also known as "cancer bush", is claimed to alleviate numerous chronic diseases including diabetes, cancer, as well as infections (18-23). Several bioactive compounds have been identified in S. frutescens, including L-canavanine, D-pinitol, and gammaaminobutyric acid $(24,25)$, as well as novel components such as the sutherlandiosides A-D (a group of cycloartane triterpenoids) (26) and sutherlandins A-D (a group of flavonoids) $(27,28)$. 
Previous studies demonstrated that D-pinitol and L-canavanine exhibited anti-diabetic and anti-hyperlipidemic effects $(19,25,29,30)$. Even though there is no scientific evidence about beneficial effects of sutherlandiosides A-D and sutherlandins A-D on metabolic disorders, some studies showed that triterpenoids improved glucose metabolism, enhanced fatty acid oxidation (31), and reduced inflammation in liver and white adipose tissues of mice subjected to a high-fat diet (HFD) (32). Furthermore, other studies have demonstrated that flavonoids alleviated hepatic steatosis in diet-induced obese mice $(33,34)$. Importantly, aqueous extracts of Sutherlandia frutescens (subsp. microphylla) were shown to increase glucose uptake in muscle and adipose tissues in obese rats (21), decrease plasma free fatty acids, prevent the development of insulin resistance in HFD-fed rats $(22,23)$, and to modulate expression of 27 diabetes-related genes in a fructose-induced insulin resistant human Chang liver cell model (35). Molecular mechanisms responsible for these advantageous affects need to be elucidated. Therefore, this study aims to provide a better understanding of how $S$. frutescens improves lipid metabolism in vivo.

Male Wistar rats (12 animals/group) were fed either a standard low-fat diet or a high-fat diet ad libitum. The HFD-fed rats were treated for 12 weeks with or without extracts of $S$. frutescens in drinking water $(50 \mathrm{mg}$ extract $/ \mathrm{kg}$ body weight/day) or $1 \%$ dried Sutherlandia vegetative material incorporated into the HFD. Liver triglycerides, histology, and transcriptional expression of genes involved in hepatic lipid oxidation and synthesis were examined in order to verify 
the hypothesis that $S$. frutescens consumption alleviates obesity-induced hepatic steatosis by decreasing hepatic de novo lipogenesis and/or by increasing fatty acid oxidation in the livers of HFD-fed rats.

Chapter two will summarize biological information on NAFLD (including its definition, pathogenesis, diagnosis and prevalence), as well as on bioactive compounds and medicinal properties of $S$. frutescens. 


\section{CHAPTER TWO}

\section{LITERATURE REVIEW}

\section{Hepatic steatosis}

\section{Introduction}

Obesity refers to a medical condition when there is a substantial increase in caloric intake exceeding the caloric expenditure, leading to an accumulation of fat throughout the body (36). There are about 500 million people worldwide sufferring from obesity (defined as having a body mass index (BMI) of greater than $30 \mathrm{~kg} \mathrm{per} \mathrm{m}^{2}$ ) in 2011 , and that these numbers are estimated to double in 2030 (37). Moreover, Ogden et al. (2015) reported that over one-third of adults and $17 \%$ of youth in the United States were obese in 2011-2014, and that obesity was more prevalent among women than among men (38). Furthermore, obesity has been also increasing remarkably in developing countries; for instance, more than $29 \%$ of men and $56 \%$ of women were categorized as overweight $(\mathrm{BMI}>25)$ or obese $(\mathrm{BMI}>30)$ in South Africa (39).

Obesity is a risk factor for developing a number of chronic diseases including high blood pressure, type 2 diabetes mellitus (T2DM), heart disease and stroke (40). More importantly, obesity is associated with hepatic steatosis (fatty liver), the hallmark feature of non-alcoholic fatty liver disease (NAFLD) (41). 


\section{Definition of non-alcoholic fatty liver disease (NAFLD)}

The defining feature of NAFLD is the accumulation of triglycerides (lipids) within the cytoplasm of hepatocytes, in the absence of excessive alcohol consumption (42), i.e. more than 2 drinks/day by men or more than 1 drink/day by women (a standard drink is equal to $14 \mathrm{~g}$ ( $0.6 \mathrm{oz})$ of alcohol) (43). NAFLD covers a wide spectrum of liver damage based on histological hepatocellular characteristics, initiating from benign, asymptomatic hepatic steatosis, then transforming to a complex pattern with hepatocellular injury and inflammation called non-alcoholic steatohepatitis (NASH), and ultimately ending with severe liver disease such as fibrosis, cirrhosis and hepatocellular carcinoma (HCC or liver cancer) in some cases $(5-7,44)$.

\section{Pathogenesis of NAFLD}

The liver is one of the largest organs in the human body and is essential for normal physiology, and has a central role in glucose and lipid metabolism in the body (45-48). Hepatocytes are the epithelial component of the liver and perform most of the liver's physiologic functions (49).

Simple hepatic steatosis results from the accumulation of triglycerides within the cytoplasm of hepatocytes in the liver and generally represents a nonprogressive disease condition with minimal treatment requirements and low risk of development of end-stage liver disease $(44,50)$. Hepatic steatosis is clinically defined when triglycerides (TG) exceed $5 \%$ of the total liver weight $(12,13)$. Liver lipid homeostasis is dependent on the balance of the following metabolic pathways: 1) hepatic uptake of plasma free fatty acids (FFA) from lipolysis of 
adipose tissue triglycerides, 2) hepatic de novo lipogenesis, (3) hepatic fatty acid oxidation, and (4) fatty acid secretion in the form of triglyceride in the core of very low density lipoproteins (VLDL) $(51,52)$. Changes in the equilibrium of one or more of these processes can lead to hepatic steatosis (14).

Transition from steatosis to NASH occurs when the capacity of hepatocytes to store fat is overloaded by sustained uptake, local synthesis or impaired breakdown of fatty acids, which eventuates in cell death and inflammation $(53,54)$. It is estimated that about $30 \%$ of people having fatty liver can develop NASH $(55,56)$.

Untreated NASH can progress to end-stage liver disease characterized by fibrosis and cirrhosis through deposition of collagen and scar tissue due to mitochondrial injury, stellate cell activation and microvascular injury (57). Approximately $20-25 \%$ of individuals affected by NASH can develop cirrhosis with the subsequent risk of $\operatorname{HCC}(56,58)$.

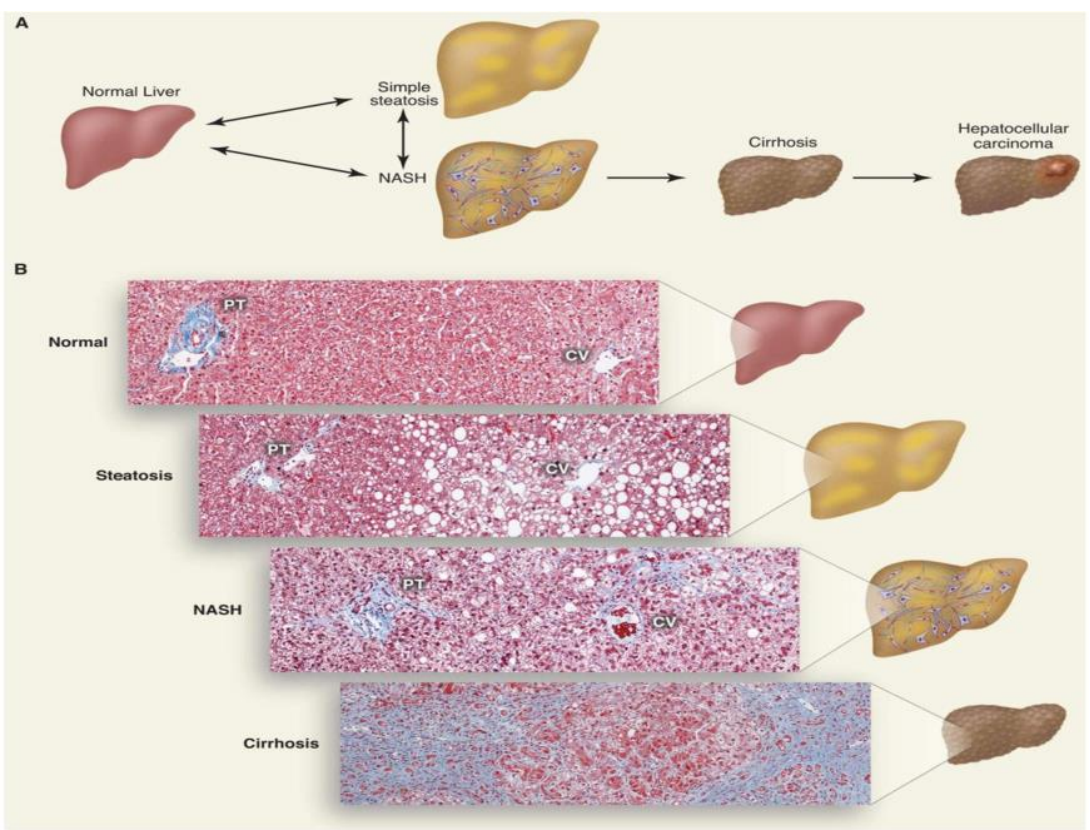

Figure 2.1. Progression of non-alcoholic fatty liver disease (NAFLD) (44). 


\section{Diagnosis of NAFLD}

The spectrum of NAFLD can be categorized into four different types based on histological hepatocellular characteristics as summarized in Table 2.1 below $(59-61)$.

Table 2.1. Diagnostic criteria for NAFLD

\begin{tabular}{|l|l|l|}
\hline Type & Histological Characteristics & Clinical Information \\
\hline Type 1 & Simple steatosis & Non-progressive \\
\hline Type 2 & Steatosis + lobular inflammation & Benign \\
\hline Type 3 & $\begin{array}{l}\text { Type 2 characteristics + } \\
\text { ballooning degeneration }\end{array}$ & $\begin{array}{l}\text { Considered NASH without } \\
\text { fibrosis and may progress to } \\
\text { liver cirrhosis }\end{array}$ \\
\hline Type 4 & Type 3 characteristics + fibrosis & $\begin{array}{l}\text { Considered NASH with } \\
\text { fibrosis and may progress to } \\
\text { liver cirrhosis/failure }\end{array}$ \\
\hline
\end{tabular}

Liver biopsy remains the gold standard for the diagnosis and staging of NAFLD; nevertheless, its widespread use as a screening tool is not feasible due to its invasive nature (62). Physicians, instead, have been employing serum enzyme markers such as alanine aminotransferase (ALT) and aspartate aminotransferase (AST) to determine hepatocellular damage (63). ALT (specific for the liver) and AST (found in both liver and muscle cells) will leak out of the cells, under cell membrane damage, into liver sinusoids (small fenestrated capillary-like tubes that extend from the portal veins and arteries and facilitate 
exchange of blood and nutrients to the hepatocytes), and then into systemic circulation (64). Yano et al. in 2001 showed that the sensitivity of ALT and AST tests to detect fatty liver was $35.7 \%$, which is inferior to the use of the body mass index (65). However, about 70\% overweight/obese patients with T2DM were diagnosed with NAFLD even in the presence of normal $\operatorname{ALT}$ levels $(8,66,67)$. Moreover, currently available serum biomarkers are not sufficiently sensitive and specific to differentiate steatosis from NASH or to stage the presence and extent of liver fibrosis $(53,68)$. Therefore, there is a need for developing better noninvasive tools and biomarkers to identify the progression of NAFLD (69). Elastography, magnetic resonance elastography and acoustic radiation force imaging are imaging techniques that can distinguish a variety of chronic liver conditions in addition to NAFLD (70-72). Evaluation of changes in the lipid profiles (phospholipids and diacylglycerols) in the blood or urine could be powerful in classifying the progression of NAFLD (73).

\section{Prevalence of NAFLD}

NAFLD is the most prevalent form of liver disease worldwide, and is the most common cause of chronic liver disease in both developed and developing countries (1-4). A recent study determined that one-third of the United States adult population has hepatic steatosis (74). Other studies showed that NAFLD impacts $30 \%$ of the United States population; $30 \%$ of the South American population; $27 \%$ of Asian populations; $24 \%$ of the European population; and $13 \%$ of the African population $(5,75,76)$. Approximately $70 \%$ of overweight/obese patients with T2DM worldwide have been diagnosed with $\operatorname{NAFLD}(8,52,66)$. The 
elevation of NAFLD is proportional to increasing body mass index (BMI), and is anticipated to become the most prominent grounds for final stage liver disease in the United States by $2020(77,78)$.

\section{Medicinal plants}

Medicinal plants have been utilized as food, flavoring, medicine, or perfume to treat a variety of diseases or to improve human health by stabilizing physiological function (79). Herbal medicines have been employed for as dietary supplements for millennia even though there is a lack of understanding about their efficacy and safety $(80,81)$. Approximately $40 \%$ of Americans consume some types of dietary supplement $(82,83)$.

On one hand, medicinal plants offer several beneficial aspects including relatively low cost, widespread availability, and high acceptability (84). Using traditional medicine, on the other hand, is also associated with a number of disadvantages such as contamination with toxins, limited knowledge on the dosage, poor understanding of the medicinal interactions, lack of regulation, and possible serious physiological effects (79).

A number of interdisciplinary research centers have been funded by two components of the National Institutes of Health - the National Center for Complementary and Alternative Medicine and the Office of Dietary Supplements since 1999 - with the goal of determining mechanisms of action, efficacy and safety of botanicals, performing clinical investigation, and exploring new therapeutic approaches for medical treatment of diseases $(81,85)$. 
Traditional medicine has been widely used in Africa, and therefore play essential roles in culture and life of Africans (86). About 3,000 medicinal plants have been traditionally used in southern Africa for treatment of a wide variety of diseases, including cancer, inflammation, and diabetes (18). However, little research has been conducted to establish the scientific rationale for the use of botanicals in Africa (86).

Phytotherapies are extensively utilized for mitigating obesity $(16,17,87-$ 90). Among these phytotherapies, Sutherlandia frutescens (L.) R.Br (Sutherlandia), a southern African medicinal plant, has been claimed for alleviation of various chronic diseases including diabetes, cancer, as well as infections (18-23).

Development of advanced biological technologies leads to more investigation into the chemical composition, biological functions, as well as underlying mechanisms of medicinal properties of herbs. Not only do these findings offer a better appreciation of herbal medicine, they also initiate novel implications for clinical treatment.

\section{Sutherlandia frutescens}

\section{Introduction}

Sutherlandia frutescens (L.) R.Br (Sutherlandia) (Figure 2.2) is a South African medicinal plant, which is commonly known as "cancer bush". The Sutherlandia genus is named after James Sutherland who was the first administrator of the Edinburgh Botanic Garden. Sutherlandia belongs to the Fabaceae family, which 
features a group of pod-bearing, flowering plants found all over the world (18). There are six species in the genus Sutherlandia, which are endemic to Southern Africa. These six species are reduced to two, i.e. Sutherlandia frutescens and Sutherlandia tomentosa; the former is further divided into three subspecies (subsp.), namely subsp. frutescens, subsp. microphylla, and subsp. speciosa. These subspecies are distinguished from one another by their habitat, the shapes of the pods and leaflets (91). Sutherlandia frutescens is a perennial, erect shrub having compound leaves, bladder-like pods and bright red flowers with a height of 0.2-2.5 meters (18). These plants are easily grown from the seeds collected from the pods; moreover, they well tolerate most soil types, are resistant to frost, flourish in full sun and well-drained soils, as well as perform at best when enjoying ample moisture in winter and spring seasons (92).

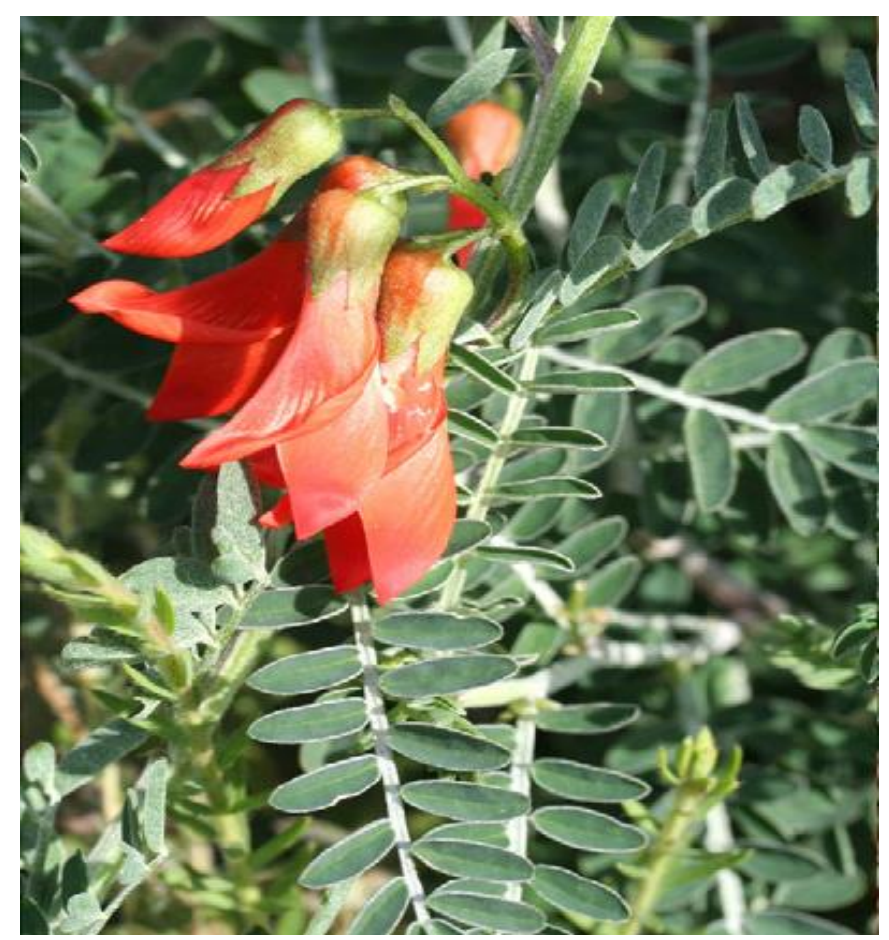

Figure 2.2. Sutherlandia frutescens (18) 


\section{Compounds in Sutherlandia frutescens extracts}

Several bioactive compounds in Sutherlandia have been identifed in extracts of Sutherlandia frutescens including: D-pinitol, L-canavanine, gammaaminobutyric acid (25), sutherlandiosides A, B, C and D (cycloartane glycosides) (26, 93), sutherlandins $A, B, C$ and $D$ (3-hydroxy-3-methylglutaro-yl containing flavonol glycosides) $(27,28)$, and polysaccharides (94).

\section{Amino acids}

D-pinitol was found to be most abundant $(18.17 \mathrm{mg} / \mathrm{g})$, followed by GABA (3.48 mg/g), and L-canavanine $(0.08 \mathrm{mg} / \mathrm{g})$, in leaf extracts (95).

D-pinitol (3-O-Methyl-D-chiro-inositol) (Figure 2.3 A), one of the common compounds in Sutherlandia leaves, has been reported to reduce blood sugar levels (29). In addition, this compound has been demonstrated to exhibit antiinflammatory (96) and anti-hyperlipidemic (30) effects.

The non-protein amino acid L-canavanine (2-Amino-4-(guanidinooxy) butyric acid) (Figure 2.3 B) is able to interfere with arginine uptake essential for Nitrogen Oxide $(\mathrm{NO})$ production $(19,25)$ that can destroy beta cells of the pancreas (97), thus inhibiting transcription and translation of insulin (98).

Gamma-aminobutyric acid (GABA) (Figure 2.3 C), an inhibitory neurotransmitter, has been shown to mitigate anxiety (Smith and van Vuuren, 2013). Significant amounts of GABA present in Sutherlandia shoots may be account for this anti-stress effects of this medicinal plant $(18,99)$. Furthermore, GABA was shown to suppress tumor cell migration (100), and influence steroid production through the hypothalamic-pituitary-adrenal axis $(101,102)$. 
(A)

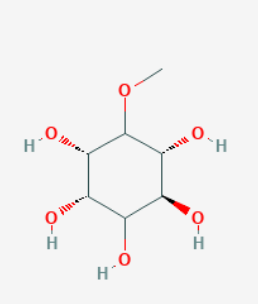

(B)

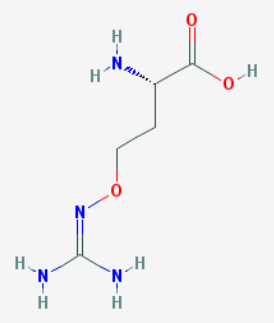

(C)

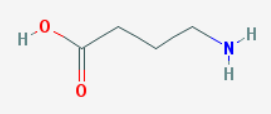

Figure 2.3. Chemical structures of A) D-pinitol $\left.{ }^{a}, B\right)$ L-canavanine ${ }^{b}$, and C) GABA $^{\mathrm{c}}$.

a National Center for Biotechnology Information. PubChem Compound Database; CID=164619, https://pubchem.ncbi.nlm.nih.gov/compound/164619

${ }^{b}$ National Center for Biotechnology Information. PubChem Compound Database; CID=439202, https://pubchem.ncbi.nlm.nih.gov/compound/439202

${ }^{c}$ National Center for Biotechnology Information. PubChem Compound Database; $C I D=119$, https://pubchem.ncbi.nlm.nih.gov/compound/119

\section{Triterpenoids and flavonoids}

Unique compounds of $S$. frutescens including sutherlandiosides A through D (cycloartanol glycosides) (Figures 2.4) and sutherlandins A through D (flavonol glycosides) (Figures 2.5) were characterized in the recent years (26-28).

Sutherlandioside B is the major cycloartene-type tetracyclic triterpene saponin in S. frutescens (2.75\%, weight by total weight of dry plant sample), followed by sutherlandiosides $A(0.61 \% \mathrm{w} / \mathrm{w}, \mathrm{C}(0.22 \% \mathrm{w} / \mathrm{w})$ and $\mathrm{D}(0.64 \% \mathrm{w} / \mathrm{w})$ (27). Saponins are generally known as non-volatile, surface active compounds that are widely found in the plant kingdom $(103,104)$. The name 'saponin' is derived from the Latin word sapo, which means 'soap', due to the soap-like foams of saponin molecules in aqueous solutions (105). The triterpene saponins 
are featured by a hydrophobic triterpenoid structure (aglycone) containing a hydrophilic sugar chain (glycone) (104), and are grouped into the following classes: oleananes, cycloartanes, dammaranes, tirucallanes, lupanes, hopanes, taraxasteranes, ursanes, lanostanes, and cucurbitanes (105). None of these sutherlandiosides showed anti-microbial and anti-malarial activities (26). However, Lin et al. (2016) discovered that sutherlandioside D, the most potent compound in the $S$. frutescens methanol extract, could suppress Gli-reporter in prostate cancer cells (106). Moreover, several studies have established biological impacts of triterpenoid glycosides. These compounds exerted antidiabetic effects by improving glucose metabolism and enhancing fatty acid oxidation (31). In addition, they were reported to inhibit nociceptive responses (107), and suppress the nuclear factor-kappa light chain enhancer of activated B cells (NF-kB) inflammatory signaling pathway in human TNF-a induced astroglial cells (108) as well as in liver and white adipose tissues of male C57BL/6J mice fed a high-fat diet for 19 weeks (32). Furthermore, triterpenoid glycosides also exhibited anti-cancer effects by hindering abnormal cell proliferation and inducing apoptosis through mitochondrial pro-apoptotic mechanisms in rats initiated by 7,12-dimethylbenz(a)anthracene (DMBA) mammary carcinogenesis (109).

Flavonoids, classified into flavones, isoflavones, flavanols, flavan-3-ols and anthocyanidins (110), are also presentin S. frutescens extracts. These compounds are linked to several therapeutic values. Five types of flavonoids (3',4'-dihydroxy-4-methoxydalbergione, 4-methoxydalbergion, isoliquiritigenin, chrysin, and cearoin) displayed anti-inflammatory effects by significantly inhibiting 
the NF-KB activity after the onset of lipopolysacharide (LPS)-induced inflammation (111). In addition, quercetin, a well-recognized flavonoid, elicited beneficial effects in alleviation of hepatic steatosis in C57/BL6J mice fed a highfat, high-cholesterol and high-sucrose Western diet for 20 weeks by reducing hepatic triglycerides, decreasing oxidative stress and improving hepatic lipid metabolism by significantly increasing transcriptional expression of peroxisome proliferator-activated receptor alpha (PPAR- $\alpha$ ) as well as suppressing expression of peroxisome proliferator-activated receptor gamma (PPAR-y), cluster of differentiation 36 (CD36) or fatty acid translocase, as sterol regulatory elementbinding protein-1C (SREBP-1C), and fatty acid synthase (FAS) (33). Moreover, kaempferol (3,5,7,4'-tetrahydroxyflavone), another well-known flavonoid, was shown to lower hepatic triglycerides and lipid droplet accumulation by increasing lipid metabolism through upregulation of PPAR-a, acyl-CoA oxidase (ACO), cytochrome P450 isoform 4A1 (CYP4A1), and downregulation of SREBPs in the livers of rats fed a high-fat diet for 10 weeks (34). Although flavonoid compounds within $S$. frutescens extract have been shown to be present in relatively low concentrations (112), Avula et al. (2010) identified and quantified the four flavonol glycosides, namely sutherlandins A-D $(0.53 \%, 0.49 \%, 0.94 \%$, and $0.54 \%$ (w/w), respectively), in the $S$. frutescens extracts (27). Sutherlandins A-D and sutherlandiosides A-D contributed very little to the anti-inflammatory effects in RAW 264.7 murine macrophage cells stimulated by LPS/interferon gamma (IFN-y) (113). 

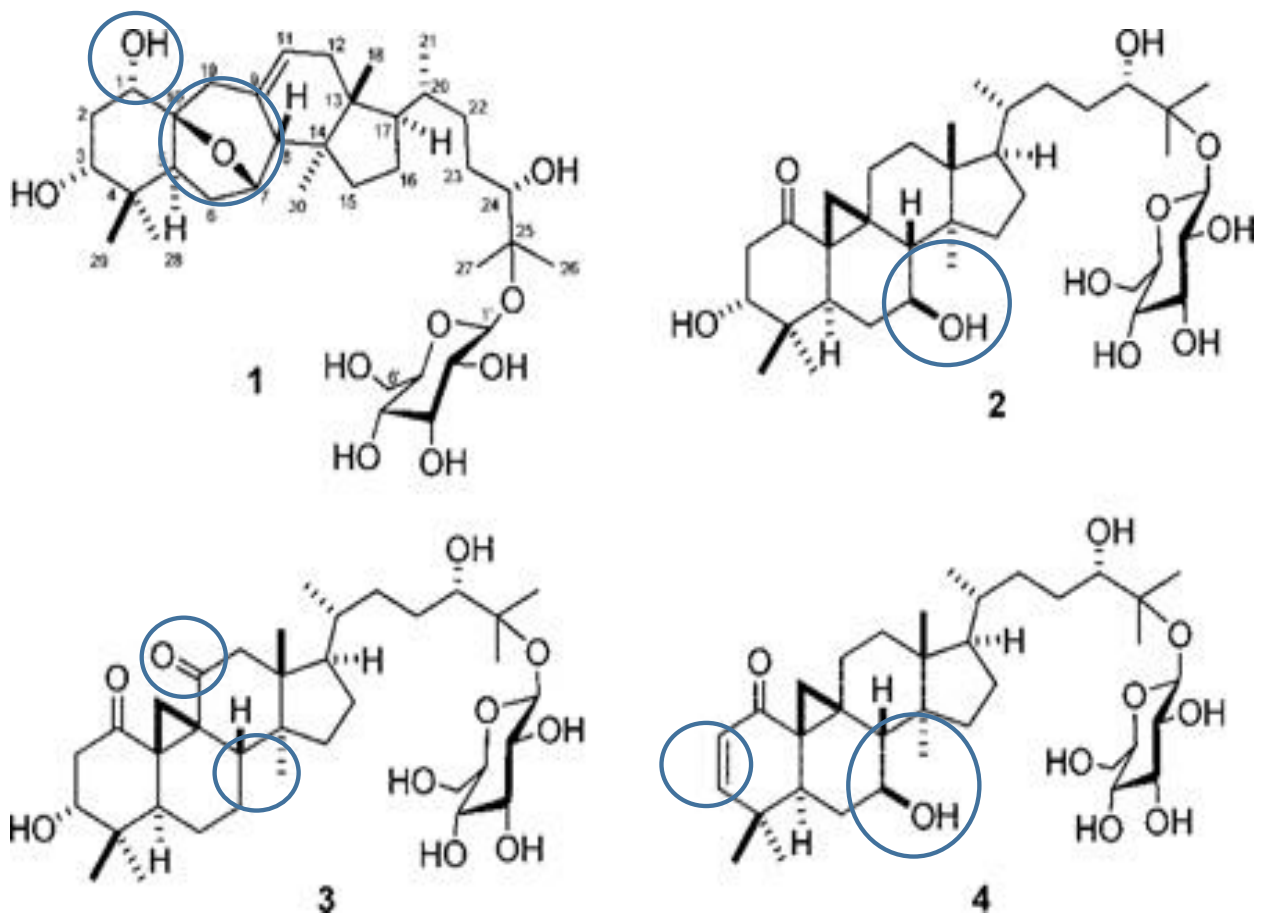

Figure 2-4. Structures of sutherlandiosides A to D (26). The circles indicate the structural differences of sutherlandiosides.

1: Sutherlandioside A, 1S,3R,24S,25-tetrahydroxycycloartane-7S,10S-epoxy9,10-seco-9,19-cyclolanost-9(11)-ene 25-O- $\beta$-D-glucopyranoside, 2: Sutherlandioside B, 3R,7S,24S,25-tetrahydroxycycloartane-1-one 25-O- $\beta$-Dglucopyranoside, 3: Sutherlandioside C, 3R,24S,25-trihydroxycycloartane-1,11-dione 25-O- $\beta$-Dglucopyranoside, 4: Sutherlandioside D, 7S,24S,25-trihydroxycycloartane-2-en-1-one 25-O- $\beta$-Dglucopyranoside. 

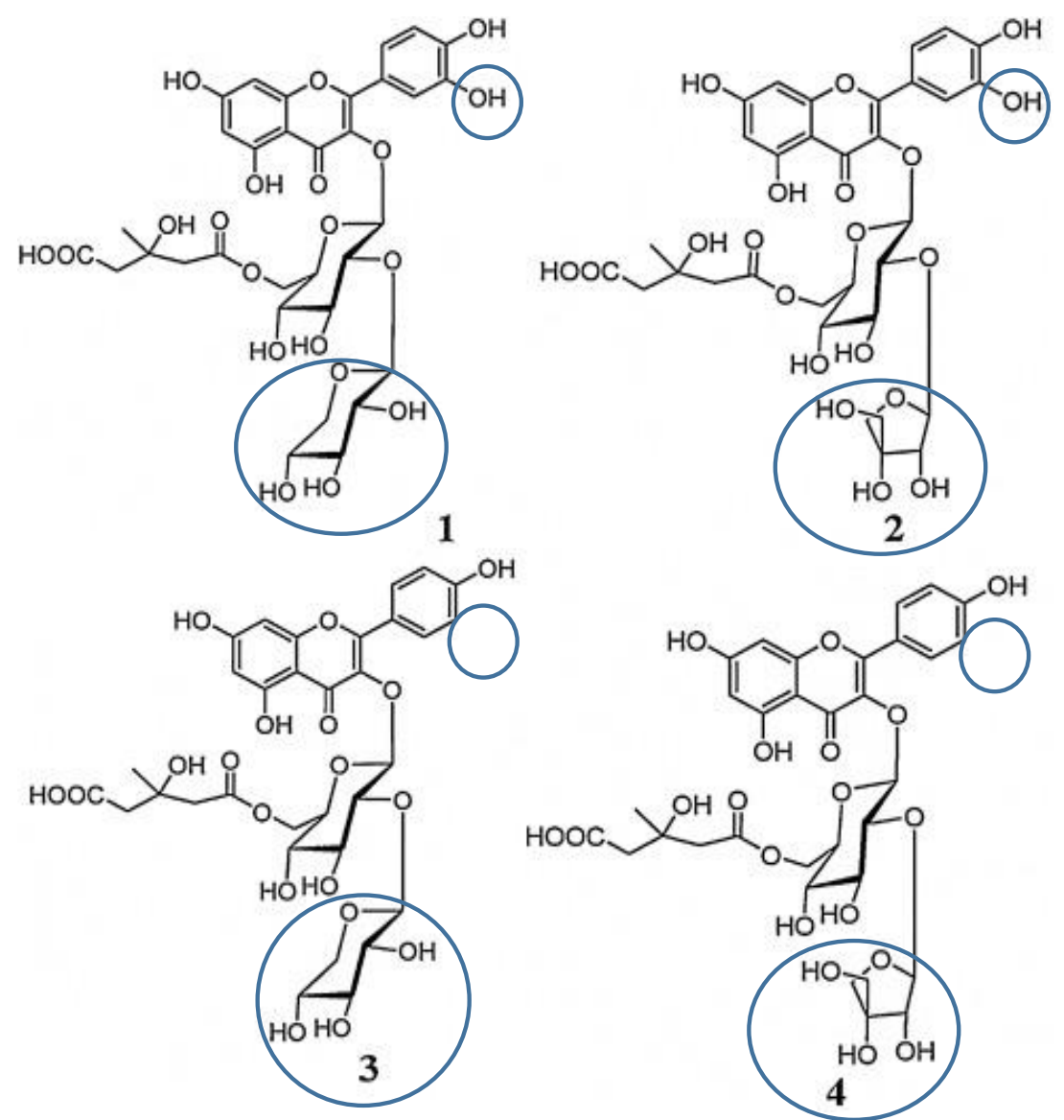

Figure 2-5. Structures of sutherlandins A to D (28). The circles indicate the structural differences of sutherlandins.

1: Sutherlandin A, quercetin 3-O- $\beta$-D-xylopyranosyl (1 $\rightarrow$ 2)-[6-O-(3-hydroxy-3methylglutaroyl)]- $\beta$-D-glucopyranoside, 2: Sutherlandin B, 3R quercetin 3-O- $\beta$-D-apiofuranosyl $(1 \rightarrow 2)$-[6-O-(3-hydroxy3-methylglutaroyl)]- $\beta$-D-glucopyranoside, 3: Sutherlandin C, kaempferol 3-O- $\beta$-D-xylopyranosyl ( $1 \rightarrow 2)$-[6-O-(3-hydroxy-3methylglutaroyl)]- $\beta$-D-glucopyranoside, 4: Sutherlandin D, kaempferol 3-O- $\beta$-D- apiofuranosyl $(1 \rightarrow 2)$-[6-O-(3-hydroxy-3methylglutaroyl)]- $\beta$-D-glucopyranoside. 


\section{Other bioactive components}

First, high levels of polysaccharides of the pectin type were found in the leaves of $S$. frutescens (94). These polysaccharides were shown to display immunomodulatory properties by facilitating complement fixation; more specifically, the complement fixation activity was highly associated with regions rich in galactose and xylose (94).

Second, alpha-linolenic acid was isolated from the dichloromethane: methanol (1:1) extracts $S$. frutescens (114). The authors illustrated antituberculosis effects of this extract as it was shown to inhibit recombinant shikimate kinase - an effective drug target for Mycobacterium tuberculosis.

Furthermore, cardenolides, a type of cardiac glycosides that has been used to treat congestive heart failure (115), have recently been identified in leaf and seed extracts of $S$. frutescens (112).

Lastly, some other compounds were also reported to be present in $S$. frutescens ethanol extracts, including hexadecanoic acid, $\mathrm{y}$-sitosterol, and stigmast-4-en-3-one (25).

\section{Medicinal properties and potential mechanisms of S. frutescens}

The aqueous extract of the stems and leaves of $S$. frutescens has been widely used in alleviating conditions of various chronic diseases such as T2DM, inflammation, cancer, stomach problems, influenza, and HIV/AIDS in southern Africa (18-23). The possible mechanisms for the medicinal properties of this medicinal plant have been evaluated in cell and animal models. 


\section{Diabetes}

Rodent studies in South Africa have reported that administration of $S$. frutescens ( $800 \mathrm{mg} / \mathrm{kg}$ bodyweight) diminished blood glucose concentrations in streptozotocin-induced diabetic rats and that this beneficial effect was maintained longer than chlorpropamide - a conventional hypoglycemic agent (116). Moreover, traditional aqueous extracts of Sutherlandia frutescens (subsp. microphylla) increased glucose uptake in muscle and adipose tissues in high-fat fed rats (21). In addition, a commercial aqueous Sutherlandia frutescens (subsp. microphylla) extract (Pinosundia, Value Added Life Health Products (Pty) Ltd, South Africa; Registered trade mark with application number 2008/19581) at a dose of $50 \mathrm{mg} / \mathrm{kg}$ body weight/day decreased plasma free fatty acids and prevented the development of insulin resistance in male Wistar rats fed a high-fat diet for $12-16$ weeks $(22,23)$.

Recently, S. frutescens aqueous extracts were shown to alter expression of 27 diabetes-related genes including peroxisome proliferator-activated receptor $\alpha($ PPAR- $\alpha)$ - one of the key transcription factors responsible for hepatic lipid metabolism - in a fructose-induced insulin resistant human Chang liver cell model (35).

\section{Inflammation}

S. frutescens has been used to target several chronic inflammatory conditions, such as rheumatoid arthritis, osteoarthritis, and gout (99). Ojewole (2004) demonstrated that Sutherlandia aqueous extracts at a dose of $800 \mathrm{mg} / \mathrm{kg}$ per os significantly reduced acute inflammation of paw edema caused by the 
fresh egg albumin in Wistar rats (116). A commercial aqueous $S$. frutescens (subsp. microphylla) extract (Pinosundia, Value Added Life Health Products (Pty) Ltd, South Africa) at a dose of $50 \mathrm{mg} / \mathrm{kg}$ body weight/day, however, did not lead to alteration in circulating plasma cytokine TNF- $\alpha$ and chemokine monocyte chemotactic protein-1 (MCP-1) in high-fat fed Wistar rats (23). Furthermore, no significant modification of host inflammatory response towards either gram negative ( $E$. coli) or gram positive (L. monocytogenes) bacteria was detected in both C57BL/6 and BALB/c female and male mice fed an AIN-93G basal rodent diet incorporated with $0.25 \%$ or $1 \% \mathrm{w} / \mathrm{w}$ ground powder of the vegetative parts of S. frutescens for four weeks (117).

Regarding in vitro studies, a hot water extract of $S$. frutescens displayed antioxidant and/or anti-inflammatory activities in human neutrophils, Chinese hamster ovary cells, human hepatoma cells, and human pulmonary alveolar carcinoma $(19,118)$. Moreover, a methanolic extract of this plant was shown to decrease 12-O-tetra-decanoylphorbol-13-acetate (TPA)-induced cyclooxygenase-2 (COX-2) expression in mouse skin by diminishing the activity of extracellular signal-regulated protein kinase (ERK) and activator protein-1 (AP1) (119). In addition, a $70 \%$ ethanol extract of $S$. frutescens did not remarkably suppress nitric oxide production or inhibit mRNA expression of pro-inflammatory cytokines interleukin-1 $\beta$ (IL-1 $\beta$ ) and tumor necrosis factor- $\alpha$ (TNF- $\alpha)$ in murine macrophage RAW 264.7 cells (25). S. frutescens extracts, nonetheless, was reported to modulate the inflammatory responses by altering levels of IL-8 and TNF in HL60 cell lines stimulated by phorbol 12-myristate 13-acetate (24). Also, 
ethanolic extracts of $S$. frutescens $(20 \mu \mathrm{g} / \mathrm{ml})$ suppressed $\mathrm{N}$-methyl-D-aspartic acid (NMDA)-induced reactive oxygen species (ROS) production in neurons and LPS- and IFN- $\gamma$-induced ROS and nitric oxide production in microglial cells, as well as reduced activation of the ERK and signal transducer and activator of transcription 1 (STAT1) signaling pathways in microglial cells (120). Moreover, Lei et al. (2015) suggested that chlorophyll present in ethanolic extracts of $S$. frutescens $(200 \mu \mathrm{g} / \mathrm{ml})$ contribute to a decrease in TNF- $\alpha$ and IL-6 production, as well as an inhibition of the NF-KB activity in RAW 264.7 mouse macrophage cells induced by lipopolysacharide (LPS) and interferon gamma (IFN-y) (113). Interestingly, polysaccharide-enriched fraction of $S$. frutescens significantly elevated production of ROS, NO, and TNF- $\alpha$ in RAW 264.7 cells in a dosedependent manner, and these activities were completely abolished by cotreatment with CLI-095 - a specific inhibitor of toll-like receptor-4 (TLR-4) (121).

\section{Immunodeficiency disorders}

S. frutescens has been traditionally employed as an immune-stimulating tonic for human immunodeficiency virus (HIV) infected patients, and this practice has been acknowledged by the South African Ministry of Health (122).

Bessong et al. (2005) reported that a methanolic extract of this plant stimulated recombinant HIV-1 reverse transcriptase (RT) activity (123); in contrast, Harnett et al. (2005) suggested that tannins, a compound present in S. frutescens aqueous extracts, may contribute to inhibition of HIV-1 RT and HIV-1 target enzymes including $\alpha$ - and $\beta$-glucosidase (124). In addition, $S$. frutescens may affect anti-retroviral drug metabolism because it was discovered to inhibit 
P450 3A4 (CYP3A4), a hepatic cytochrome P450 enzyme involved in drug metabolism (20).

Moreover, Korb et al. (2010) suggested that consumption of ethanolic $S$. frutescens extracts may lead to induction of apoptosis in cluster of differentiation (CD) 4+ cells and T lymphocytes in normal human lymphocytes in vitro, which would exacerbate the condition of immunocompromised patients as they have low CD4+ cell counts (125). Wilson et al. (2015), however, challenged this finding by illustrating that HIV viral load, CD4+ cells and T lymphocyte counts were not significantly different in HIV seropositive individuals with or without $S$. frutescens treatment. Moreover, there was a greater burden of infection in the group receiving $S$. frutescens as two subjects of this group subsequently contracted tuberculosis while undergoing isoniazid preventative therapy, a first line regimen used worldwide for prevention and treatment of tuberculosis (Wilson et al., 2015). This unexpected side effect may be attributed to the indication that $S$. frutescens inhibited expression of genes involved in oxidative stress, inflammatory signaling and toll-like receptor pathways, which can lessen the host's immune response to infection and reactivation of latent Mycobacterium tuberculosis (126).

A S. frutescens hexane extract was also shown to have strong antibacterial activity against Staphylococcus aureus, Enterococcus faecalis, and Escherichia coli (127). S. frutescens and alpha-linolenic acid, isolated from the extracts, impeded the metabolic action of shikimate kinase enzyme (MtSK) of Mycobacterium tuberculosis (114). MtSK is the key enzyme in the shikimate biosynthetic pathway from $M$. tuberculosis that only takes place in microbes and 
some plants, rendering this shikimate pathway an excellent target for developing novel anti-tuberculosis agents (128). Masoko et al. (2016) discovered that alphalinolenic acid purified from the dichloromethane: methanol (1:1) extract of $S$. frutescens elicited a significant inhibition of MtSK with a half maximal inhibitory concentration ( $\left.\mathrm{IC}_{50}\right)$ of $3.7 \mu \mathrm{g} / \mathrm{ml}$. (114).

\section{Cancer}

The potential mechanisms towardcancer of $S$. frutescens, the well-known "cancer bush", have been extensively investigated. S. frutescens was shown by Tai et al. (2004) to be capable of limiting the growth, proliferation, and mutagenic activities, and of promoting the process of apoptosis in various human cancer cell lines including MCF7, MDA-MB-468, Jurkat, and HL60 (25). These effects of $S$. frutescens may be linkedto its ability to suppress growth, morphology and proliferation of MCF-7 human breast adenocarcinoma cells (129). Also, $S$. frutescens treatment led to typical signs of apoptosis such as cell shrinkage and plasma membrane blebbing in esophageal cancer cells (130).

Moreover, S. frutescens ethanolic extracts was found to inhibit approximately $50 \%$ of Hedgehog-signaling responsive genes in TRAMPC2 prostate cancer cells (131), which implies that by $S$. frutescens has significant potential in cancer treatments because Hedgehog signaling has been associated with advanced prostate cancer. In addition, Lin et al. (2016) suggested that sutherlandioside $\mathrm{D}$, which was identified in the $S$. frutescens methanol extract, may exert anti-cancer effects by repressing Gli-reporter in prostate cancer cells 
and by reducing formation of prostate carcinoma in TRAMP mice fed a diet supplemented with $1 \% \mathrm{w} / \mathrm{w}$ of this plant (106).

\section{Other functions}

S. frutescens has been traditionally used for several other diseases/symptoms including the stress-related ailments, shock, trauma, and severe depression (18).

S. frutescens could inhibit glucocorticoid production and mitigate symptoms related to psychological stress through inhibition of the catalytic activity of adrenal steroidogenic P450 enzymes, P450 17a-hydroxylase/17,20lyase (CYP17A1) and P450 21-hydroxylase (CYP21A2) (132, 133). Moreover, a low dose of that $S$. frutescens aqueous extracts $(4 \mathrm{mg} / \mathrm{kg}$ body weight) modulated steroidogenesis by eliminating the down-regulation of glucocorticoid receptor in Wistar male rats subjected to acute psychological stress (134). More recently, Sergeant et al. (2017) reported that sutherlandioside B, a compound unique to $S$. frutescens, significantly inhibited CYP17A1 and 3ß-hydroxysteroid dehydrogenase type 2 (3ß-HSD2) in monkey kidney COS-1 cells, and decreased cortisol and androgen precursors in an angiotensin-II-responsive steroidproducing adrenocortical H295R cell line (135). In addition, this study also showed that the methanolic $S$. frutescens extracts significantly decreased total steroid production and mineralocorticoid metabolites under forskolin-stimulated steroid conditions.

Ojewole (2008) described the anticonvulsant and anticoagulant properties of $S$. frutescens (99). Recently, dietary S. frutescens was reported to decrease 
ischemia-induced neuronal cell death and mitigate p47phox and of ERK1/2 phosphorylation in microglial cells (136).

\section{Safety and efficacy}

The use of $S$. frutescens has not been linked with severe side effects even though symptoms such as dryness of the mouth, occasional mild diarrhea or mild diuresis, and dizziness in cachectic patients have been documented (20).

The traditional dose of this herb is infusion or decoctions of 2.5 to $5 \mathrm{~g}$ of dry material per day, and no ill effect was illustrated after taking a decoction of 5 $\mathrm{g}$ of dried material daily (twice a day) for more than six years (18).

Clinical and toxicological studies in South Africa determined that oral consumption of the Sutherlandia leaf powder ( $800 \mathrm{mg}$ per day) is well tolerated by healthy and HIV-infected adults, and demonstrated no significant clinically relevant effects in biochemical and hematologic measures, with elevated appetites being the most significant difference between the treatment and placebo group $(137,138)$. Moreover, Wilson et al. (2015) observed that the HIV viral load and CD4+ T-lymphocytes were similar in control and treatment groups when S. frutescens was administered to HIV seropositive adults (138). Importantly, this study pointed out that the total burden of infection was considerably greater in the group receiving $S$. frutescens with two subjects developing tuberculosis while receiving isoniazid preventative therapy.

Assessment of the safety of $S$. frutescens consumption was also conducted in animal studies. Seier et al. (2002) fed vervet monkeys a carefully monitored standard diet containing $0,1,3$ and 9 times of $S$. frutescens compared 
to the recommended daily dose of $9 \mathrm{mg} / \mathrm{kg}$ body weight (i.e. $0,9.0,27.0$, and 81 $\mathrm{mg}$ of leaf powder per day, respectively) for three months, and found no clinically significant side effects (139). In addition, BALB/c mice were given graded shoot aqueous extracts of $S$. frutescens $(25,50,100,200,400,800$, and $1600 \mathrm{mg} / \mathrm{kg}$ body weight) by intraperitoneal injection for an acute toxicity investigation (116). The results showed that crude extracts of $S$. frutescens are probably relatively safe in mammals based on the calculated median lethal dose (LD50) of $1280 \pm$ $71 \mathrm{mg}$ of extract per $\mathrm{kg}$ body weight.

\section{Bioavailability of phytochemicals}

Many bioactive compounds have been shown to exert various medicinal effects in vitro; nevertheless, it is not uncommon that these effects are not always observed in vivo. The discrepancy between in vivo and in vitro effects can be attributed to the bioavailability of the natural compounds in the target tissues because these compounds would be subjected to digestion, absorption, metabolism, and degradation by gut flora, hepatic enzymes and potential transport within circulation. Consequently, these compounds may not reach their intended target in the active form.

Lipinski (2004) described a guideline for identifying potential new drugs that would be bioavailable after oral intake (140). There are four physicochemical characteristics that should be taken into account, including limitations for molecular weight $(\leq 500 \mathrm{Da})$, lipophilicity $(\log \mathrm{P} \leq 5)$ and the number of hydrogen donors and acceptors ( $\mathrm{H}$-bond donors $\leq 5$ and $\mathrm{H}$-bond acceptors $\leq 10)$. These features have been employed to predict the aqueous solubility and intestinal 
permeability of compounds, and have been associated with about $90 \%$ of oral medications that have reached phase II clinical trials.

Compounds with relatively simple chemical structures such as GABA, Dpinitol and L-canavanine in S. frutescens extracts are most likely to be readily absorbed from the intestines; however, the more complex molecules such as flavonoids and triterpenoids may be less likely to be absorbed in vivo (141). The digestion and absorption of triterpenoids in Wistar rats was investigated by oral administration of mogroside $\mathrm{V}$ (a pentaglucose-conjugated mogroside) - the main sweetening component and also a type of triterpenoids found in the traditional Chinese fruit Siraitia grosvenori - into rats (142). The authors discovered that mogroside $\mathrm{V}$ had been degraded to tetra and triglucose mogroside conjugates by digestive enzymes and intestinal microflora and was excreted in the feces as mogrol and its mono- and diglucosides whereas a trace amount of mogrol and its monoglucoside were detected in the portal blood as sulfates and/or glucuronides conjugates.

Ginsenosides, which are components of Panax ginseng and classified into the dammarane-type tetracyclic and oleanane-type pentacyclic triterpene saponin groups (143), were shown to be present in hepatic tissues at much higher concentrations than plasma and other tissues (kidney, stomach and intestine) of Sprague-Dawley rats (144). The addition of small molecule fractions to the dried rhizome Anemarrhena asphodeloides extracts improved the bioavailability of steroidal saponins - active compounds in this herb - in rat plasma (145). 
In order to increase the bioavailability of natural compounds, a number of advanced technologies have been developed including the application of nanosized drug carrier particles such as liposomes and micelles, crystal engineering, micronization, and cyclodextration (146-151).

\section{Summary and Conclusion}

NAFLD is the most prevalent form of liver disease worldwide, and is associated with obesity, insulin resistance, and type 2 diabetes mellitus. Hepatic steatosis refers to the excessive accumulation of lipids in the liver, is a fundamental feature of NAFLD, and may progress to nonalcoholic steatohepatitis, fibrosis, cirrhosis, and hepatocellular carcinoma.

The great majority of the South African people depend upon traditional medicine for either part of or their entire primary health care. South Africans have extensively used traditional remedies such as $S$. frutescens decoctions regardless of lacking thorough understanding about the impact of the constituents of this plant on the disease conditions. The scientific validation of the use of $S$. frutescens extracts as therapeutic targets for diabetes, depression, inflammation and cancer may foster the use of this herbal remedy by the general public beyond Africa. Unlike western pharmaceuticals, no significant side effects

have been connected with the application of $S$. frutescens. This herb, therefore, may provide safe, affordable treatment for the aforementioned ailments.

South Africa is one of the three richest floristic areas in southern Africa; nevertheless, there is still a lack of commercialization of marketable medicinal products in spite of a remarkable increase in the scientific substantiation of the 
use of botanicals and of increasing commercial and scientific interest in this area. It is important to support the sustainable development of the natural product industry in both developing and developed countries because the successful integration of science and traditional medicine has great potential for both economic and scientific benefits.

A number of medicinal uses of Sutherlandia frutescens have been documented in southern Africa. Previous studies showed that $S$. frutescens extracts reduced plasma free fatty acids and inhibited the development of insulin resistance in high-fat fed rats, and that $S$. frutescens extracts altered diabetesrelated gene expression in a fructose-induced insulin resistant human Chang liver cell model. Molecular mechanisms of how Sutherlandia corrects the insult of high-fat diets, prevents insulin resistance and improves lipid metabolsim, however, remain unknown. The experiments described in the following chapters were designed and conducted to determine the impact of $S$. frutescens on obesity-induced hepatic steatosis. 


\section{CHAPTER THREE}

\section{SUTHERLANDIA FRUTESCENS CONSUMPTION}

\section{MITIGATES HEPATIC STEATOSIS BY INCREASING \\ EXPRESSION OF FATTY ACID OXIDATION-RELATED}

\section{GENES IN MALE WISTAR RATS FED A HIGH-FAT DIET}

\section{Abstract}

Hepatic steatosis (fatty liver) is closely associated with the development of obesity and type II diabetes mellitus, which are dramatically increasing worldwide due to changes in nutrition and lifestyle. The pathophysiology of hepatic steatosis is multifactorial and not well-addressed by current pharmacological treatments, many of which are not accessible to those at greatest risk, because of cost, availability, and need for clinical monitoring. These impediments might be addressed by phytotherapies for which adequate evidence of safety and efficacy can be provided.

Sutherlandia frutescens (L.) R.Br. (Sutherlandia) is a southern African medicinal plant that is widely used for a number of diseases and health conditions, including diabetes. Clinical studies have determined that consumption of Sutherlandia is well tolerated by healthy and HIV-infected adults, and limited evidence from cell culture and animal studies suggests Sutherlandia moderates glucose homeostasis and lipid metabolism; however, the pertinent molecular mechanisms remain unknown. 
This study was conducted to determine the effects of Sutherlandia consumption on hepatic steatosis of rats consuming a high-fat diet and to determine the basis for observed changes in lipid metabolism. Male Wistar rats received either a standard low-fat diet (LFD) or a high-fat diet (HFD) ad libitum. The HFD-fed rats were treated with or without aqueous extracts of Sutherlandia or Sutherlandia incorporated into feed.

The results exhibited that Sutherlandia treatments significantly reduced liver triglycerides, steatosis and lipid droplet size in rats fed HFD compared to those fed HFD without treatment. These treatments significantly upregulated hepatic fatty acid oxidation-associated genes including the transcription factor peroxisome proliferator-activated receptor alpha (PPAR- $\alpha$ ) and its target genes peroxisomal acyl-coenzyme A oxidase-1 (ACOX-1) and Cytochrome P450, family 4, subfamily A, polypeptide 14 (CYP4A14), but did not significantly alter genes associated with de novo lipid synthesis such as sterol regulatory element-binding protein-1C (SREBP-1C), carbohydrate-responsive element-binding protein (ChREBP), or fatty acid synthase (FAS).

In conclusion, Sutherlandia reduces HFD-induced accumulation of liver triglycerides in rats by increasing fatty acid oxidation and deserves additional study as a phytotherapy for hepatic steatosis and related conditions. 


\section{Introduction}

Nonalcoholic fatty liver disease (NAFLD) has become a prominent chronic liver disease in developed nations and also is increasing worldwide (4). This disease impacts $30 \%$ of the U. S. population; $30 \%$ of South Americans; $27 \%$ of Asians; $24 \%$ of Europeans and $13 \%$ of Africans $(5,75,76)$. Approximately $70 \%$ of overweight/obese patients with type 2 diabetes mellitus (T2DM) worldwide have $\operatorname{NAFLD}(8,52,66)$, which is related to increasing body mass index (BMI), and will become the most prominent contributor to final stage liver disease in the United States by $2020(77,78)$. In South Africa, more than 29\% of men and 56\% of women are categorized as overweight $(\mathrm{BMI}>25)$ or obese $(\mathrm{BMI}>30)$ in South Africa (39), and for whom NAFLD is common (152).

NAFLD begins with asymptomatic hepatic steatosis (fatty liver), which leads to steatohepatitis (fatty liver and inflammation), and may end with liver fibrosis, cirrhosis and hepatocellular carcinoma (5-7). Hepatic steatosis is clinically defined when triglycerides (TG) exceed $5 \%$ of the total liver weight (12, 13). De novo lipogenesis and fatty acid oxidation are two key processes contributing to the development of hepatic steatosis $(13,51,153)$.

Phytotherapies are widely employed for mitigating obesity and other metabolic disorders such as hepatic steatosis $(16,17,87-90)$. These remedies are usually more affordable and accessible than pharmaceuticals to many people in developing countries (84). Among the phytotherapies widely used in South Africa, Sutherlandia frutescens (L.) R.Br (Sutherlandia), also known as "unwele and cancer bush", has been claimed to alleviate various chronic diseases 
including diabetes, cancer, as well as infections (18-23). Clinical and toxicological studies determined that consumption of Sutherlandia leaf powder is well tolerated by healthy and HIV-infected adults and caused no significant clinically relevant effects in biochemical and hematologic measures $(137,138)$.

Studies in rodents indicate that aqueous preparations of Sutherlandia decreased plasma free fatty acids and prevented the development of insulin resistance in male Wistar rats fed a high-fat diet (HFD) (21-23). The molecular mechanism(s) for such effects, however, remains to be established. This study tests the hypothesis that Sutherlandia consumption prevents hepatic steatosis in HFD-fed rats by reducing hepatic de novo lipogenesis and/or by increasing fatty acid oxidation.

\section{Materials and Methods}

\section{Animals and experimental design}

Male Wistar rats at 4 weeks of age were purchased from Harlan Laboratories and housed individually at the University of Missouri Animal Sciences Research Center (ASRC). They were maintained at $25^{\circ} \mathrm{C} \pm 3^{\circ} \mathrm{C}$ on a $12 \mathrm{~h}: 12 \mathrm{~h}$ light-dark cycle with free access to food and water. All animal procedures adhered to Institutional Animal Care and Use Committee's guidelines. The rats (12 animals/group) received either a standard 3.5\% soybean oil (SBO) low-fat diet (LFD) (Harlan Teklad, TD.06683, Wisconsin, USA: 20.7\% protein, $69.8 \%$ carbohydrates and $9.5 \%$ fat (expressed as $\%$ energy per $100 \mathrm{~g}$ )) or a high-fat diet (HFD) (Harlan Teklad, TD.95217, Wisconsin, USA: 18.8\% 
protein, $41.4 \%$ carbohydrates, and $39.8 \%$ fat (34\% saturated, $18 \%$ trans, $29 \%$ monounsaturated and 19\% polyunsaturated fat) (expressed as \% energy per 100g)) ad libitum. The HFD-fed rats were treated with or without Sutherlandia (aqueous extracts in drinking water at a daily dose of $50 \mathrm{mg}$ extract $/ \mathrm{kg}$ body weight or dried, milled vegetative material in the feed $(1 \% \mathrm{w} / \mathrm{w}))$ for 12 consecutive weeks. Body weight was recorded weekly.

At weeks 1 - 3 after Sutherlandia treatments, all rats were fasted overnight, and blood from tail vein was collected into ethylenediaminetetraacetic acid (EDTA)-containing collection tubes. The collected blood was then centrifuged at $2000 \times \mathrm{g}$ for 20 minutes. Plasma was removed and snap frozen in liquid nitrogen and stored at $-80^{\circ} \mathrm{C}$ for further analysis.

After 12 weeks of treatments, all rats were fasted overnight and euthanized by $\mathrm{CO}_{2}$ inhalation and cervical dislocation. Blood was removed via heart puncture and plasma was collected the same way as above. Liver tissues were removed, weighed, snap frozen in liquid nitrogen and kept at $-80^{\circ} \mathrm{C}$ for further analysis.

\section{Sutherlandia preparation}

Dried, milled vegetative material of $S$. frutescens (L.) R.Br. was purchased from Big Tree Nutraceutical (Fish Hoek, South Africa), and its composition was verified by high-performance liquid chromatography (HPLC). Extracts were prepared by mixing $50 \mathrm{~g}$ dried, crushed leaves with 2 liters of boiling water, and allowing it to cool overnight. The extract was filtered using a sterilized $0.2 \mu \mathrm{m}$ nylon filter (Fisher Scientific, Pittsburgh, PA, USA), and then stored in small 
aliquots at $-20^{\circ} \mathrm{C}$ until use. A dose of $50 \mathrm{mg}$ extract $/ \mathrm{kg}$ body weight $/$ day approximates the human equivalent dose of 3 cups of tea per day (21), and was employed in this study. Every morning, fresh Sutherlandia extract was provided to the rats, whose consumption was measured daily (approximately $25 \mathrm{~mL}$ per day), and the appropriate amount of Sutherlandia aqueous extract was adjusted according to the body weights of the rats.

Moreover, a commercial aqueous $S$. frutescens extract (ProBetix ${ }^{\circledR}$, Value Added Life Health Products (Pty) Ltd, South Africa) - a nutritional supplement widely distributed over the counter in South Africa - was also employed in this study. ProBetix ${ }^{\circledR}$ contains $90 \mathrm{mg}(39 \%)$ of Pinosundia ${ }^{\circledR}$ from the aerial parts of the S. frutescens plant and $75 \mathrm{mg}(33 \%)$ of alpha-lipoic acid (ALA or 1,2-dithiolane-3pentanoic acid) - a potent biological antioxidant naturally distributed in small amounts in plants and animals (154-156), and $65 \mathrm{mg}(28 \%)$ of excipient (e.g., inactive fillers and preservatives). An amount of 25.58 grams of the dried powder from ProBetix capsules was added to 2 liters of water. The mixture was filtered using a sterilized $0.2 \mu \mathrm{m}$ nylon filter (Fisher Scientific, Pittsburgh, PA, USA), and then stored in small aliquots at $-20^{\circ} \mathrm{C}$ until use. Rats received a dose of $50 \mathrm{mg}$ extract/kg body weight/day - the dose that Mackenzie et al. claimed to diminish plasma free fatty acids and ameliorate insulin resistance in HFD-fed rats $(22,23)$.

Sutherlandia (Su) did not appear to alter the amount of liquid or diet consumed, as rats in the LFD control, HFD control, HFD + Su tea, and HFD + Pino tea groups drank similar amounts of liquid $(25 \mathrm{~mL})$ per day (Appendix 
Figure 3-2), and HFD with or without Sutherlandia was consumed at approximately the amount expected (23 g diet per day) (157).

In addition, this dried, milled vegetative material of Sutherlandia was incorporated into the Harlan Teklad 95217 HFD. The concentration of Sutherlandioside $B\left(\mathrm{SuB}: \mathrm{C}_{36} \mathrm{H}_{60} \mathrm{O}_{10}\right.$ ) - a cycloartene-type tetracyclic triterpene saponin present in Sutherlandia $(26,93)$ - in the feed (calculated as $0.12 \mathrm{mg}$ $\mathrm{SuB} / \mathrm{g}$ diet) was adjusted to be roughly comparable to that consumed by rats when Sutherlandia was incorporated in the drinking water $(0.18 \mathrm{mg} \mathrm{SuB} / \mathrm{mL})$. In addition, the concentration of SuB in the commercial Pinosundia ${ }^{\circledR}$ is $0.64 \mathrm{mg}$ $\mathrm{SuB} / \mathrm{mL}$. High-performance liquid chromatography (HPLC) analyses of SuB in the teas are displayed in Appendix Figure 3-1 B-C.

Determination of plasma glucose, insulin, and triglycerides (TG)

Plasma concentrations of glucose and triglycerides (TG) were determined by Dr. Charles E. Wiedmeyer from the Veterinary Clinical Pathology lab using a Beckman-Coulter AU680 Clinical Chemistry instrument. Plasma insulin was measured using a commercial Rat Insulin enzyme-linked immunosorbent assay (ELISA) kit (ALPCO; Salem, New Hampshire). Duplicate measurements were performed according to the manufacturer's protocols.

\section{Determination of liver weights and TG}

Liver from each rat was weighed, and a sample was homogenized and subjected to TG measurement using commercial kits (Wako L-type TG M kit; Wako Diagnostics, Richmond, Virginia) and expressed per gram tissue. 
Duplicate measurements were performed according to the manufacturer's protocols.

\section{Liver histological analysis}

Frozen liver tissues were sectioned at $10 \mu \mathrm{m}$ with a cryomicrotome (Leica), and three sections at $50-\mu \mathrm{m}$ intervals were placed on a slide. Neutral lipids (i.e., triglycerides, diacylglycerols and cholesterol esters) in the liver sections on these slides were stained with Oil Red O (Sigma-Aldrich) as instructed in the Biological Stain Commission guidelines (158), counterstained with Mayer's hematoxylin (Sigma-Aldrich), and cover-slipped using an aqueous mounting media for microscopic examination. Four images from one randomly chosen section per slide were acquired with a Leica DM 5500B microscope fitted with a Leica DFC290 color camera. All images were acquired using a 20x HCX PL Fluotar objective and identical illumination and camera settings. The images were analyzed using Fiji image analysis software (159) by a cytologist who was unaware of treatment allocations. The number and area size of lipid droplets were calculated using a custom-written macro. Images of ORO-stained lipid droplets were separated from blue hematoxylin counterstain using the Color Deconvolution plugin for ImageJ that implements the stain separation method (160). Data from 4 different areas of the same section were averaged and used to calculate group means and standard errors of the mean (SEM).

\section{Determination of mRNA levels}

Frozen liver tissues were homogenized in TRIzol solution (Sigma-Aldrich, St. Louis, MO) using a tissue homogenizer (TissueLyser LT, Qiagen, Valencia, 
CA). Total RNA was then isolated using an RNeasy Kit (QIAGEN) and analyzed using a Nanodrop spectrophotometer (ThermoScientific, Wilmington, DE) to assess purity and concentration. Complementary DNA (cDNA) was synthesized from $1 \mu \mathrm{g}$ of total RNA using High-Capacity cDNA Reverse Transcription Kits (Applied Biosystems). Quantitative reverse transcription polymerase chain reactions (rt-q PCRs) were conducted in a $20-\mu \mathrm{L}$ final reaction volume using SYBR Green Master Mix (Biotool ${ }^{\mathrm{TM}}$ ) on a QuantStudio real-time PCR system (Applied Biosystems) to measure the relative hepatic mRNA concentrations of genes involved in the following: 1) fatty acid oxidation: peroxisome proliferatoractivated receptor $\alpha$ (PPAR- $\alpha$ ), acyl-coenzyme A oxidase-1 (ACOX-1) and cytochrome P450, family 4, subfamily A, polypeptide 14 (CYP4A14), 2) de novo lipogenesis: sterol regulatory element-binding protein-1C (SREBP-1C), carbohydrate-responsive element-binding protein (ChREBP), and fatty acid synthase (FAS), and 3) inflammation: TNF- $\alpha$, MCP-1, IL-6 and IL-4. PCR conditions were as follows: $50.0^{\circ} \mathrm{C}$ for 2 minutes ( 1 repetition), $95^{\circ} \mathrm{C}$ for 10 minutes ( 1 repetition), and $95^{\circ} \mathrm{C}$ for 15 seconds, followed by $60^{\circ} \mathrm{C}$ for 45 seconds (40 repetitions). PPAR- $\alpha$, ACOX-1, CYPA414, ChREBP, FAS, TNF- $\alpha$, MCP-1, IL6, IL-4, and 18S rRNA primers have previously been published (161-163), and were synthesized by Integrated DNA Technologies. SREBP-1C primers were designed and synthesized by Sigma-Aldrich. Primer sequences are provided in Table 3-1. All primers were tested for PCR efficiency relative to the internal control (18S rRNA) by using serial dilutions of the cDNA template. The internal control gene was determined based on its comparable expressions across the 
treatment groups. All the mRNA data were determined using the $\Delta \Delta C T$ approach (164), comparing expression of target genes relative to the housekeeping gene (18S rRNA), and the data were expressed as fold differences relative to the highfat diet control group.

Table 3-1. Sequences of primers used for rt-q PCR assays.

\begin{tabular}{|c|c|}
\hline Genes & Primer sequences \\
\hline PPAR- $\alpha$ & $\begin{array}{l}\text { Forward: 5'-GAGGTCCGATTCTTCCACTG-3' } \\
\text { Reverse: 5'-ATCCCTGCTCTCCTGTATGG-3' }\end{array}$ \\
\hline ACOX-1 & $\begin{array}{l}\text { Forward: 5'-TCAGCAGGAGAAATGGATGC-3' } \\
\text { Reverse: 5'-TGGAAGTTTTCCCAAGTCCC-3' }\end{array}$ \\
\hline CYPA414 & $\begin{array}{l}\text { Forward: 5'-CTTGATGACACTGGACAC-3' } \\
\text { Reverse: 5'-ACTCCATCTGTGTGCTCATG-3' }\end{array}$ \\
\hline SREBP-1C & $\begin{array}{l}\text { Forward: 5'-AAACCTGAAGTGGTAGAAAC-3' } \\
\text { Reverse: 5'-TTATCCTCAAAGGCTGGG-3' }\end{array}$ \\
\hline ChREBP & $\begin{array}{l}\text { Forward: 5'-CCTGAAGACCCAAAGACCAA-3' } \\
\text { Reverse: 5'-AGATGGAGTGCAGGGCTCTA-3' }\end{array}$ \\
\hline FAS & $\begin{array}{l}\text { Forward: 5'-AGTGAGTGTACGGGAGGGCT-3' } \\
\text { Reverse: 5'-GCTGGGACACATGTGATGGT-3' }\end{array}$ \\
\hline TNF- $\alpha$ & $\begin{array}{l}\text { Forward: 5'-ATTGCTCTGTGAGGCGACTG-3' } \\
\text { Reverse: 5'-GGGGCTCTGAGGAGTAGACG-3' }\end{array}$ \\
\hline MCP-1 & $\begin{array}{l}\text { Forward: 5'-CTGTCTCAGCCAGATGCAGTTAA-3' } \\
\text { Reverse: 5'-AGCCGACTCATTGGGATCAT-3' }\end{array}$ \\
\hline IL-6 & $\begin{array}{l}\text { Forward: 5'-AGAGACTTCCAGCCAGTTGC-3' } \\
\text { Reverse: 5'-AGCCTCCGACTTGTGAAGTG-3' }\end{array}$ \\
\hline $\mathrm{IL}-4$ & $\begin{array}{l}\text { Forward: 5'-CGTGATGTACCTCCGTGCTT-3' } \\
\text { Reverse: 5'-GTGAGTTCAGACCGCTGACA-3' }\end{array}$ \\
\hline $18 \mathrm{~S}$ & $\begin{array}{l}\text { Forward: 5'-GCCGCTAGAGGTGAAATTCTTG-3' } \\
\text { Reverse: 5'-CATTCTTGGCAAATGCTTTCG-3' }\end{array}$ \\
\hline
\end{tabular}




\section{Statistical analysis}

Data are expressed as mean \pm standard errors of the mean (SEM). Comparisons between group means were carried out using one-way analysis of variance (ANOVA) followed by the Tukey-Kramer multiple comparisons test. The level of significance was set at $p$-value $<0.05$. Minitab statistical software package version 17 (Minitab Inc., State College, PA) was used for all statistical tests.

\section{Results}

\section{Effects of Sutherlandia consumption on body weight and liver weight}

Wistar, male rats were fed either a 3.5\% SBO low-fat diet (LFD: $9.5 \%$ fat) or a high-fat diet (HFD: $39.8 \%$ fat) ad libitum. The HFD-fed rats were treated with or without Sutherlandia (Su) in the aqueous extracts at a daily dose of $50 \mathrm{mg}$ extract/kg body weight (HFD + Su tea or HFD + Pinosundia ${ }^{\circledR}$ (Pino) tea) or in the feed (HFD + 1\%Su diet) for 12 consecutive weeks. The average body weight in all animal groups was comparable within the first three weeks of treatment (Figure 3-1 A); however, by the end of the 12-week treatment, the average body weight of the untreated HFD-fed rats was significantly greater than that of the LFD-fed rats $(p<0.025$, Figure 3-1 A). Remarkably, Sutherlandia treatments reduced body weight of the rats fed HFD compared to the untreated HFD group, and the average body weights of those rats fed HFD with Sutherlandia (HFD + Su tea, HFD + Pino tea, or HFD + $1 \%$ Su diet) were intermediate to those of the LFD and HFD controls $(p>0.05$, Figure 3-1 A). 
At week 12 of treatment, all of the rats were fasted overnight, euthanized, and several tissues including livers were collected. All three forms of Sutherlandia treatments also reduced fasting liver weight in rats fed HFD compared to those fed HFD alone (Figure 3-1 B). Even though this reduction was not statistically significant ( $p>0.05$, Figure 3-1 B), all Sutherlandia treatments, especially the $1 \%$ Sutherlandia powder integrated in the HFD, brought the liver weight down to be comparable with the LFD control group.

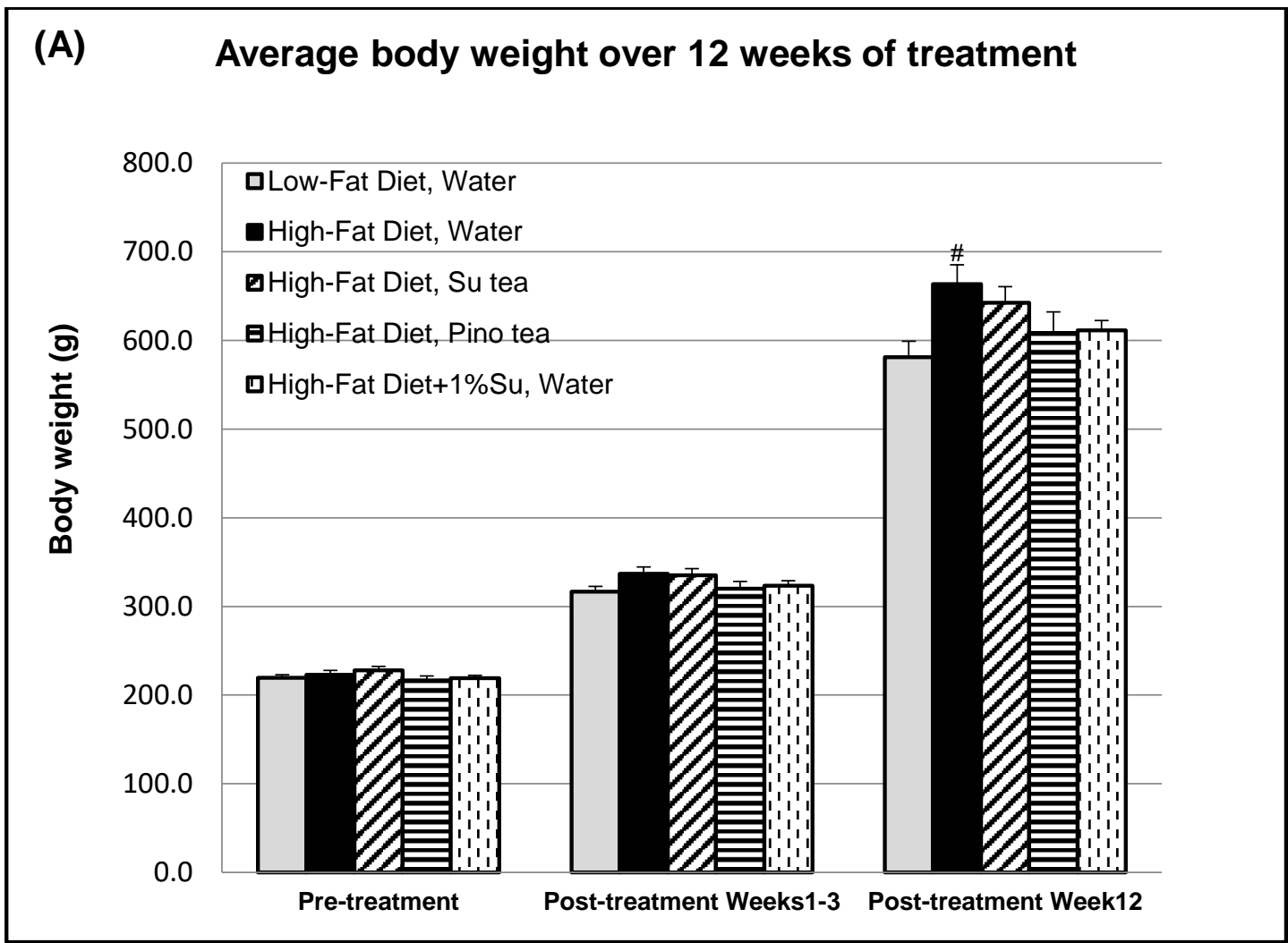




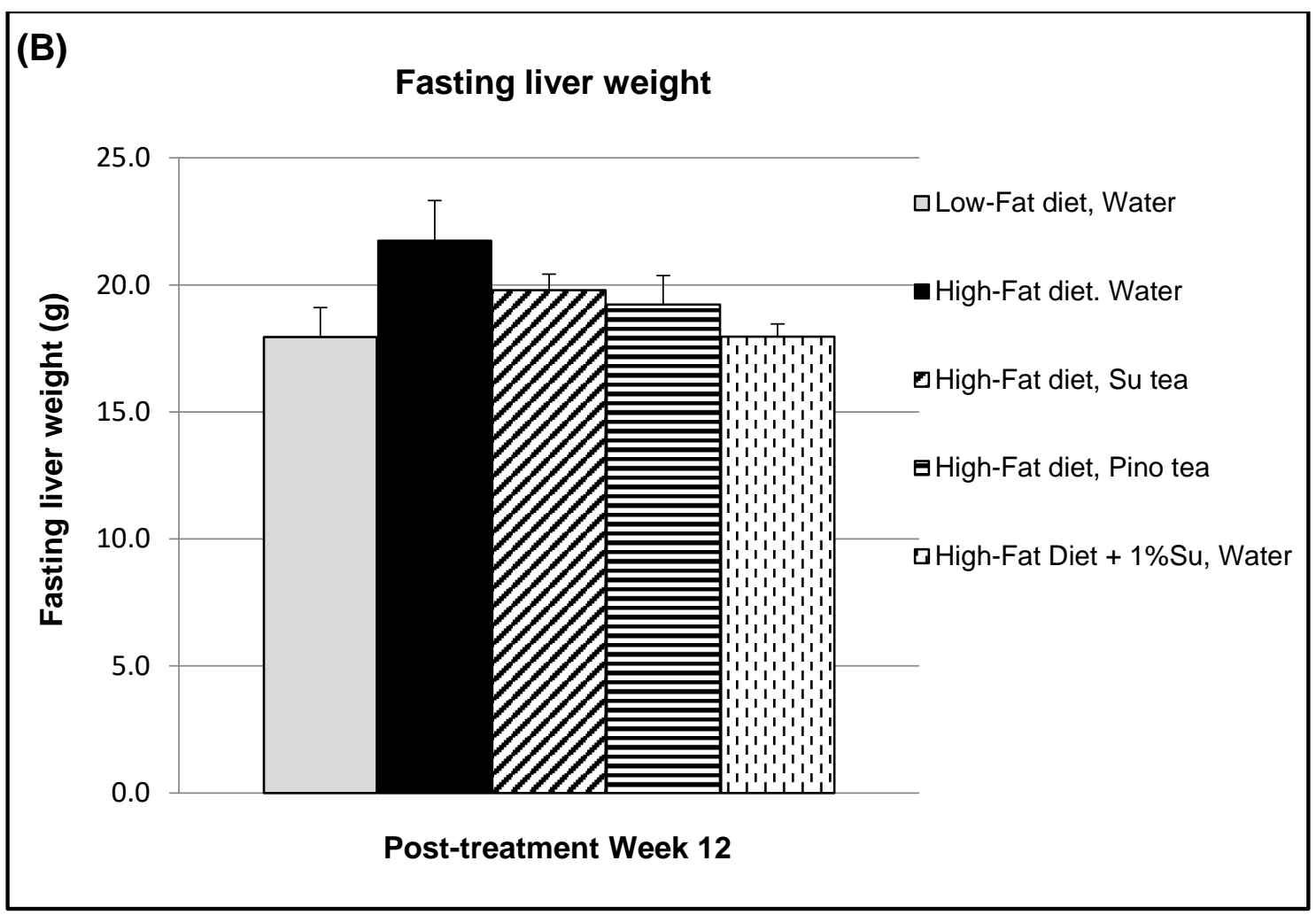

Figure 3-1. Effects of Sutherlandia on body weight (A) and fasting liver weight (B) of HFD-fed rats. Data are expressed as mean \pm standard errors of the mean (SEM) of each group; $n=11-12$ per group. Comparisons between groups were carried out using one-way analysis of variance (ANOVA) followed by Tukey-Kramer multiple comparisons test. ${ }^{\#} p<0.025$ versus the LFD group.

\section{Effects of Sutherlandia consumption on plasma homeostasis}

Levels of fasting plasma glucose, insulin, triglycerides (TG), and free fatty acids (FFA) were not of significant difference among five groups at initial and final post-treatment (Figure 3-2 A), indicating that these rats did not develop diabetes or insulin resistance. 
A decrease in plasma insulin and FFA in HFD-fed rats medicated with all three forms of Sutherlandia administrations compared to the untreated HFD group was also observed ( $p>0.05$, Figure 3-2 B, D).

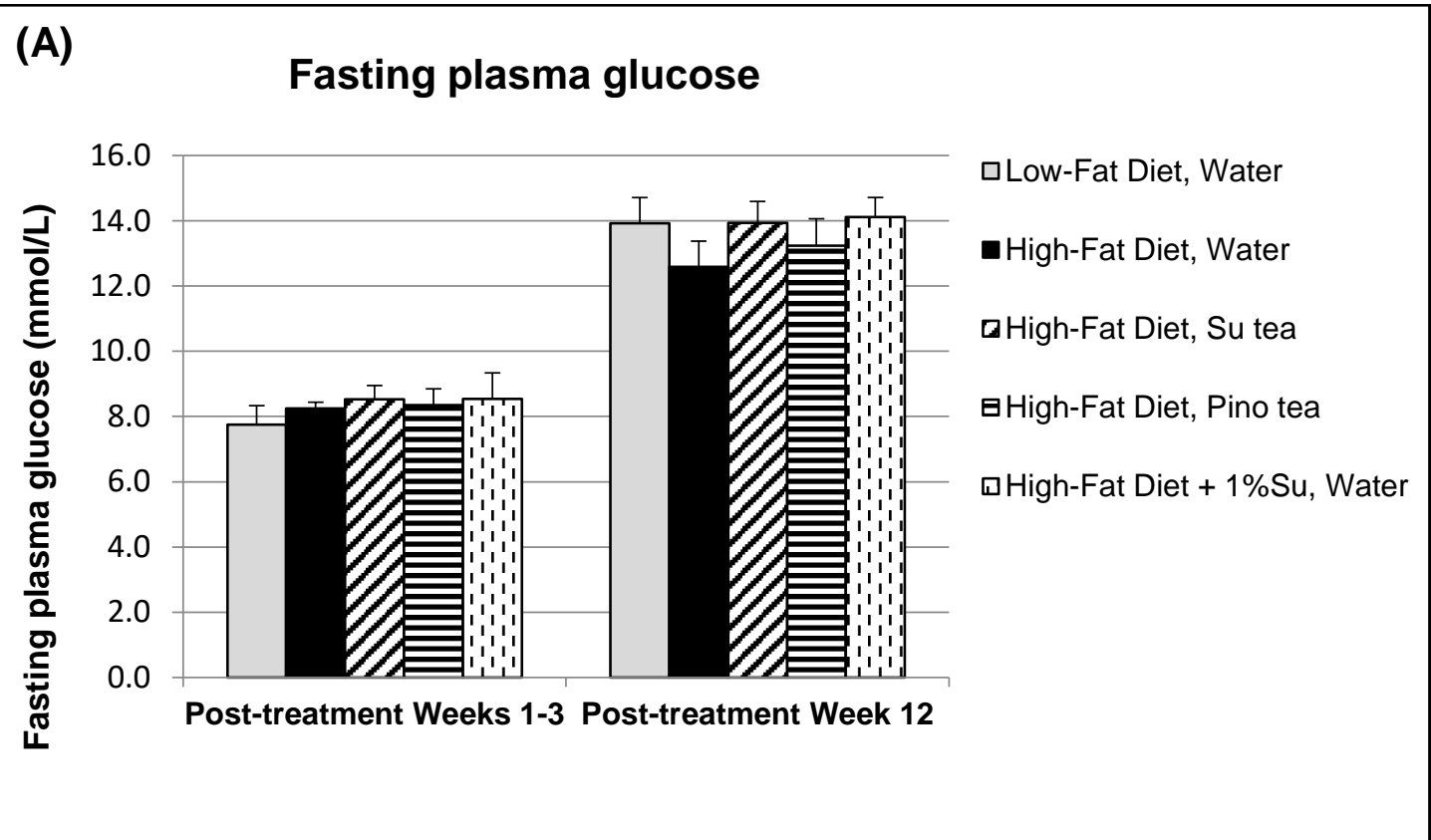

(B)

Fasting plasma insulin

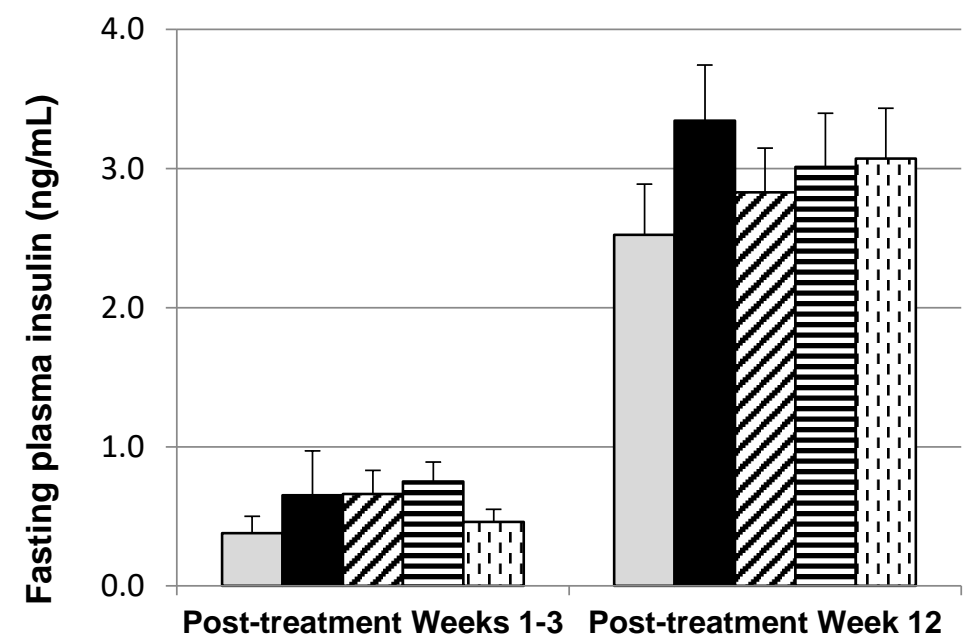

$\square$ Low-Fat Diet, Water

- High-Fat Diet, Water

bigh-Fat Diet, Su tea

घHigh-Fat Diet, Pino tea

口High-Fat Diet + 1\%Su, Water 


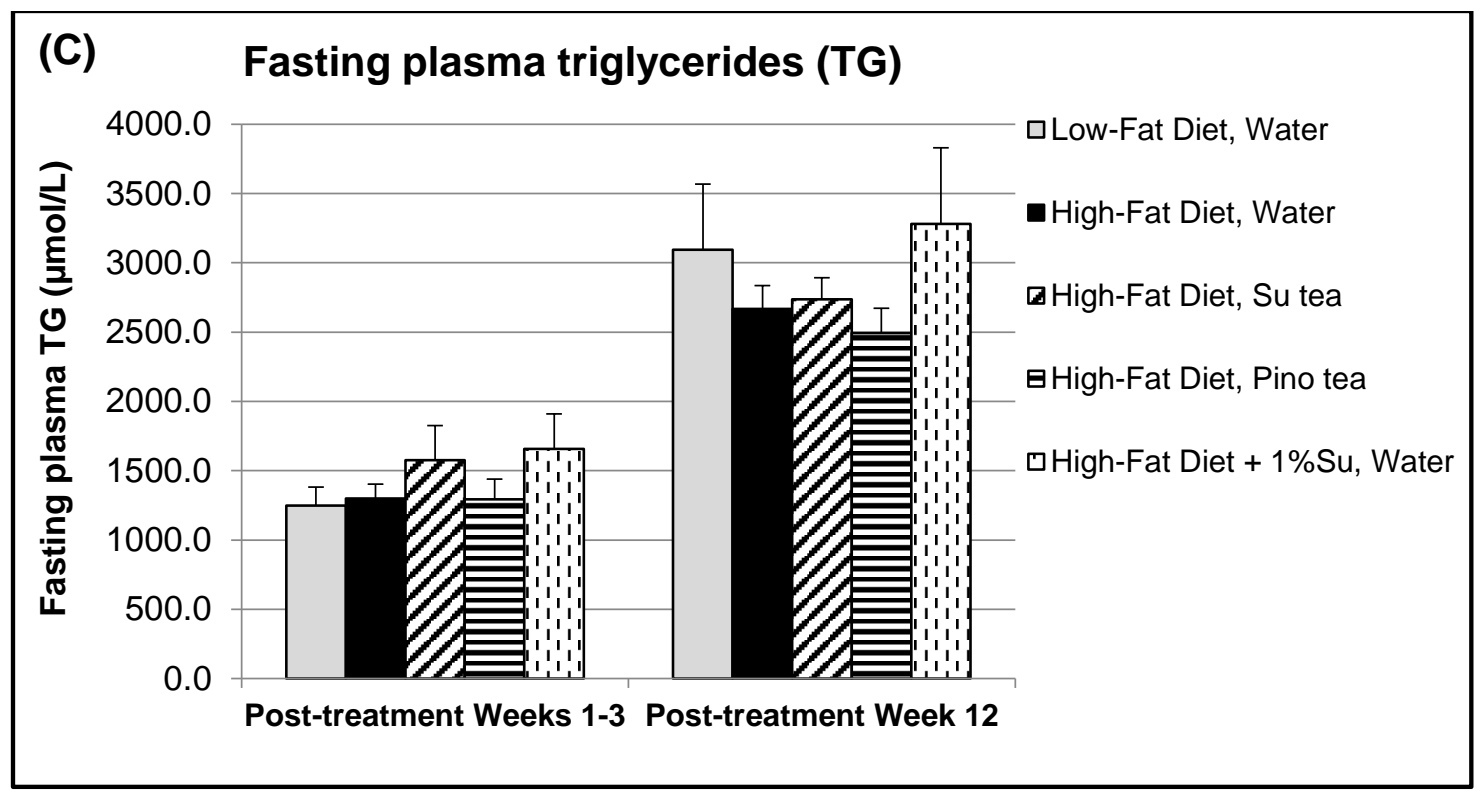

\section{(D) Fasting plasma free fatty acids (FFA)}

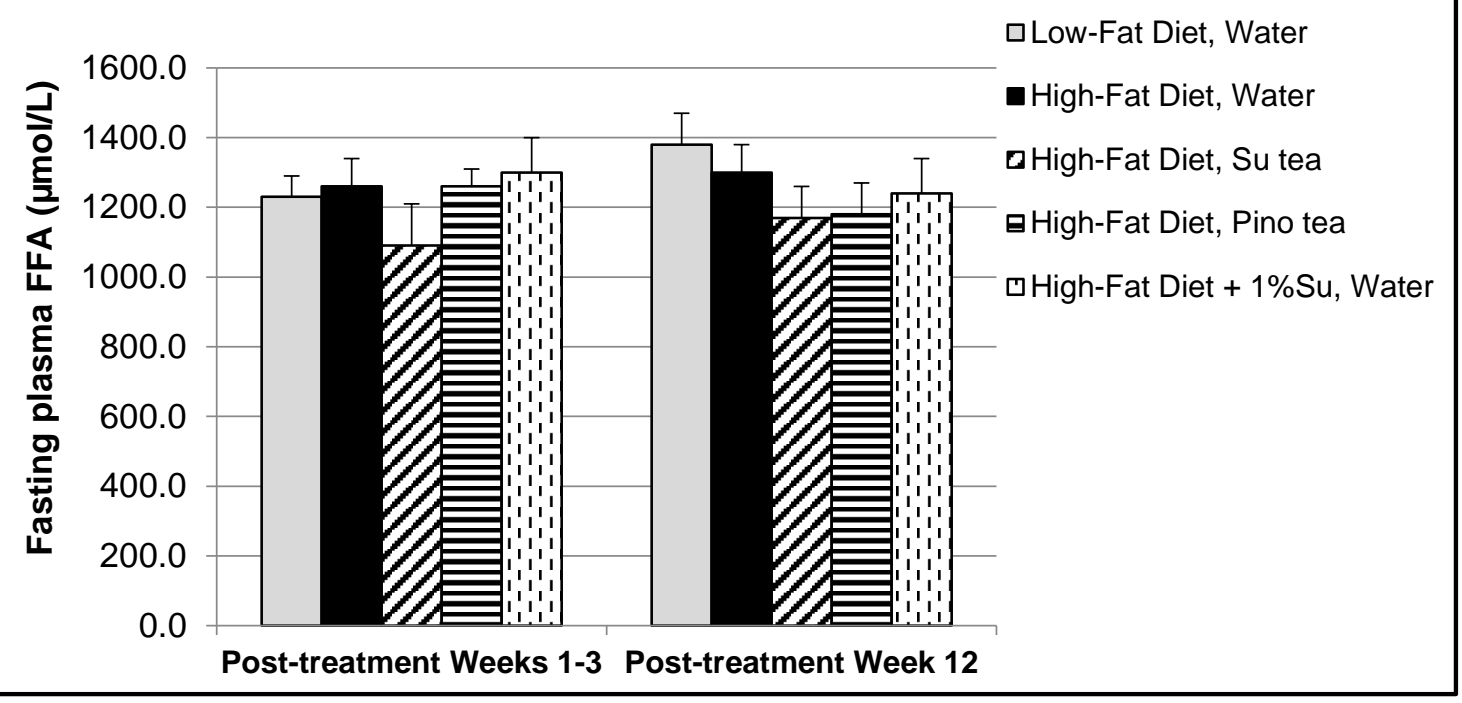

Figure 3-2. Effects of Sutherlandia on fasting plasma glucose (A), insulin (B), triglycerides (C), and free fatty acids (D) of HFD-fed rats. Data are expressed as mean \pm standard errors of the mean (SEM) of each group; $n=11$ 12 per group. Comparisons between groups were carried out using one-way analysis of variance (ANOVA) followed by Tukey-Kramer multiple comparisons test. ${ }^{\#} p<0.025$ versus the LFD group. 


\section{Sutherlandia treatments mitigate hepatic steatosis in HFD-fed rats}

To determine whether Sutherlandia regulates hepatic steatosis, we investigated hepatic TG content. HFD rats developed hepatic steatosis by week 12 and both Sutherlandia tea and Sutherlandia powder in the feed significantly reduced total liver TG levels (Figure 3-3 A) as well as TG fraction of liver weight (Figure 3-3 B) compared to the untreated HFD-fed rats $(p<0.05)$, showing that Sutherlandia inhibits hepatic steatosis in obese animals. In addition, Pinosunsia tea also diminished total liver TG levels (Figure 3-3 A) as well as TG fraction of liver weight (Figure 3-3 B), albeit this decrease was not statistically significant ( $p$ $>0.05)$.

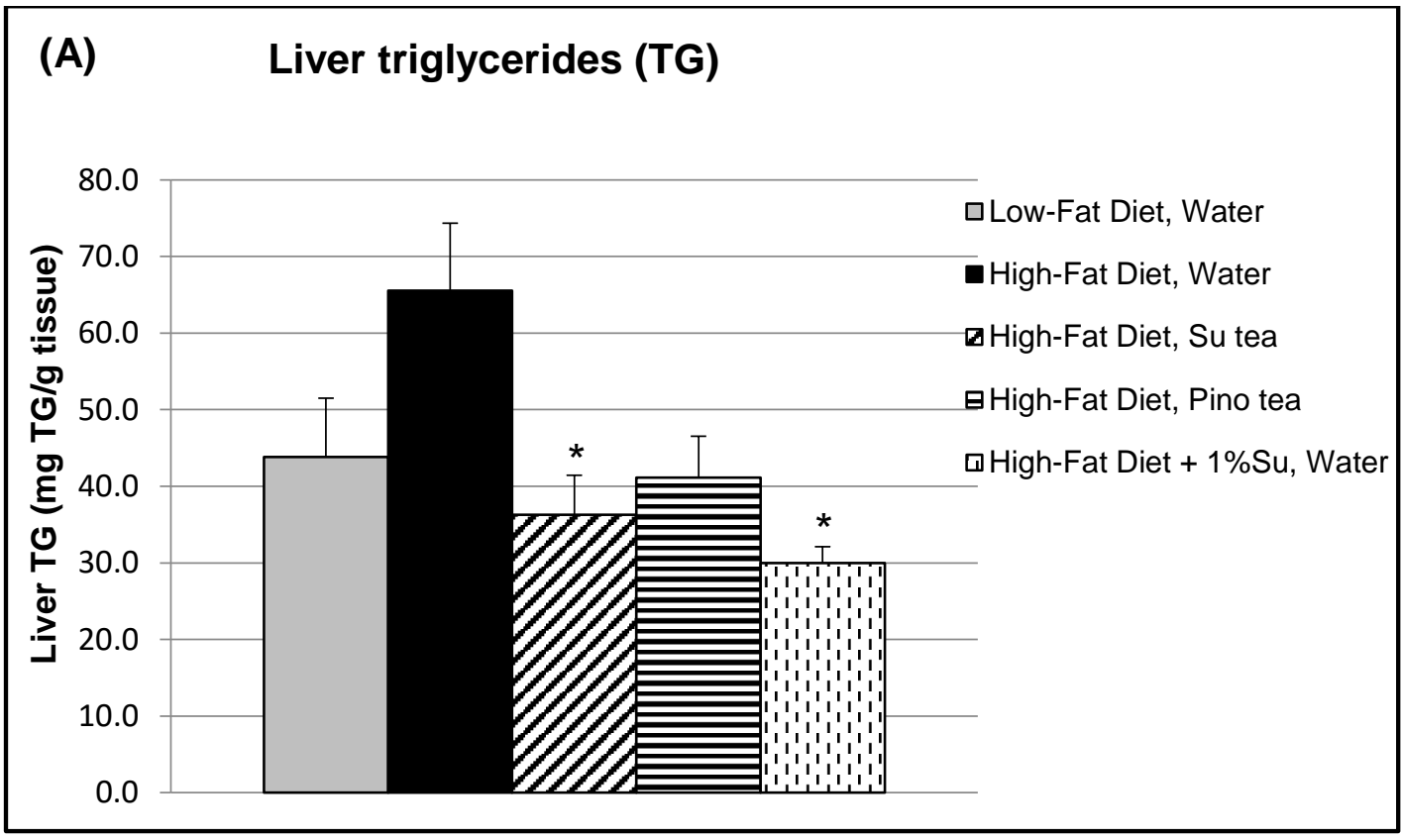


(B) Percentage of Liver Triglycerides (TG) in the total liver

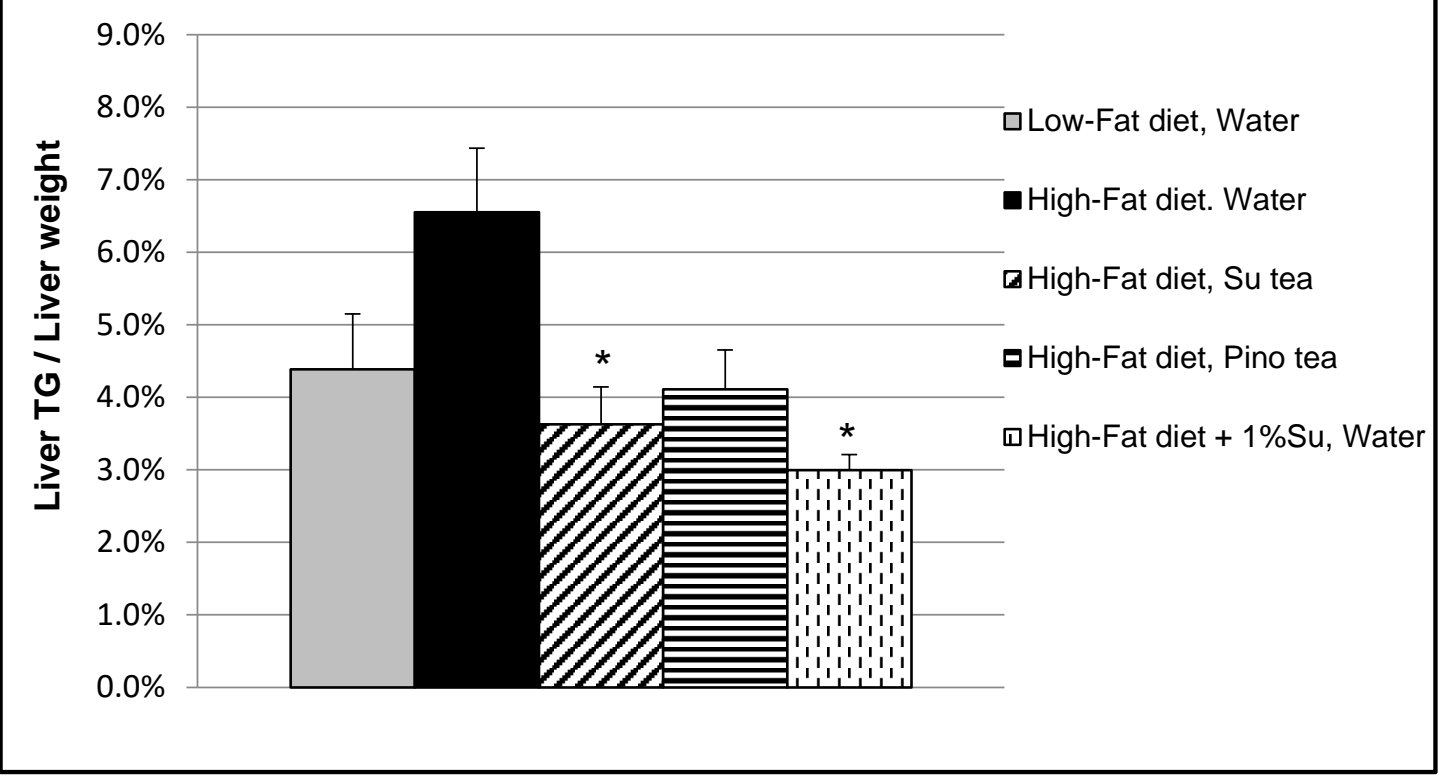

Figure 3-3. Inhibition of hepatic steatosis by Sutherlandia treatments in HFD-fed rats. (A) Liver TG concentrations, and (B) Percentage of Liver Triglycerides (TG) in the total liver weight. Data are expressed as mean \pm standard errors of the mean (SEM) of each group; $n=11-12$ per group. Comparisons between groups were carried out using one-way analysis of variance (ANOVA) followed by Tukey-Kramer multiple comparisons test. ${ }^{*} p<$ 0.05 versus the HFD group.

Sutherlandia treatments reduce intrahepatocellular lipid accumulation in HFD-fed rats

Frozen livers were sectioned and stained by Oil Red O (ORO) and counterstained with Mayer's hematoxylin to visualize and assess changes in lipid droplets that comprise neutral lipids (primarily triglycerides and cholesterol esters). Larger, but fewer lipid droplets were observed in the HFD control group compared to the LFD control and the Sutherlandia treatment groups (Figure 3-4). 
(A)

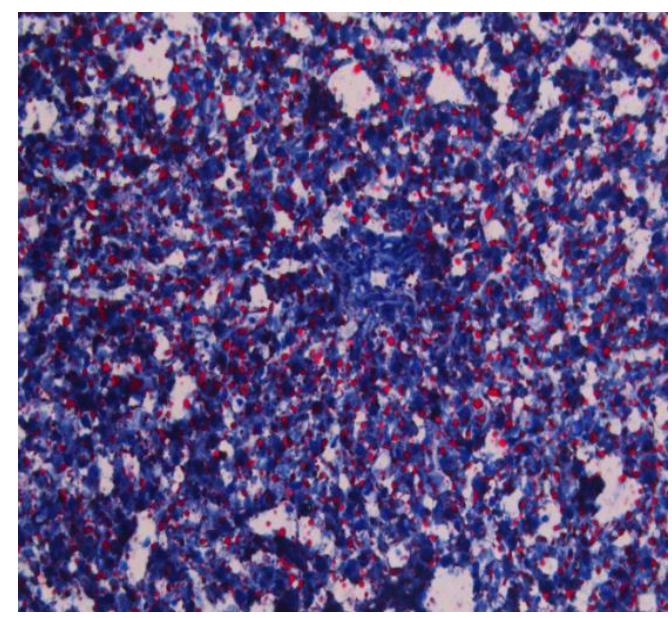

(C)

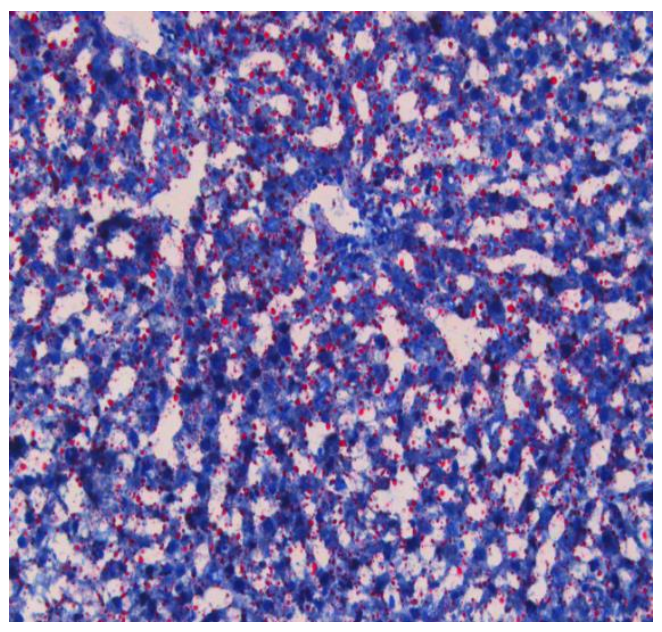

(B)

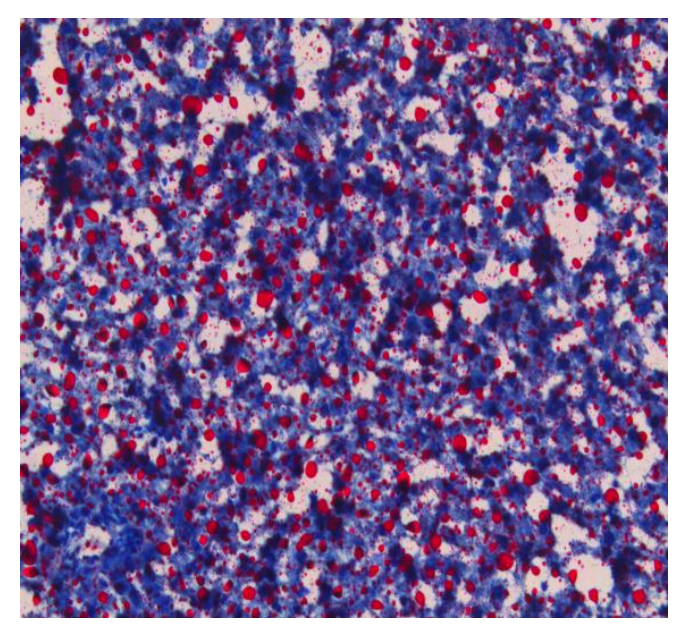

(D)

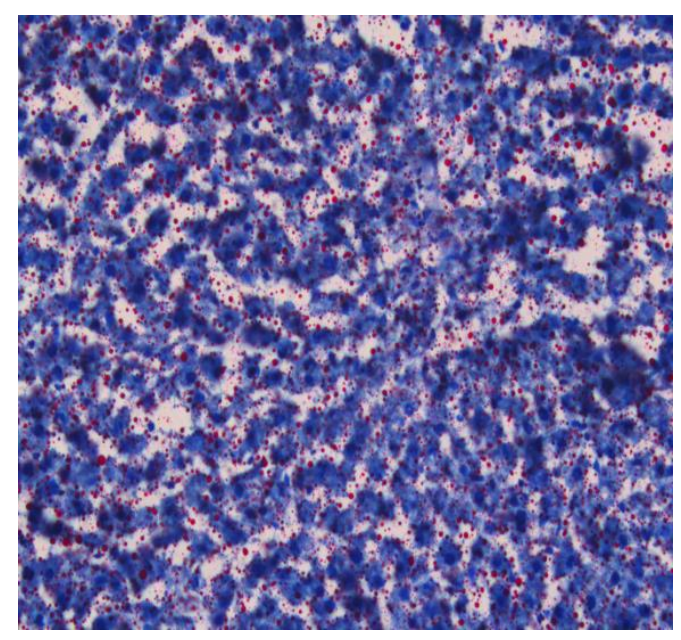

Figure 3-4. Effects of Sutherlandia treatments on morphology of lipid

droplets. Representative sections of livers from rats fed (A) LFD, (B) HFD, (C) HFD + Su tea, or (D) HFD + 1\%Su were stained by ORO and counterstained with Mayer's hematoxylin (original magnification, 20X).

Livers of rats in both the Sutherlandia treatment groups had lipid droplets with significantly smaller area compared to those in the HFD control group $(p<$ 0.05 , Figure $3-5 \mathrm{~A})$. The smaller lipid droplet size in these two treatment groups was associated with a slightly higher number of lipid droplets in the HFD + Su tea 
group and with a remarkably higher number of lipid droplets in the HFD $+1 \%$ Su diet (Figure 3-5 B) compared to the HFD control group.

Lipid droplet volume was also evaluated to examine the degree of TG storage in cytoplasmic lipid droplets (165). Total volume was measured by multiplying the number of lipid droplets by the mean volume of lipid droplets (166). The smaller lipid droplet size in both Sutherlandia treatment groups resulted in remarkably less total droplet volume $(p<0.05$, Figure 3-5 C) even though these two treatment groups accumulated more, smaller lipid droplets compared to the HFD control group. This is consistent with the measurements of hepatic TG (Figure 3-3) and may reflect compositional differences in neutral lipids deserving further study.

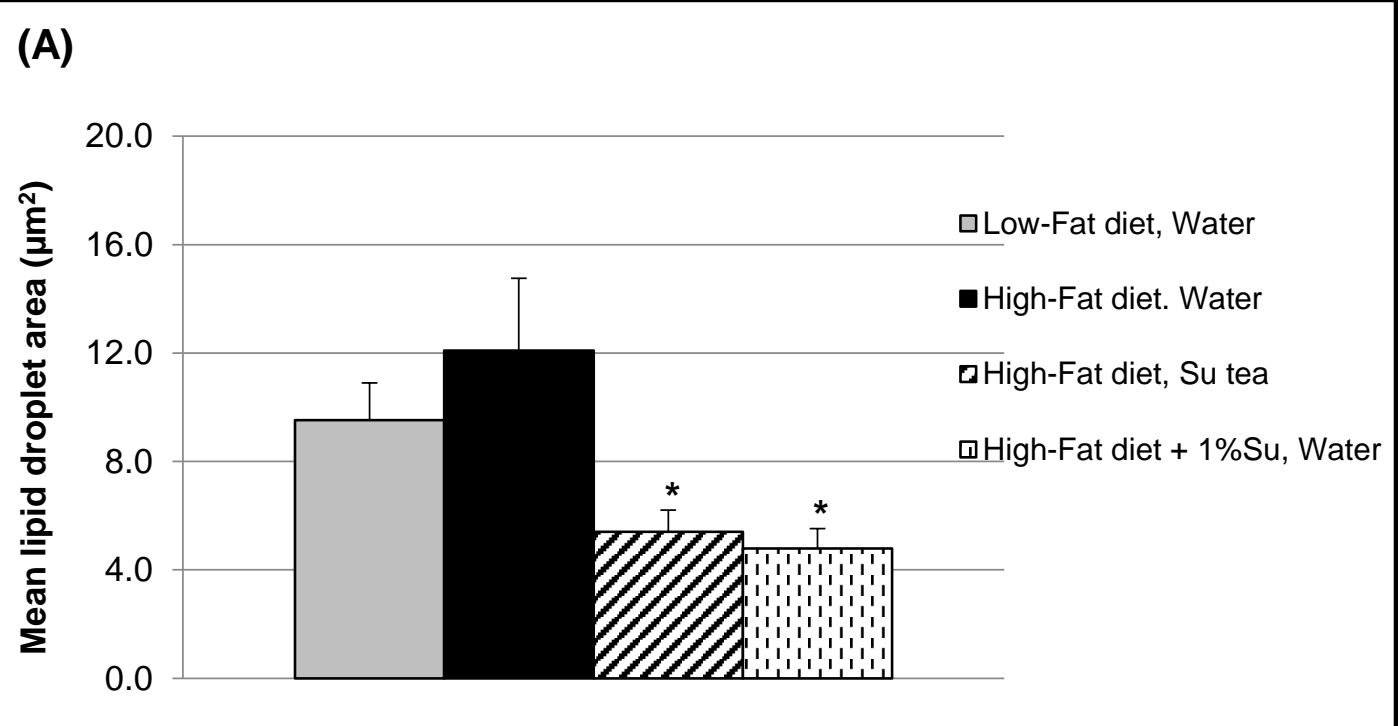


(B)
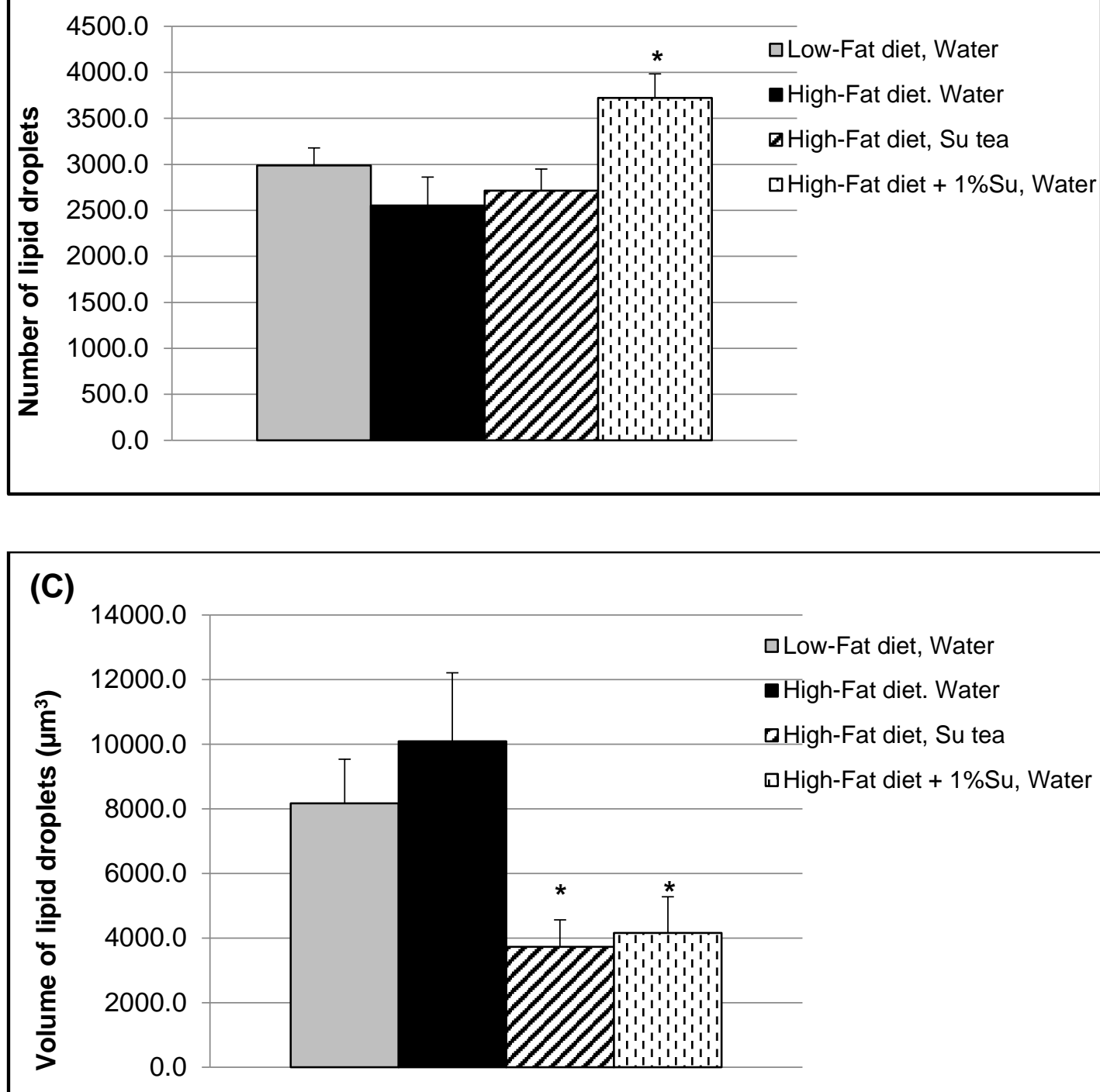

Figure 3-5. Effects of Sutherlandia treatments on size and number of lipid droplets in livers of HFD-fed rats. (A) Mean lipid droplet area. (B) Number of lipid droplets. (C) Volume of lipid droplets. Data are expressed as mean \pm standard errors of the mean (SEM) of each group; $n=8-9$ per group.

Comparisons between groups were carried out using one-way analysis of variance (ANOVA) followed by Tukey-Kramer multiple comparisons test. ${ }^{*} p<$ 0.05 versus the HFD group. 


\section{Sutherlandia treatments alter expression of lipid metabolism genes}

To evaluate whether the effects of Sutherlandia on hepatic steatosis are due to modification of fatty acid oxidation, we measured mRNA levels of the PPAR- $\alpha$ transcription factor as well as its target genes ACOX-1 and CYP4A14 by rt-q PCR. The mRNA expression of PPAR- $\alpha$, ACOX-1 and CYP4A14 was significantly lower in the HFD control group compared to the LFD control group ( $p$ $<0.01$, Figure 3-6 A-C). All Sutherlandia treatments reversed this negative effect of HFD by significantly increasing hepatic mRNA expression of PPAR- $\alpha(p<$ $0.01)$, ACOX-1 $(p<0.01)$, and CYP4A14 $(p<0.05)$ (Figure 3-6 A-C).

De novo lipogenesis also plays a role in development of hepatic steatosis. Therefore, we quantified mRNA expression of transcription factors sterol regulatory element-binding protein-1C (SREBP-1C) and carbohydrate-responsive element-binding protein (ChREBP) as well as its target gene fatty acid synthase (FAS). Feeding the HFD for 12 consecutive weeks remarkably increased mRNA expression of SREBP-1C $(p<0.05$, Figure 3-6 D) and ChREBP $(p<0.01$, Figure 3-6 E), but not FAS ( $p>0.05$, Figure 3-6 F). Treatment with either Sutherlandia or Pinosundia tea caused slightly reduced expression of SREBP-1C, ChREBP, and FAS genes; however, there was no statistically significant difference at $p<$ 0.05 (Figure 3-6 D-F). Similarly, dried Sutherlandia in the feed caused slightly decreased expression of ChREBP and FAS, but not SREBP-1C, but this was not statistically significant $(p>0.05$, Figure 3-6 D-F). 
These results suggest that Sutherlandia consumption mitigates hepatic steatosis by upregulating fatty acid oxidation-associated genes without significantly changing de novo lipid synthesis.

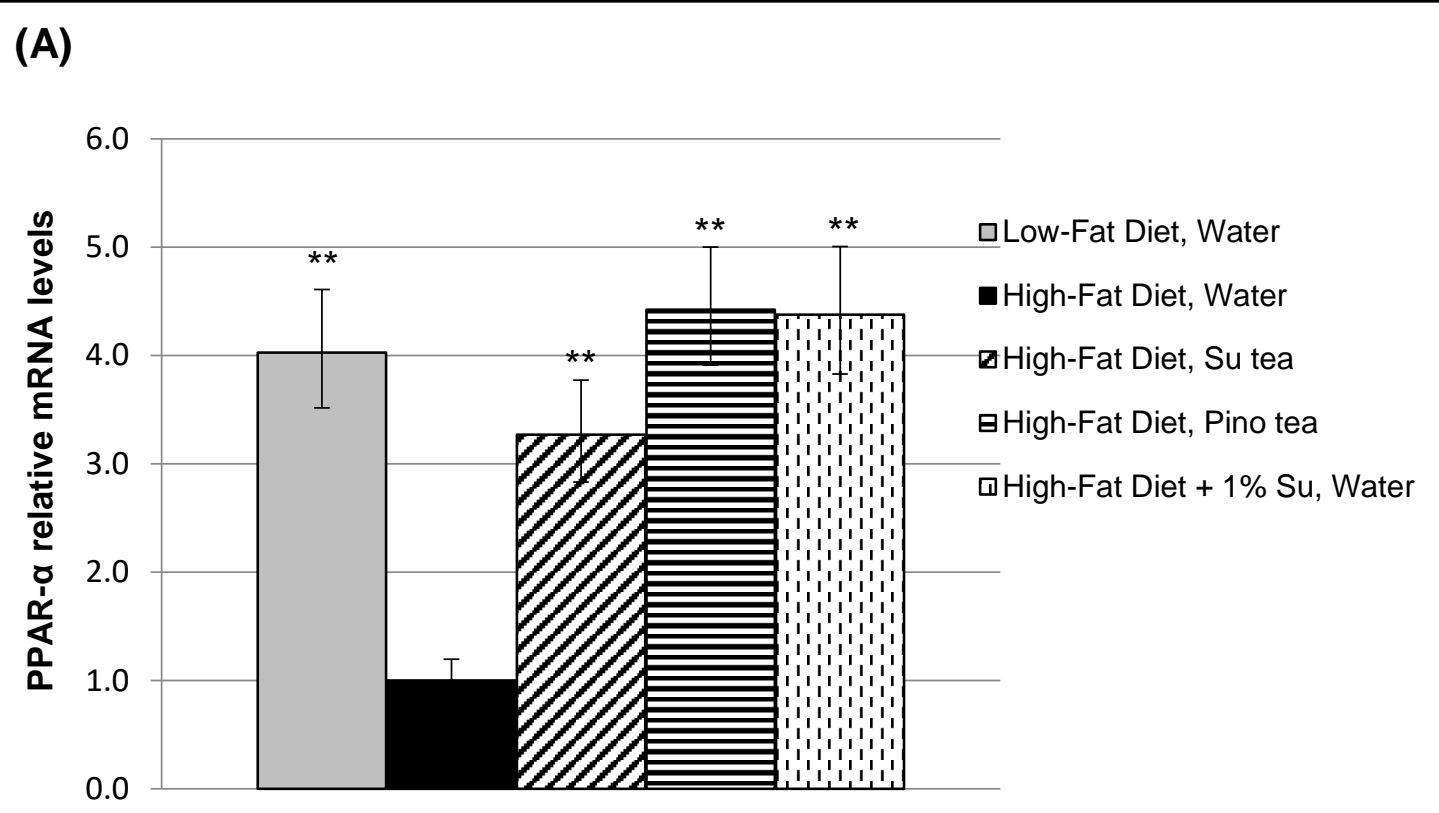

(B)

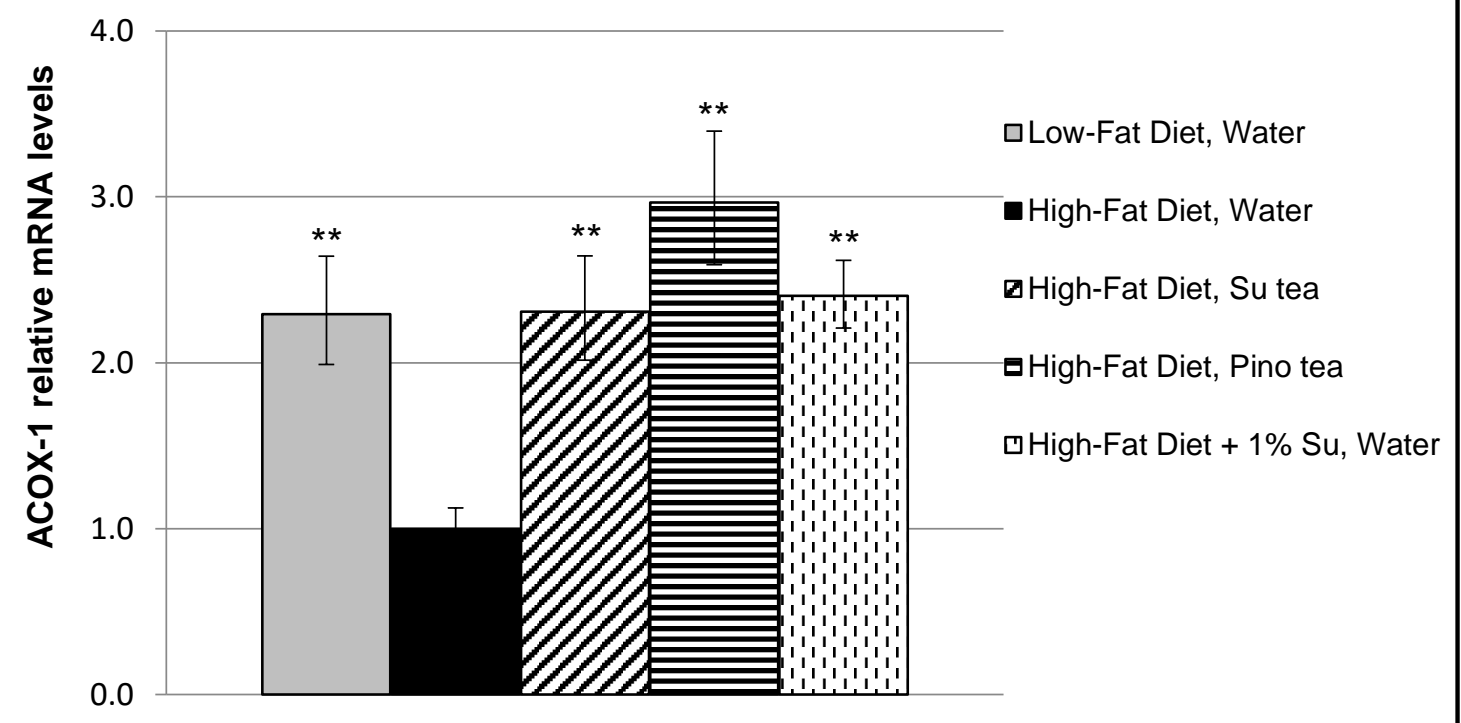




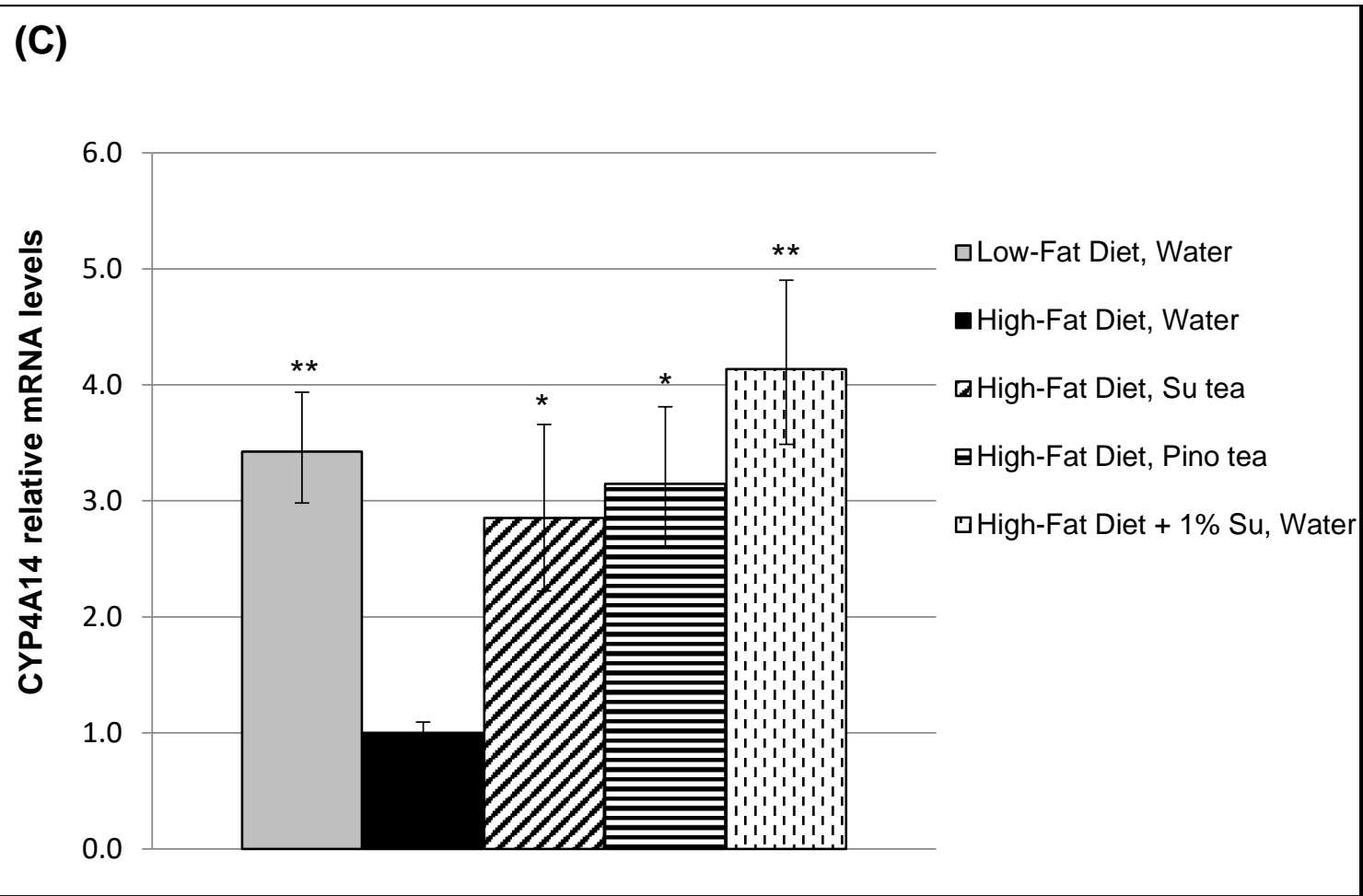

(D)

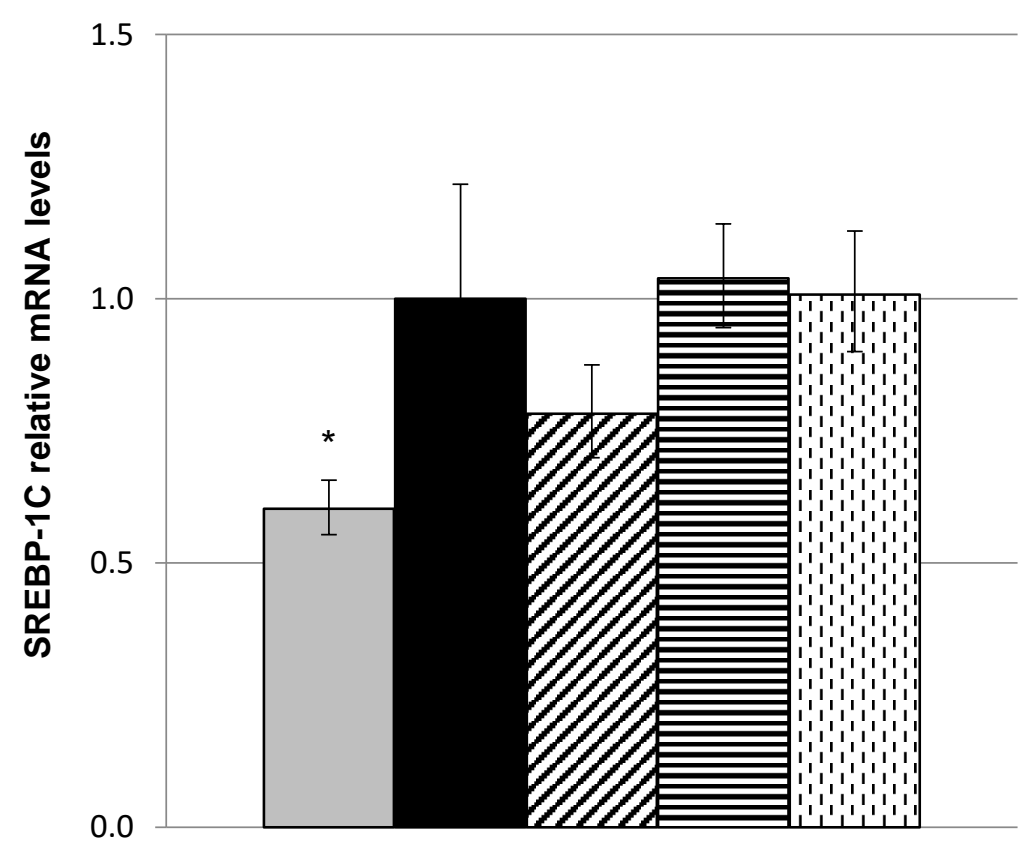

$\square$ Low-Fat Diet, Water

- High-Fat Diet, Water

च High-Fat Diet, Su tea

घHigh-Fat Diet, Pino tea

$\square$ High-Fat Diet + 1\% Su, Water 
(E)

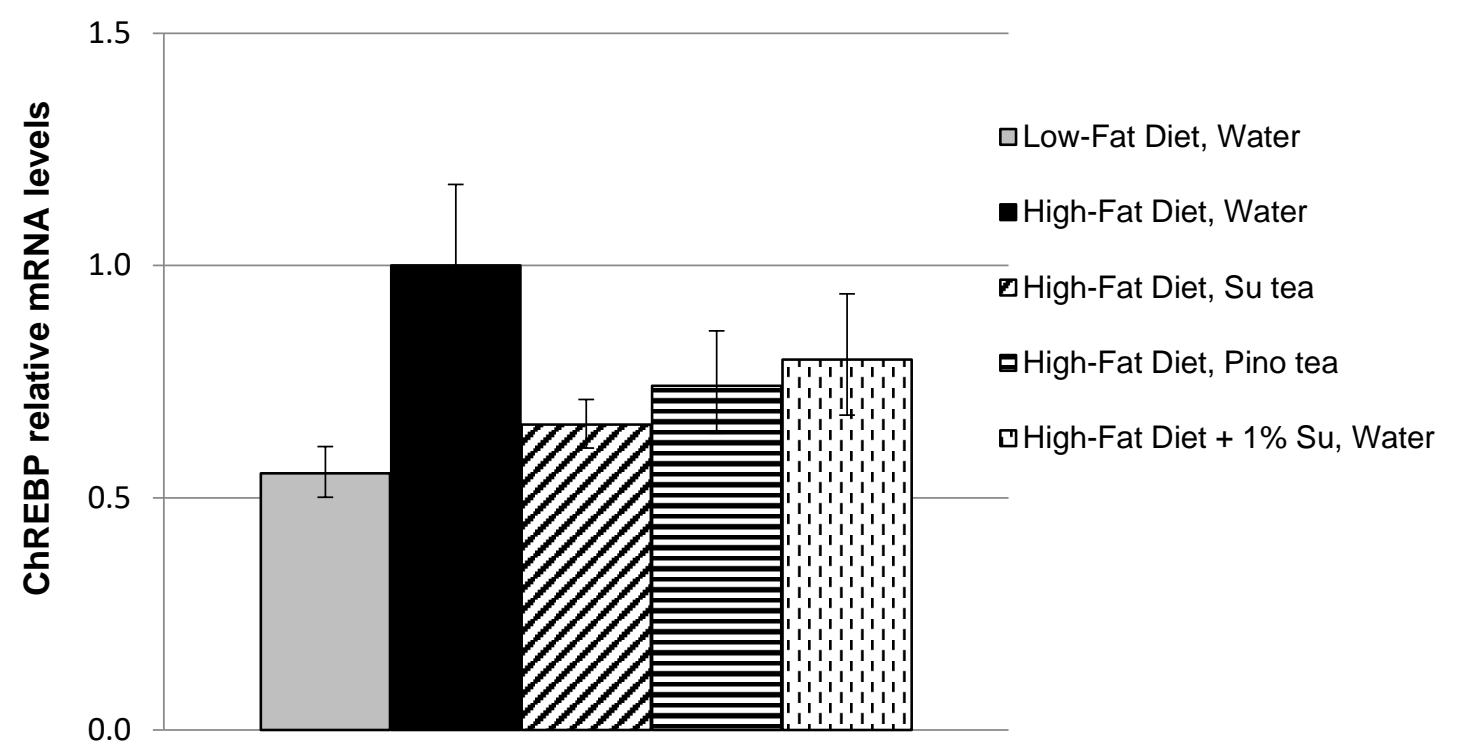

(F)

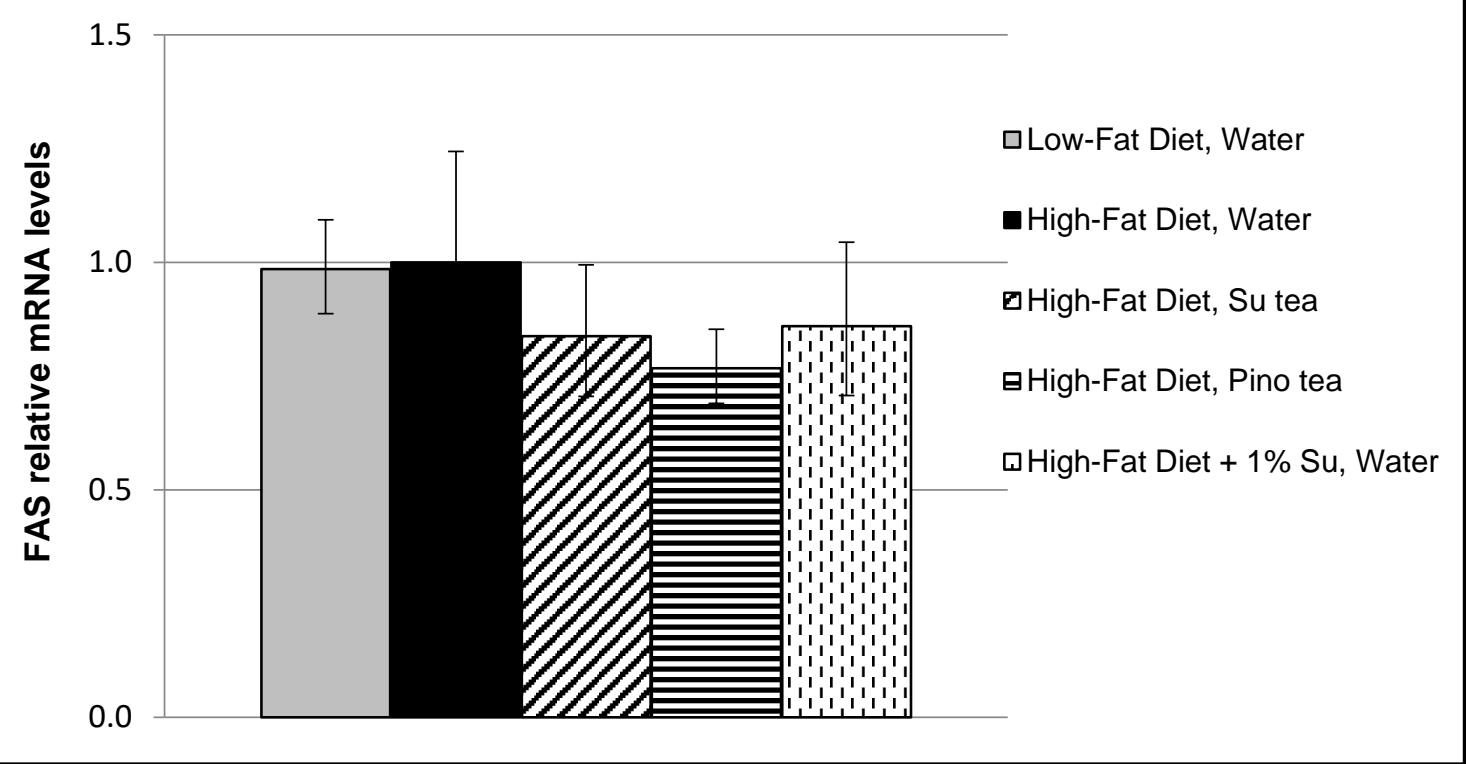

Figure 3-6. Effects of Sutherlandia on mRNA expression of genes involved in hepatic lipid metabolism. mRNA levels of (A) PPAR-a, (B) ACOX-1, (C) CYP4A14, (D) SREBP-1C, (E) ChREBP, and (F) FAS were measured by rt-q PCRs. Data are expressed as mean \pm standard errors of the mean (SEM) of 
each group; $n=11-12$ per group. Comparisons between groups were carried out using one-way analysis of variance (ANOVA) followed by Tukey-Kramer multiple comparisons test. ${ }^{*} p<0.05$ versus the HFD group, ${ }^{* *} p<0.01$ versus the HFD group.

\section{Effects of Sutherlandia treatments on hepatic inflammation}

Hepatic steatosis may be accompanied with hepatic inflammation (167, 168), so the impact of Sutherlandia treatments on inflammation was examined.

The mRNA levels of pro-inflammatory cytokines TNF- $\alpha$, IL-6 and MCP-1, and of anti-inflammatory cytokine IL-4 were not considerably different among five groups ( $p>0.05)$; moreover, these changes were highly variable (Figure 3-7).

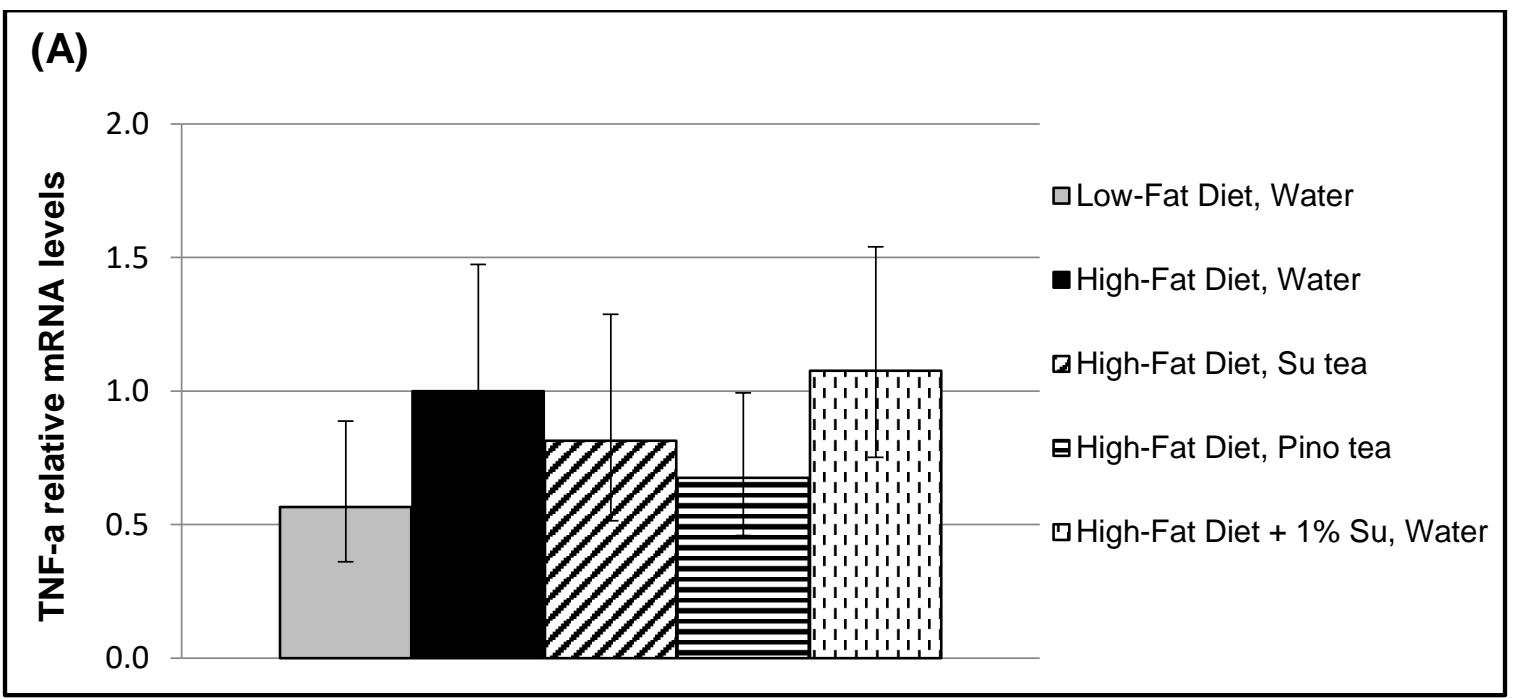


(B)
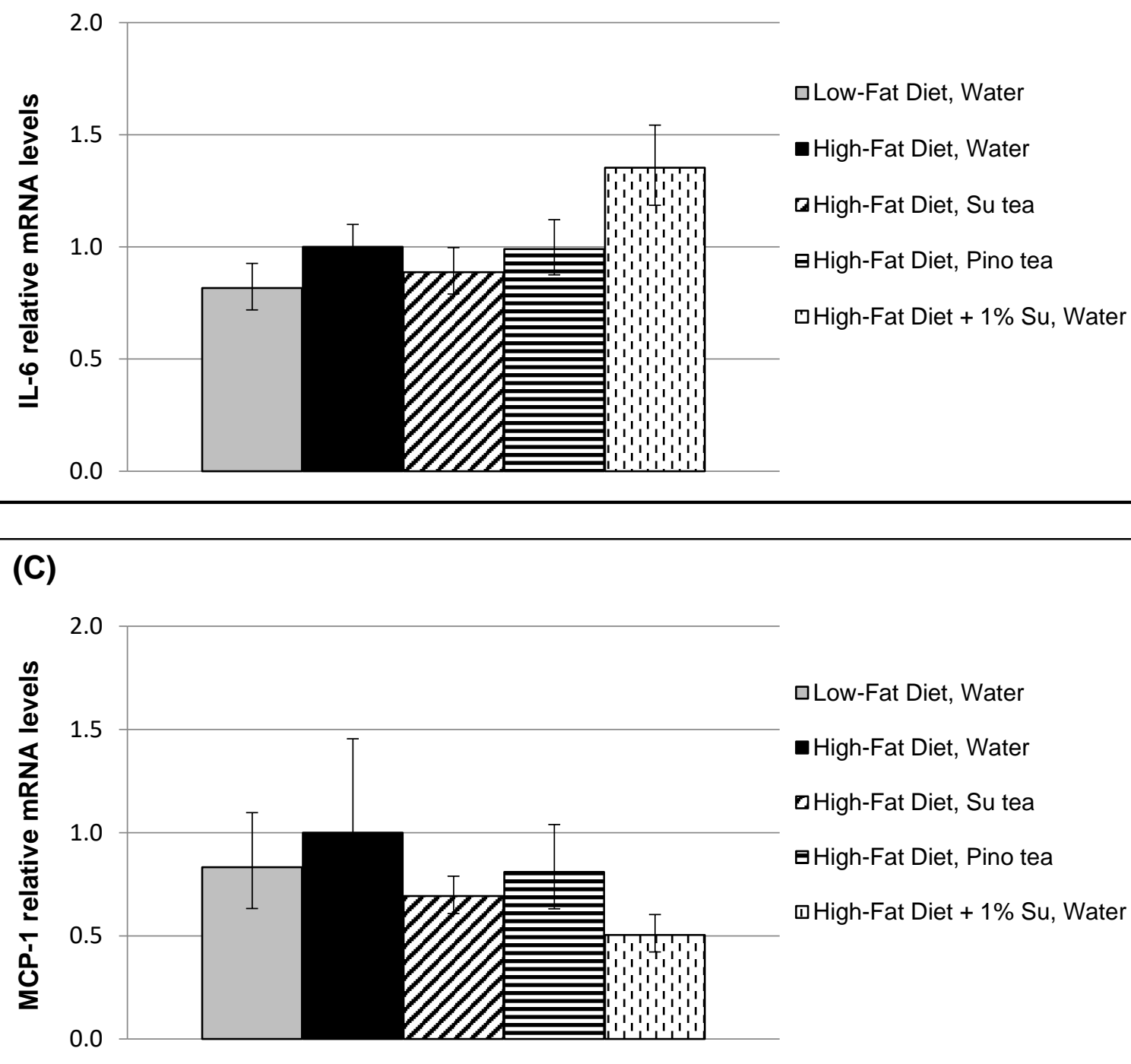


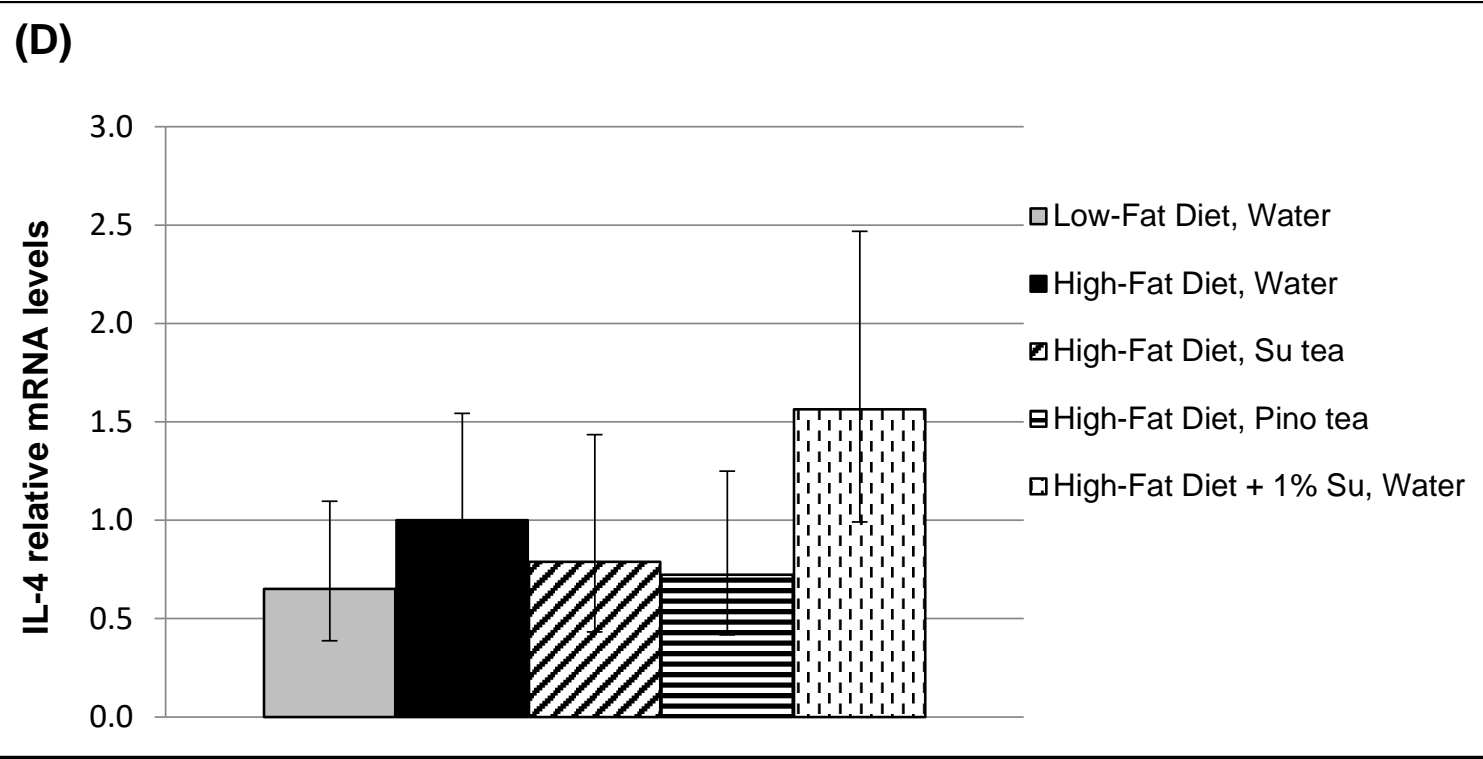

Figure 3-7. Effects of Sutherlandia on mRNA expression of inflammatory genes. mRNA levels of (A) TNF- $\alpha$, (B) IL-6, (C) MCP-1, and (D) IL-4 were measured by rt-q PCRs. Data are expressed as mean \pm standard errors of the mean (SEM) of each group; $n=11-12$ per group. Comparisons between groups were carried out using one-way analysis of variance (ANOVA) followed by Tukey-Kramer multiple comparisons test. ${ }^{*} p<0.05$ versus the HFD group, ${ }^{* *} p<$ 0.01 versus the HFD group.

\section{Discussion and Conclusion}

NAFLD, pathologically ranging from hepatic steatosis to steatohepatitis, fibrosis, and cirrhosis and hepatocellular carcinoma in some cases, is the most common liver disease in developed nations (5-7), and has been increasing rapidly in the developing world including South Africa (4). Hepatic steatosis, also known as fatty liver, is closely associated with obesity, T2DM, and hyperlipidemia $(169,170)$. Phytotherapies are increasingly being employed for metabolic 
diseases $(16,17,87-90)$, and for which Sutherlandia has been extensively used in complementary and alternative medicines for diabetes in South Africa (18).

Studies in rodents have shown that aqueous extracts of Sutherlandia reduced plasma free fatty acids and inhibited the development of insulin resistance (21-23). Recently, Williams et al. (2013) reported that Sutherlandia extracts altered diabetes-related gene expression in a fructose-induced insulin resistant human Chang liver cell model (35). Numerous bioactive compounds in Sutherlandia have been identifed that might be responsible for such effects, including L-canavanine, D-pinitol, gamma-aminobutyric acid (GABA), triterpenoid glycosides, and modified flavonoids (18); but mechanisms of action remain to be elucidated. D-pinitol has been reported to reduce blood sugar levels (29), and Lcanavanine has been shown to interfere with arginine uptake essential for Nitrogen Oxide (NO) production $(19,25)$ that can destroy beta cells $(97)$, thus preventing the inhibition of insulin production (98). Triterpenoid glycosides exerted hypoglycemic effects and enhanced fatty acid oxidation (31). Quercetin, a well-recognized flavonoid, elicited beneficial effects in alleviation of hepatic steatosis in C57/BL6J mice fed a high-fat, high-cholesterol and high-sucrose Western-style diet for 20 weeks by reducing hepatic triglycerides, decreasing oxidative stress and improving hepatic lipid metabolism by significantly increasing transcriptional expression of PPAR- $\alpha$ as well as suppressing expression of PPAR-y, CD36, SREBP-1c, and FAS (33). Moreover, kaempferol (3,5,7,4'-tetrahydroxyflavone), another well-known flavonoid, lowered hepatic triglycerides and lipid droplet accumulation by increasing lipid metabolism 
through upregulation of PPAR- $\alpha$, acyl-CoA oxidase (ACO), cytochrome P450 isoform 4A1 (CYP4A1), and downregulation of SREBPs in the livers of rats fed a high-fat diet (34).

This study demonstrates anti-steatotic effects of Sutherlandia extracts in HFD-fed rats, including reduced hepatic triglycerides, decreased lipid droplet accumulation, and elevated expression of fatty acid oxidation pathway members. That is, Sutherlandia aqueous extracts delivered in tea and Sutherlandia powder delivered in feed both significantly attenuated liver triglyceride accumulation in HFD-fed rats compared to those fed HFD only.

Hepatocytes are responsible for mobilizing lipids for energy and storing excess lipids in the form of lipid droplets, mainly triglycerides and cheloestrol esters, thereby rendering the liver a crucial organ accounting for lipid homeostasis $(171,172)$. In this study, Sutherlandia tea and Sutherlandia powder in feed led to increased numbers of hepatic lipid droplets, but the smaller sizes of these droplets reflects the lesser lipid content of the liver. The greater total number of lipid droplets may have been due to augmented lipid efflux; indeed, droplets can undergo fission to expand surface area as well as the amount of lipids accessible to enzymes involved in lipid efflux and lipolysis (171). The smaller lipid droplet phenotype also may be indicative of greater mitochondrial fat oxidation as indicated by gene expression profiling.

Remarkably, the striking improvements observed in the livers of rats treated with Sutherlandia were not paralleled by robust changes in body weight, liver weight, plasma glucose, plasma insulin, plasma triglyceride, and plasma free fatty acids levels, suggesting Sutherlandia presents metabolic effects in a 
tissue-specific manner and the effects are not contingent upon weight loss. More specifically, plasma glucose displayed no significant changes in these five groups, which was documented by Chadwick et al. (21) and Mackenzie et al. (22, 23). In this case, the pancreas is supposed to release higher amounts of insulin to transport the same glucose levels into target tissues so as to maintain normoglycemia (173). Analysis of fasting insulin levels showed slightly higher values in the untreated HFD group compared to other groups, implying that these animals were not insulin resistant. This outcome contrasts the observations from Chadwick et al. (21) and Mackenzie et al. (22, 23). One reason accounting for the fact that the animals in this study were neither diabetic nor insulin resistant would be because these Wistar rats are outbred, meaning that they possess considerable genetic variation reminiscent of the genetic heterogeneity of the human condition (174).

Peroxisome proliferator-activated receptor $\alpha$ (PPAR- $\alpha)$ is a ligandactivated transcription factor that modulates the expression of several genes responsible for fatty acid oxidation in the liver such as peroxisomal acylcoenzyme A oxidase-1 (ACOX-1) and microsomal cytochrome P450, family 4, subfamily A, polypeptide 14 (CYP4A14) (175-178). The CYP4 family of cytochrome P450s catalyzes omega hydroxylation of saturated, branched chain, and unsaturated fatty acid; in particular, the cytochrome P450 4A (CYP4A) subfamily is one of the 18 subfamilies that consists of 20 individual forms in 9 different mammalian species $(179,180)$. The expression of CYP4A14 is selectively induced by PPAR- $\alpha$ (180-182). Our study showed that all three forms 
of Sutherlandia treatments significantly increased hepatic mRNA expression of PPAR- $\alpha$ and its target genes including ACOX-1 and CYP4A14 in the liver of the rats fed HFD with Sutherlandia versus those fed HFD alone. Moreover, SREBP$1 \mathrm{C}$ and ChREBP control the expression of genes involved in the fatty acid biosynthetic pathway or de novo lipogenesis (183). However, in this study, none of the Sutherlandia treatments altered hepatic mRNA expression of SREBP-1C and ChREBP or their target gene, FAS. Taken together, this implies that the antisteatotic effect of Sutherlandia is likely due to an elevation in hepatic fatty acid oxidation.

Furthermore, fatty liver may be accompanied with hepatic inflammation $(167,168)$, but this phenomenon was not observed in this study due to the very subtle signs of hepatic steatosis in this rodent model under this diet regimen. In fact, the mRNA levels of pro-inflammatory cytokines TNF- $\alpha$, IL-6 and MCP-1, and of anti-inflammatory cytokine IL-4 were not substantially different among five groups.

In addition, alpha-lipoic acid was shown to elicit beneficial effects on glucose and lipid metabolism (184-186), as well as attenuate hepatic steatosis in HFD-fed mice (187). Nonetheless, it was not detected in Pinosundia tea by current HPLC analysis (Appendix Figure 3-1 C), which is contrasting to what was shown on the label of the ProBetix ${ }^{\circledR}$ bottle (Value Added Life Health Products (Pty) Ltd, South Africa). Instead, HPLC analysis displayed that Pinosundia tea has a mixture of sutherlandiosides $B, C$, and D (Appendix Figure 3-1 C). In light of the fact that the standard of alpha-lipoic acid was not included for compare 
and contrast in this analysis, further analytical methods are required to fully characterize the metabolite profile of Pinosundia tea.

The findings of this study should be considered in light of its limitations. As mentioned above, hepatic mitochondrial oxidative capacity was not directly measured; rather, histological and gene expression analyses together served as indirect measures of hepatic lipid metabolism. Future in vivo and in vitro studies should directly assess the effects of Sutherlandia treatment on hepatic lipid oxidation. One way to measure to directly fatty acid oxidation is to assess mitochondrial oxidation levels from the liver cells. In addition, Sutherlandia was administered ad libitum and thus specific administered dose could not be determined. However, the fact that all delivery systems (i.e., in tea and in feed) resulted in significant improvements compared to non-treated rats is noteworthy. Moreover, it is unlikely that the effects were due to taste aversion, which would have resulted in lower energy consumption, since there were no significant differences in body weight between the untreated and treated HFD-fed rats. The fact that the treated groups were not statistically different from the LFD control rats suggests a very modest body weight reduction which was consistent across treatment vehicle groups. Nonetheless, future studies should employ methods to accurately assess dose as well as food intake and systemic energy expenditure. 


\title{
CHAPTER FOUR
}

\section{QUANTIFICATION OF SUTHERLANDIOSIDES BY INDIRECT COMPETITIVE ELISA}

\begin{abstract}
Sutherlandia frutescens (L.) R. Br. (Sutherlandia) is a medicinal plant of southern Africa that is frequently employed as a dietary supplement and a traditional remedy for multiple chronic diseases such as diabetes, cancer and infections. Scientific evidence for the these claimed benefits of Sutherlandia, however, is limited. Sutherlandia contains significant quantities of novel and unique cycloartenol glycosides (sutherlandiosides). Furthermore, studies in animal models supported by the University of Missouri (MU) Center for Botanical Interaction Studies and the MU Research Board require determination of the Sutherlandia bioactive compounds in tissues and fluids. Importantly, my research demonstrated that Sutherlandia extracts, which contain sutherlandiosies, ameliorate hepatic lipid accumulation in high-fat diet-induced obese rats. In order to determine the concentrations of the unique sutherlandiosides in plasma samples of these rats, an indirect competitive enzyme-linked immunosorbent assay (ELISA) was developed in collaboration with the Department of Chemistry of Natural Compounds, Institute of Chemical Technology Prague, Czech Republic.
\end{abstract}


The results demonstrated successful development of a standard curve using purified sutherlandiosides from the Sutherlandia plant material.

Quantification of sutherlandiosides in plasma, however, was not successful due to very low levels of sutherlandiosides present in plasma. In the future, a more specific assay is required to reliably and consistently measure concentrations of sutherlandiosides in biological samples for analysis of the mechanism(s) of action of S. frutescens.

\section{Introduction}

S. frutescens is a multipurpose medicinal plant that is widely used in southern African for a variety of chronic diseases such as T2DM, inflammation, cancer, stomach problems, influenza, and HIV/AIDS in southern Africa (18-23). Recently, sutherlandiosides A through D (cycloartanol glycosides) - unique compounds of $S$. frutescens - have been characterized (Figures 2.4) $(26,27)$. Sutherlandioside $B$ is the major cycloartene-type tetracyclic triterpene glycoside in S. frutescens (2.75\%, weight by total weight of dry plant sample) (27). None of these sutherlandiosides showed anti-microbial and anti-malarial activities (26). However, a number of studies showed that Sutherlandia extracts elicited antidiabetic $(21-23,116)$, anti-inflammatory (116), anti-prostate cancer (106), and anti-psychological stress (134) effects. In my research, Sutherlandia extracts, which contain sutherlandiosies, were reported to ameliorate hepatic lipid accumulation in high-fat diet-induced obese rats (Chapter 3). Consequently, 
there is a need to determine Sutherlandia bioactive compounds in tissues and fluids.

Liquid chromatography (LC)-ultra violet (UV)/evaporative light scattering detectors (ELSD) methods have been developed to measure flavonoids and cycloartanol glycosides from aerial parts of Sutherlandia frutescens (27). Nevertheless, the limit of detection (LoD) of $7.5 \mu \mathrm{g} / \mathrm{mL}$ and limit of quantitation (LoQ) of $25 \mu \mathrm{g} / \mathrm{mL}$ (due to the low UV absorption of the sutherlandiosides) render these methods inappropriate for detection and quantitation of the minute amounts present in biological samples such as plasma, sera and tissues. Furthermore, these analytical methods require extensive sample preparation, which is often not possible. To overcome the lack of sensitivity of the currently available analytical methods, we have developed a competitive ELISA immunoassay that can detect sutherlandiosides in a more sensitive and effective way compared to the LC/ELSD method. The validation of the ELISA assay for sutherlandiosides will enable correlations between bioavailability of sutherlandiosides in biological samples and observed changes in RNAs and proteins.

The objective of this study is to develop, optimize, and validate an indirect competitive ELISA assay for quantification of the sutherlandiosides in sera, plasma, urine, and tissues of clinical samples and of animal samples.

\section{Materials and Methods}

Purified sutherlandioside B (SuB) coupled to ovalbumin (OVA) was prepared and used to raise polyclonal rabbit antibodies against the 
sutherlandioside moiety by Lukáš Huml (Department of Chemistry of Natural Compounds, Institute of Chemical Technology Prague, Czech Republic). The reaction between these antibodies and SuB-OVA coated onto wells of a polystyrene microplate was detected by goat anti-rabbit immunoglobulin $G(\lg G)$ peroxidase and 3,3',5,5'-Tetramethylbenzidine (TMB). In specific, SuB-OVA (0.4 $\mu \mathrm{g} / \mathrm{mL}$ ) was pipetted into polystyrene microplate wells and incubated overnight for absorption. Then, aliquots of the matrix to be tested or partially purified SuB standard (a dilution gradient ranging from $0.01-1,000 \mathrm{ng} / \mathrm{mL}$ or $10^{1}-10^{6}$ $\mathrm{pg} / \mathrm{mL})$ and the anti-SuB rabbit antiserum $(833 \mathrm{ng} / \mathrm{mL})$ were added and incubated. After washing, goat anti-rabbit IgG-peroxidase was added, incubated and washed, and TMB was then added to react with peroxidase. The enzyme reaction was stopped with sulfuric acid and the absorabance at $450 \mathrm{~nm}$ was measured. (Figure 4-1).
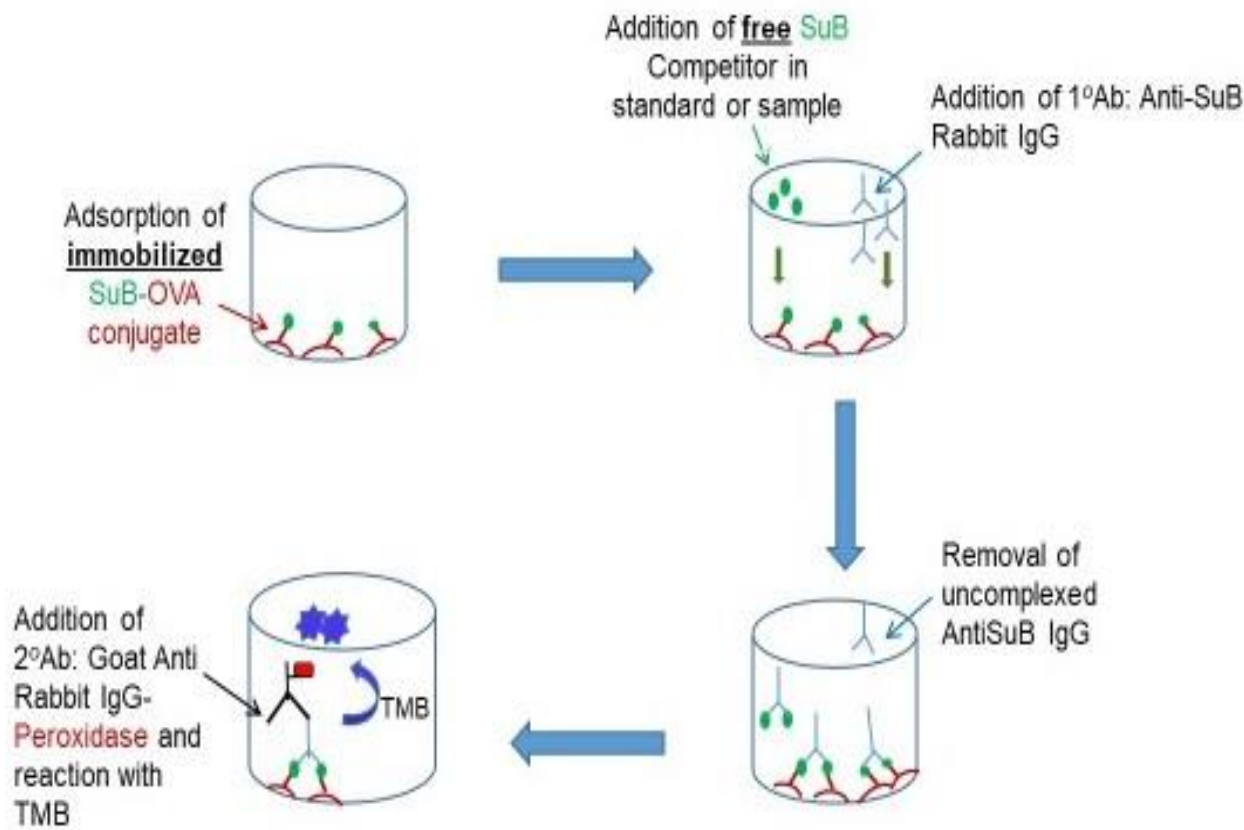

Figure 4-1. Illustration of indirect competitive sutherlandioside ELISA 


\section{Results}

The standard curves were successfully developed using partially purified sutherlandiosides. The sutherlandiosides were partially purified from the Sutherlandia plant powder as described in Appendix 3-1.

The orange line in Figure 4-2 describes the standard curve using the partially purified sutherlandiosides only while the blue line illustrates the standard curve using the mixture of the partially purified sutherlandiosides and the control rat plasma.

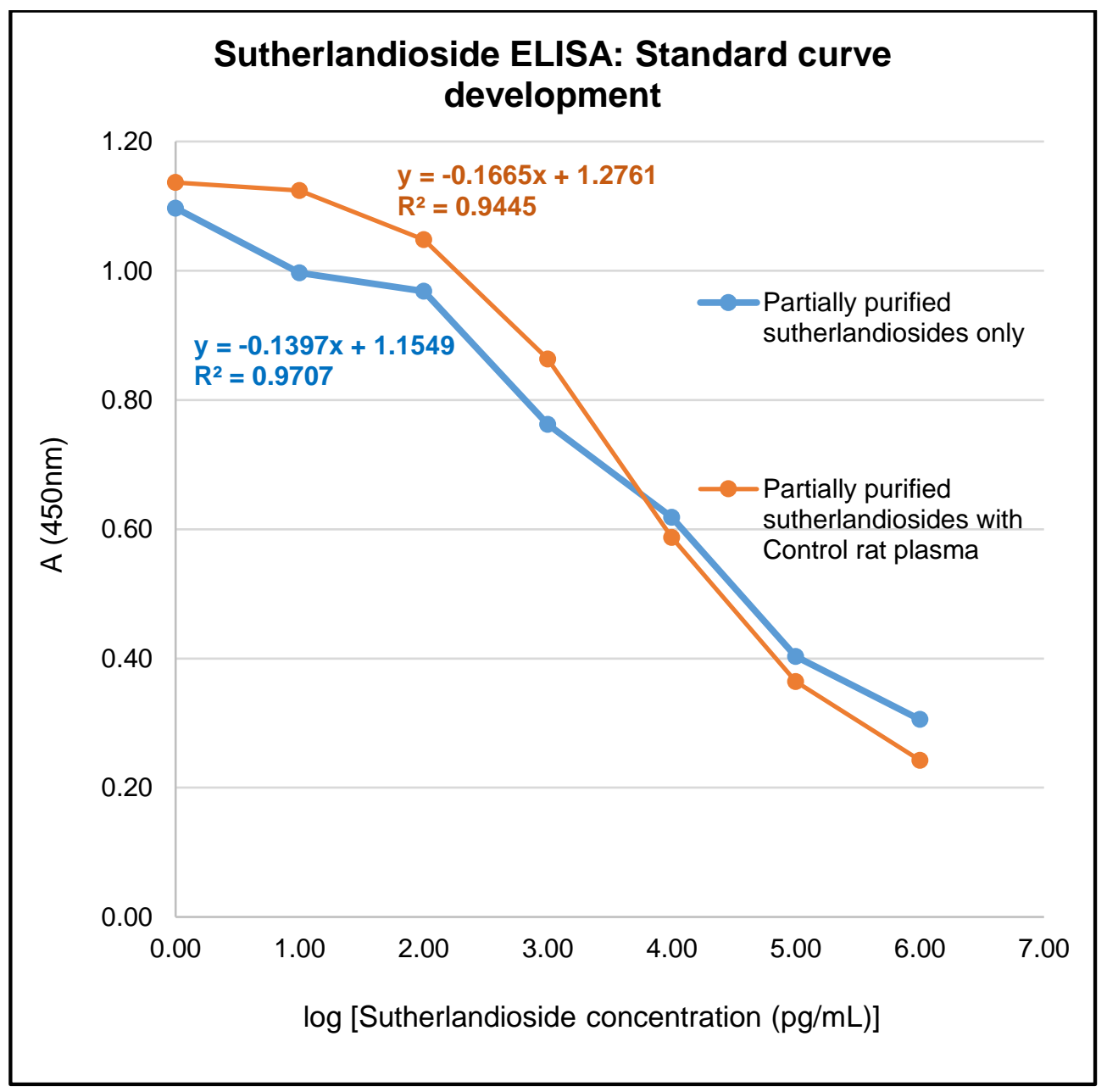

Figure 4-2. Standard curve development of sutherlandioside ELISA 
Table 4-1 summarizes concentrations of sutherlandiosides in rat plasma determined by indirect competitive sutherlandioside ELISA at different days. These results displayed inconsistent concentrations of sutherlandiosides of the same sample analyzed at different days. For example, on day 1 , the concentration of sutherlandiosides in sample 20 is $6.84 \mathrm{ng} / \mathrm{mL}$, but this concentration dramatically dropped to $0.72 \mathrm{ng} / \mathrm{mL}$ on day 3 . Another example is that there was a considerable decrease in the concentration of sutherlandiosides in sample $25 \mathrm{~N}$ from $63.89 \mathrm{ng} / \mathrm{mL}$ (day 2) to $19.51 \mathrm{ng} / \mathrm{mL}$ (day 3).

Furthermore, it is possible to distinguish between negative and positive samples within the same day of assay analysis. For instance, on day 1 , samples 5 and 8 (negative samples from rats having no Sutherlandia treatment) had a remarkably lower concentration of sutherlandiosides, i.e. 0.10 and $0.16 \mathrm{ng} / \mathrm{mL}$, respectively, compared to the positive samples $14(1.09 \mathrm{ng} / \mathrm{mL}), 14 \mathrm{~N}(2.30$ $\mathrm{ng} / \mathrm{mL}), 20(6.84 \mathrm{ng} / \mathrm{mL}), 27(9.07 \mathrm{ng} / \mathrm{mL})$ and $27 \mathrm{~N}(17.84 \mathrm{ng} / \mathrm{mL})$. Nevertheless, it is impossible to compare the concentrations of negative or positive samples at different times of analysis. To demonstrate, the negative sample 8 was assayed with the concentration of $0.16 \mathrm{ng} / \mathrm{mL}$ on day 1 , but this number cannot be taken as a standard for negative results for other samples assayed at other times because the positive sample 15 was shown to have $0.18 \mathrm{ng} / \mathrm{mL}$ of sutherlandiosides on day 3. Therefore, this ELISA is not a quantitative, but rather a qualitative assay. 
Table 4-1. Quantitation of sutherlandiosides in rat plasma samples by indirect competitive sutherlandioside ELISA.

\begin{tabular}{|c|c|c|c|}
\hline Day & Sample ID & Group & $\begin{array}{c}\text { Concentrations of } \\
\text { sutherlandiosides }(\mathrm{ng} / \mathrm{mL})\end{array}$ \\
\hline \multirow[t]{7}{*}{1} & 5 & LFD & 0.10 \\
\hline & 8 & HFD & 0.16 \\
\hline & 14 & HFD + Su tea & 1.09 \\
\hline & $14 \mathrm{~N}$ & HFD + Su tea & 2.30 \\
\hline & 20 & HFD + Pino tea & 6.84 \\
\hline & 27 & $\mathrm{HFD}+1 \% \mathrm{Su}$ & 9.07 \\
\hline & $27 \mathrm{~N}$ & HFD+1\%Su & 17.84 \\
\hline \multirow[t]{8}{*}{2} & 1 & LFD & 0.03 \\
\hline & $8 \mathrm{~N}$ & HFD & 0.004 \\
\hline & 13 & HFD + Su tea & 0.46 \\
\hline & $13 \mathrm{~N}$ & HFD + Su tea & 1.32 \\
\hline & 19 & HFD + Pino tea & 1.43 \\
\hline & $19 N$ & HFD + Pino tea & 2.40 \\
\hline & 25 & HFD+1\%Su & 13.27 \\
\hline & $25 N$ & HFD+1\%Su & 63.89 \\
\hline \multirow[t]{8}{*}{3} & 1 & LFD & Undetected \\
\hline & 15 & HFD + Su tea & 0.18 \\
\hline & $15 N$ & HFD + Su tea & 13.06 \\
\hline & 22 & HFD + Pino tea & 8.85 \\
\hline & $22 \mathrm{~N}$ & HFD + Pino tea & 4.94 \\
\hline & 20 & HFD + Pino tea & 0.72 \\
\hline & $25 N$ & HFD+1\%Su & 19.51 \\
\hline & $26 \mathrm{~N}$ & HFD+1\%Su & 4.35 \\
\hline
\end{tabular}




\section{Discussion and Conclusion}

The standard curve of the indirect competitive sutherlandioside ELISA was successfully established using the partially purified sutherlandiosides from Sutherlandia plant powder.

This ELISA assay can differentiate between negative (without Sutherlandia treatment) and positive (with Sutherlandia treatment) rat plasma samples that were analyzed at the same time. Nonetheless, it is impossible for this assay to compare the concentrations of negative or positive samples at different times of analysis or to determine the accurate amounts of sutherlandiosides in each sample due to inconsistent concentrations of sutherlandiosides of the same sample analyzed at different days. One reason accounting for this outcome is because the low bioavailability of sutherlandiosides in biological samples. In fact, these compounds are subjected to digestion, absorption, metabolism, and degradation by gut flora, hepatic enzymes and potential transport within circulation. Another reason is that the primary antibody targeting the sutherlandioside standard (free antigen) in this project was generated from purified sutherlandioside B; in contrast, this sutherlandioside standard was semi-purified because of limited availability of totally purified sutherlandioside B. In fact, it is extremely expensive and timeconsuming to isolate and purify this specific compound from the plant powder. As a result, these challenges hinder us from accurately measuring concentrations of sutherlandiosides in plasma samples. 
In the future, one way to troubleshoot this problem is to advance the process of producing a completely purified sutherlandioside so that a unique and specific antibody will target and bind to that sutherlandioside only. Moreover, with the advance of liquid chromatography-mass spectrometry (LC-MS) instrumentation and metabolomics, it becomes promising to effectively measure bioactive compounds in biological samples in a reliable manner. 


\section{CHAPTER FIVE}

\section{CONCLUSIONS AND FUTURE DIRECTIONS}

Non-alcoholic fatty liver disease (NAFLD) covers a wide spectrum of liver pathology, ranging from simple steatosis to nonalcoholic steatohepatitis, fibrosis, cirrhosis and hepatocellular carcinoma (5-7). It is not only the most prominent chronic liver disease in developed nations in recent years, but also has been increasing in the developing world including South Africa (1-4). Moreover, it has been shown to be associated with metabolic diseases including obesity, insulin resistance, type 2 diabetes mellitus, hypertension, and dyslipidemia (5, 8-10). This dissertation focuses on hepatic steatosis - the first, benign and reversible stage of NAFLD (11).

Sutherlandia frutescens has been traditionally used in southern Africa for a long time (18). Several possible mechanisms of the anti-diabetic, anti-cancer, anti-inflammatory and anti-oxidant properties of $S$. frutescens were determined in both cell and animal models (18-23). Studies in rodents indicate that an aqueous preparation of $S$. frutescens extract at a daily dose of $50 \mathrm{mg} / \mathrm{kg}$ body weight led to a reduction in plasma free fatty acids and prevention of diet-induced insulin resistance in male Wistar rats (21-23). In addition, $S$. frutescens aqueous extracts were shown to modulate expression of 27 diabetes-related genes including PPAR- $\alpha$ - one of the key transcription factors responsible for hepatic lipid metabolism - in a fructose-induced insulin resistant human Chang liver cell model (35). The molecular mechanism(s) by which $S$. frutescens alters lipid 
metabolism and insulin resistance, however, remain to be examined and established.

In chapter 3, I employed the aqueous extracts of freeze-dried and commercial Sutherlandia frutescens, i.e., Sutherlandia and Pinosundia teas, respectively, as well as the dried S. frutescens (1\%) incorporated into feed to investigate the impact of $S$. frutescens consumption on obesity-induced hepatic steatosis in the livers of HFD-fed rats. The results demonstrated that $S$. frutescens extracts, when fed ad libitum either in food or water, significantly improved HFD-induced dysfunction in hepatic lipid metabolism. This improved liver phenotype included reduced hepatic triglyceride levels and lipid droplet accumulation, as well as increased mRNA expression of fatty acid oxidationrelated genes PPAR- $\alpha, A C O X-1$, and CYP4A14. These results illuminate an underlying molecular pathway by which Sutherlandia ameliorates lipid metabolism and provide new insights into the potential use of $S$. frutescens as a phytotherapy for NAFLD. Further examinations of how specific bioactive compounds of $S$. frutescens modulate lipid metabolism via the PPAR- $\alpha$ mechanisms are warranted. Moreover, future in vivo and in vitro studies should directly evaluate the impact of $S$. frutescens treatment on hepatic lipid oxidation. In addition, the specific dose of $S$. frutescens might be accurately determined by oral gavage or intraperitoneal injection rather than by administering ad libitum as described in this study.

The fact that supplementation of $S$. frutescens extracts led to significant improvements in hepatic steatosis compared to non-treated rats is remarkable. 
Importantly, it is unlikely that these beneficial effects were due to taste aversion because there were no significant differences in body weight between the untreated and treated HFD-fed rats. An additional point worth mentioning is that physical exercise has been demonstrated as a potent strategy in the prevention of hepatic fat accumulation and metabolic disorders (188-192). Consequently, methods to precisely assess systemic energy expenditure should be employed in future studies.

A substantial effort was made to quantify and compare concentrations of sutherlandiosides - unique bioactive compounds in S. frutescens extracts - in plasma samples of untreated and treated rats using indirect competitive ELISA. In chapter 4, this assay was described. The standard curve was successfully developed using the partially purified sutherlandiosides from the $S$. frutescens plant powder. This ELISA is not a quantitative, but rather a qualitative assay, because it can only tell whether sutherlandiosides are present in a particular sample at the same time of analysis; nevertheless, it is unable to determine the exact amounts of sutherlandiosides in plasma samples. Very low amounts of sutherlandiosides are present in plasma because these compounds are subjected to digestion, absorption, metabolism, and degradation by gut flora, hepatic enzymes and potential transport within circulation. Therefore, this challenge hampers accurate measurement of the concentrations of sutherlandiosides in plasma samples. Moreover, there is a strong demand to characterize over-the-counter medications of $S$. frutescens in specific, and of medicinal plants in general. One way of generating a reliable profile of bioactive 
compounds in biological samples as well as in plant and commercial extracts is to perform metabolomic analysis.

Furthermore, global expression of lipid metabolism genes using RNA sequencing should be conducted to investigate a comprehensive picture of transcriptome profiling regarding the presence and quantity of RNA in control and S. frutescens-treated samples. We should then, based on those results, determine the exact molecular mechanism(s) by which $S$. frutescens modulates lipid metabolism in diet-induced hepatic steatosis.

In general, the findings in this dissertation shed light on the molecular mechanism by which $S$. frutescens alleviates hepatic lipid accumulation HFD-fed rats, and provide novel visions about the use of $S$. frutescens as a phytotherapy. Future studies and experiments should take the above recommendations into account to offer a better understanding of this medicinal plant in terms of pharmacological values. 


\section{APPENDIX 3-1}

\section{Determination of sutherlandioside B from $S$.}

\section{frutescens plant or from S. frutescens aqueous extracts}

\section{Materials and Methods}

\section{Preparation of aqueous extracts of S. frutescens}

The aqueous extracts of freeze-dried and commercial Sutherlandia frutescens, i.e., Sutherlandia and Pinosundia teas, respectively, were prepared as described in Chapter 3 (pp. 34-35).

\section{Isolation and quantification of sutherlandiosides}

Sutherlandiosides were isolated and quantified from $S$. frutescens by Korey Brownstein using modifications of the isolation procedure published by $\mathrm{Fu}$ et al. (26) and high-speed counter-current chromatography (HSCCC) (93). S. frutescens plant material was extracted with methanol and concentrated in vacuo. The residue was re-dissolved in water and extracted with hexane, chloroform, followed by $n$-butanol (water saturated). The $n$-butanol fraction was then concentrated in vacuo. Ethyl acetate, $n$-butanol, methanol, and water (15:1:3:15 v/v) were included in the two-phase solvent system. The solvents were comprehensively equilibrated in a $500 \mathrm{~mL}$ separating funnel and the upper and lower phases were separated before use. The rotor was filled with the upper stationary phase and the lower stationary phase was pumped at $1 \mathrm{~mL} / \mathrm{min}$ while the HSCCC apparatus (CC Biotech LLC, Rockville, MD) was run at $830 \mathrm{rpm}$. The 
samples were injected and 4-minute fractions were collected. Seventy fractions were collected. Finally, the samples were freeze-dried and examined by thin layer chromatography (TLC) to identify the fractions containing sutherlandiosides.

Fractions were run on Analtech HL silica gel TLC plates by employing the mobile phase chloroform:toluene:methanol (3:2:1) and then visualized by $p$ anisaldehyde spray. Subsequently, the sutherlandiosides from these HSCCC fractions were purified by semipreparative reversed phase high-performance liquid chromatography (HPLC) to quantify concentrations of sutherlandioside B and a mixer of sutherlandiosides A, C and D.

\section{Analysis of sutherlandiosides using LC-ESLD}

The purity and quantitation of fractions of sutherlandiosides were determined by HPLC-evaporative light scattering detectors (ELSD) as described by Avula et al. (27). In specific, twenty microliters of samples were injected and separated in a C18 column ( $150 \mathrm{~mm} \times 4.6 \mathrm{~mm} ; 5 \mu \mathrm{m}$ particle size) using a mobile phase that consisted of water/ $0.1 \%$ acetic acid $(\mathrm{A})$ and acetonitrile/ $0.1 \%$ acetic acid (B) at a flow rate of $1.0 \mathrm{~mL} /$ minute. A slightly concave gradient elution from $85 \% A / 15 \%$ B to $45 \% A / 55 \%$ B for 40 minutes was used. Each run was then followed by a 3-minute wash with $100 \% \mathrm{~B}$ and a 10-minute calibration. The ELSD $\mathrm{T}_{1}$ and $\mathrm{T}_{2}$ were $35^{\circ} \mathrm{C}$ and $55^{\circ} \mathrm{C}$, respectively. Nitrogen was used as the nebulizer gas at 20 psi. The peaks were assigned by spiking the samples with standard sutherlandioside $B$ and comparison of the retention times. 


\section{Results}

The $S$. frutescens plant material comprises of a mixture of sutherlandiosides B and C (Appendix Figure 3-1 A).

Sutherlandioside B was detected in the aqueous extracts of Sutherlandia tea $(0.5 \mathrm{~g}$ Su extract $/ 100 \mathrm{~mL}$ water) (Appendix Figure 3-1 B). Pinosundia tea $(0.5 \mathrm{~g}$ Su extract $/ 100 \mathrm{~mL}$ water) does not contain alpha-lipoic acid as claimed by the manufacturer (ProBetix ${ }^{\circledR}$, Value Added Life Health Products (Pty) Ltd, South Africa), but it has a mixture of sutherlandiosides B, C, and D (Appendix Figure 3$1 \mathrm{C})$.

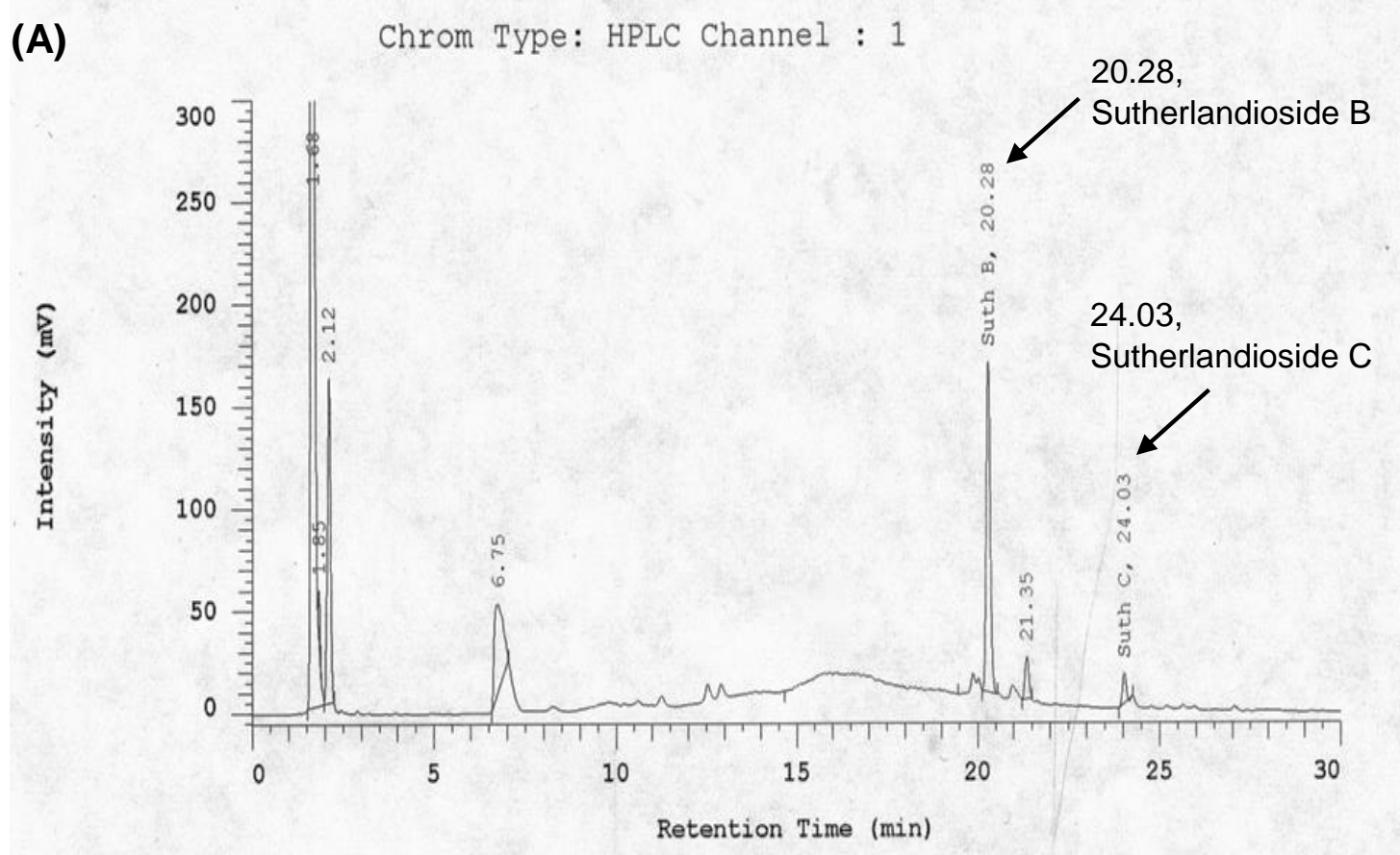


(B)

Chrom Type: HPLC Channel : 1

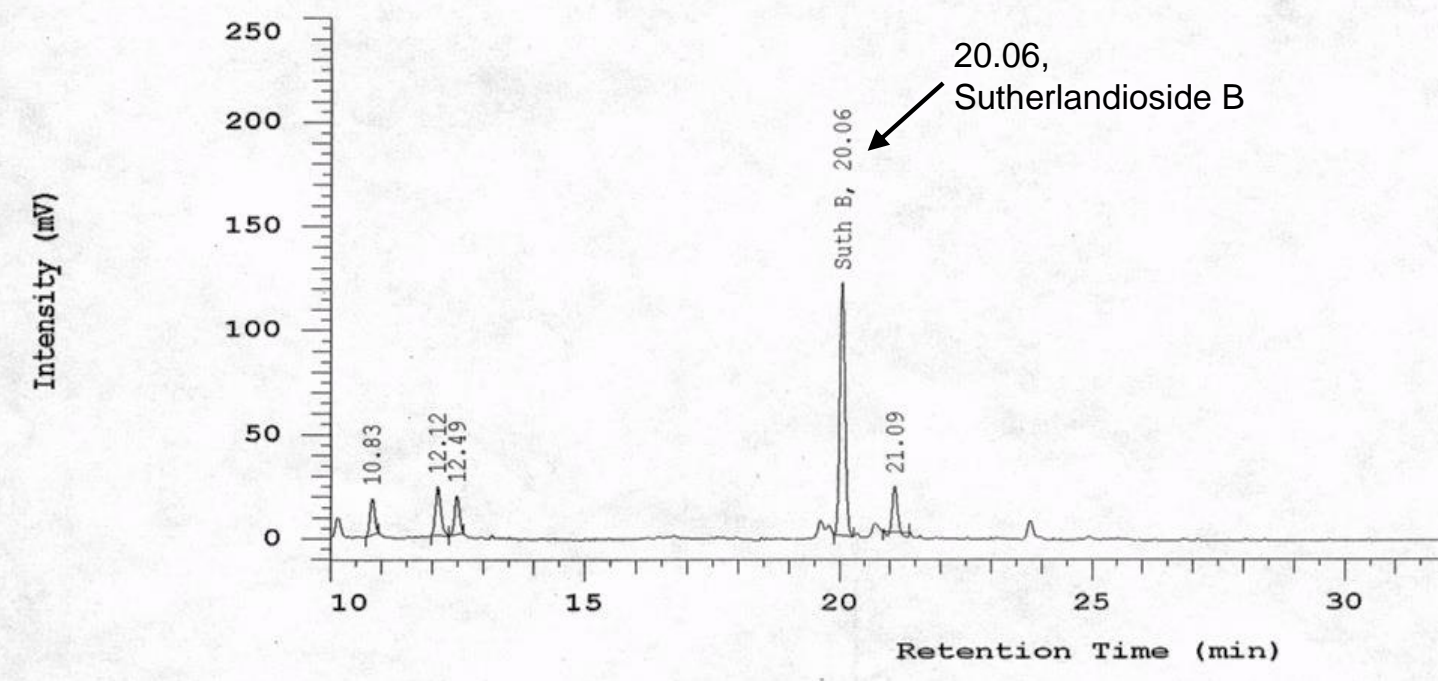

(C)

Chrom Type: HPLC Channel : 1

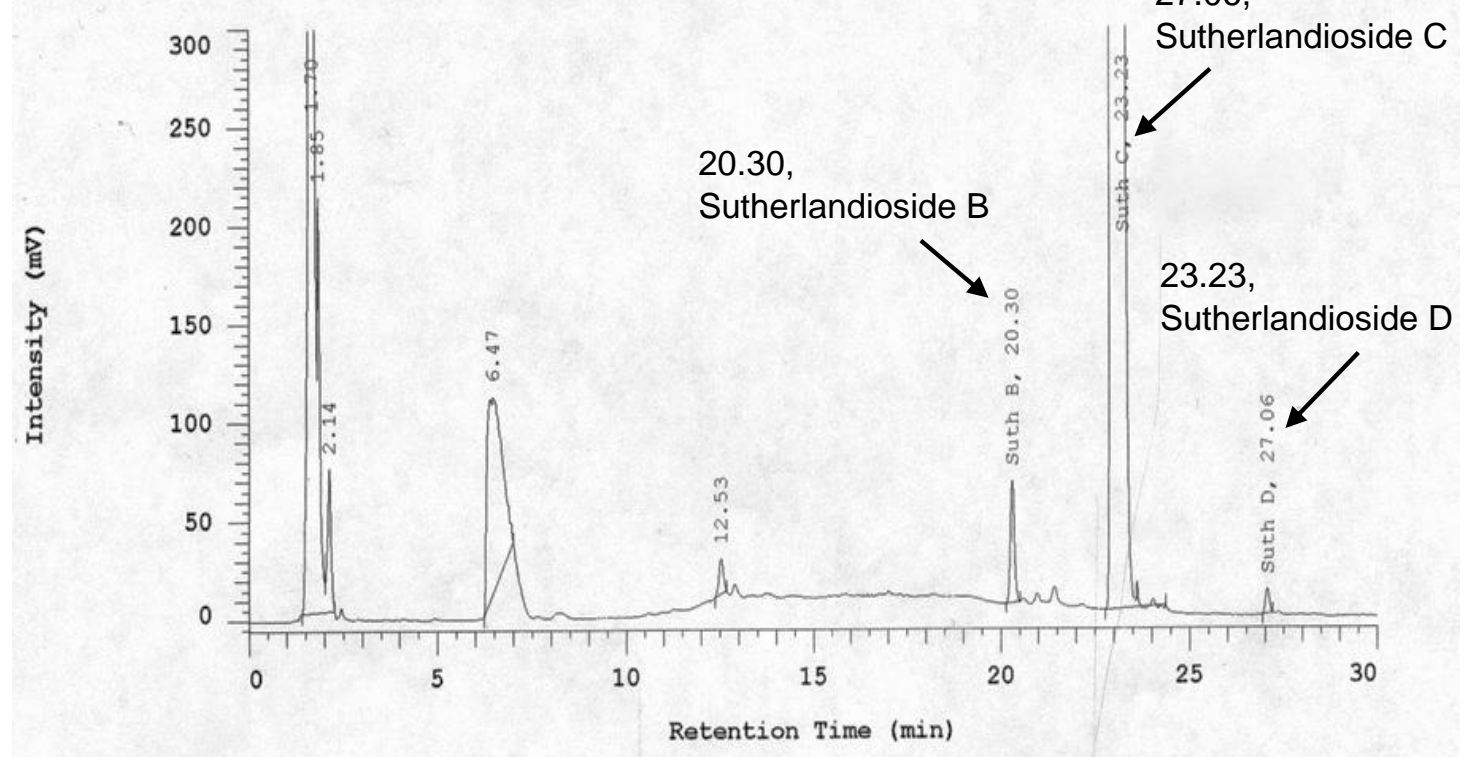

Appendix Figure 3-1. Chromatograms of purified sutherlandiosides B and C from S. frutescens (Big Tree Nutraceutical) (A), sutherlandioside B in Sutherlandia tea (B), and sutherlandiosides B, C, and D in Pinosundia tea detected by the LC-ELSD (C). 


\section{APPENDIX 3-2}

\section{Validation of taste aversion of S. frutescens}

\section{Materials and Methods}

The administration of Sutherlandia extracts to rats were illustrated in Chapter 3 (pp. 33-36).

\section{Results}

The bitterness of Sutherlandia either in teas or in feed did not alter the amount of liquid or diet the rats consumed compared to the LFD or HFD control groups (Appendix Figure 3-2). In fact, the LFD control, HFD control, and HFD + Pino tea groups drank similar amounts of liquid per day (Appendix Figure 3-2 A). Importantly, the group medicated with Sutherlandia tea consumed a significantly higher amount of liquid compared to the untreated LFD and HFD groups $(p<$ 0.05, Appendix Figure 3-2 A), which indicates that the aversion of Sutherlandia did not have a negative impact on the amount of liquid intake in these rats.

Moreover, the rats having dried Sutherlandia incorporated in the HFD consumed approximately the amount expected (23 g diet per day) (157) (Appendix Figure 3-2 B). 

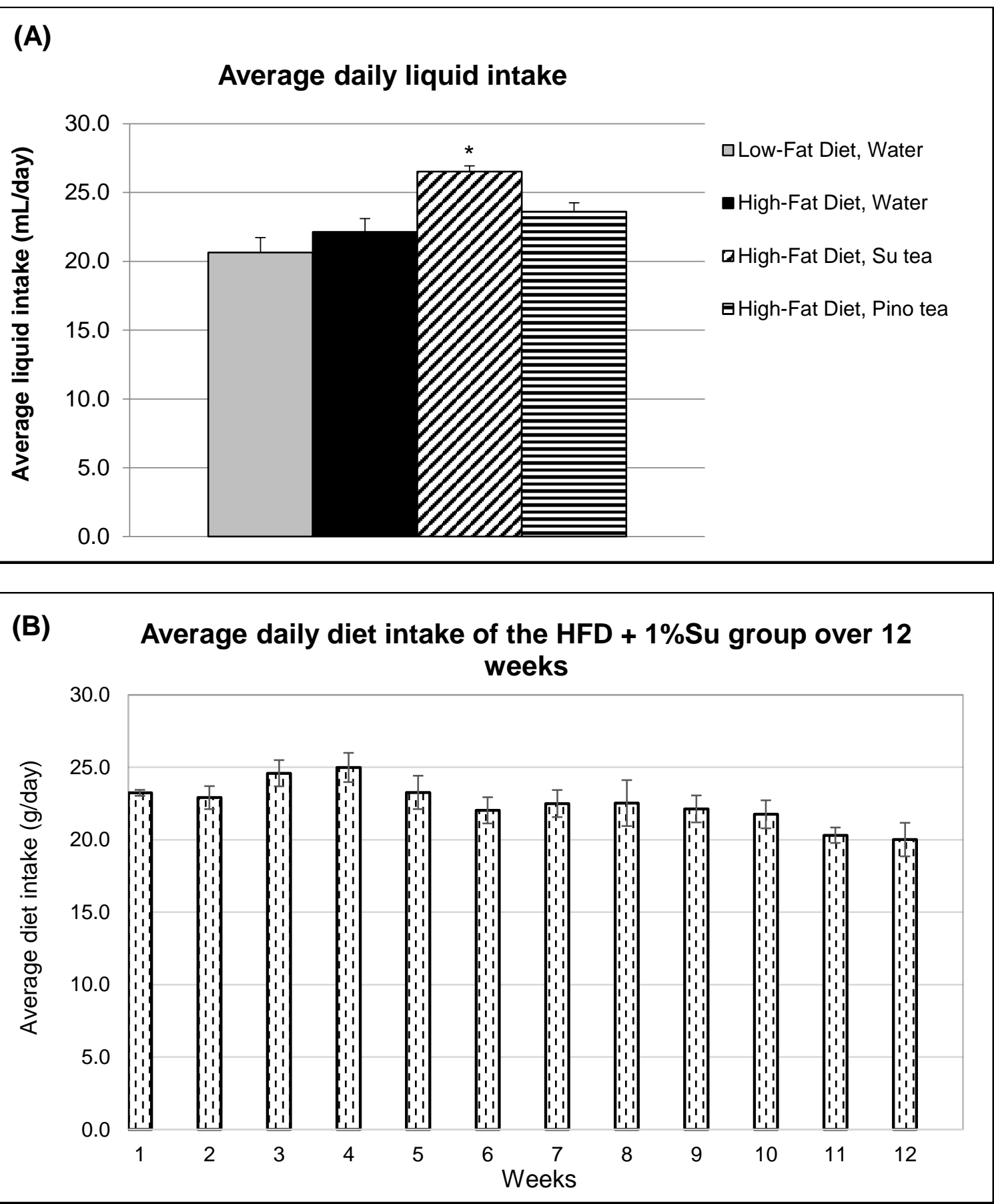

\section{Appendix Figure 3-2. Average daily liquid (A) and diet (B) intake of}

Sutherlandia. Data are expressed as mean \pm SEM of each group; $n=11-12$ per group. Comparisons between groups used ANOVA followed by Tukey-Kramer multiple comparisons test. 


\section{BIBLIOGRAPHY}

1. Angulo P. GI epidemiology: nonalcoholic fatty liver disease. Aliment Pharmacol Ther. 2007;25(8):883-9.

2. Law K, Brunt EM. Nonalcoholic fatty liver disease. Clinics in liver disease. 2010;14(4):591-604.

3. Oh MK, Winn J, Poordad F. Review article: diagnosis and treatment of non-alcoholic fatty liver disease. Aliment Pharmacol Ther. 2008;28(5):503-22.

4. Pappachan JM, Babu S, Krishnan B, Ravindran NC. Non-alcoholic Fatty Liver Disease: A Clinical Update. Journal of Clinical and Translational Hepatology. 2017;5(4):384-93.

5. Younossi ZM, Koenig AB, Abdelatif D, Fazel Y, Henry L, Wymer M. Global epidemiology of nonalcoholic fatty liver disease-Meta-analytic assessment of prevalence, incidence, and outcomes. Hepatology. 2016;64(1):73-84.

6. Calzadilla Bertot L, Adams LA. The Natural Course of Non-Alcoholic Fatty Liver Disease. Int J Mol Sci. 2016;17(5).

7. Fazel Y, Koenig AB, Sayiner M, Goodman ZD, Younossi ZM. Epidemiology and natural history of non-alcoholic fatty liver disease. Metabolism. 2016;65(8):1017-25.

8. Leite NC, Salles GF, Araujo AL, Villela-Nogueira CA, Cardoso CR.

Prevalence and associated factors of non-alcoholic fatty liver disease in patients with type-2 diabetes mellitus. Liver Int. 2009;29(1):113-9.

9. Parekh S, Anania FA. Abnormal lipid and glucose metabolism in obesity: implications for nonalcoholic fatty liver disease. Gastroenterology. 2007;132(6):2191-207. 
10. Wicklow BA, Wittmeier KD, Maclntosh AC, Sellers EA, Ryner L, Serrai H, et al. Metabolic consequences of hepatic steatosis in overweight and obese adolescents. Diabetes Care. 2012;35(4):905-10.

11. Vergani L. Fatty acids and effects on in vitro and in vivo models of liver steatosis. Current medicinal chemistry. 2017.

12. Kleiner DE, Brunt EM, Van Natta M, Behling C, Contos MJ, Cummings $\mathrm{OW}$, et al. Design and validation of a histological scoring system for nonalcoholic fatty liver disease. Hepatology. 2005;41(6):1313-21.

13. Fabbrini E, Sullivan S, Klein S. Obesity and Nonalcoholic Fatty Liver Disease: Biochemical, Metabolic and Clinical Implications. Hepatology (Baltimore, Md). 2010;51(2):679-89.

14. Koo SH. Nonalcoholic fatty liver disease: molecular mechanisms for the hepatic steatosis. Clinical and molecular hepatology. 2013;19(3):210-5.

15. Das DK, Maulik N. Resveratrol in cardioprotection: a therapeutic promise of alternative medicine. Molecular interventions. 2006;6(1):36-47.

16. Sharpe PA, Blanck HM, Williams JE, Ainsworth BE, Conway JM. Use of complementary and alternative medicine for weight control in the United States. J Altern Complement Med. 2007;13(2):217-22.

17. Valcheva-Kuzmanova S, Kuzmanov K, Tancheva S, Belcheva A. Hypoglycemic and hypolipidemic effects of Aronia melanocarpa fruit juice in streptozotocin-induced diabetic rats. Methods Find Exp Clin Pharmacol. 2007;29(2):101-5.

18. van Wyk BE, Albrecht C. A review of the taxonomy, ethnobotany, chemistry and pharmacology of Sutherlandia frutescens (Fabaceae). $\mathrm{J}$ Ethnopharmacol. 2008;119(3):620-9. 
19. Fernandes AC, Cromarty AD, Albrecht C, van Rensburg CE. The antioxidant potential of Sutherlandia frutescens. J Ethnopharmacol. 2004;95(1):15.

20. Mills E, Cooper C, Seely D, Kanfer I. African herbal medicines in the treatment of HIV: Hypoxis and Sutherlandia. An overview of evidence and pharmacology. Nutr J. 2005;4:19.

21. Chadwick WA, Roux S, van de Venter M, Louw J, Oelofsen W. Antidiabetic effects of Sutherlandia frutescens in Wistar rats fed a diabetogenic diet. J Ethnopharmacol. 2007;109(1):121-7.

22. MacKenzie J, Koekemoer T, van de Venter M, Dealtry G, Roux S. Sutherlandia frutescens limits the development of insulin resistance by decreasing plasma free fatty acid levels. Phytother Res. 2009;23(11):1609-14.

23. MacKenzie J, Koekemoer TC, Roux S, van de Venter M, Dealtry GB. Effect of Sutherlandia frutescens on the lipid metabolism in an insulin resistant rat model and 3T3-L1 adipocytes. Phytother Res. 2012;26(12):1830-7.

24. Faleschini MT, Myer MS, Harding N, Fouchè G. Chemical profiling with cytokine stimulating investigations of Sutherlandia frutescens L. R. (Br.) (Fabaceae). South African Journal of Botany. 2013;85:48-55.

25. Tai J, Cheung S, Chan E, Hasman D. In vitro culture studies of Sutherlandia frutescens on human tumor cell lines. J Ethnopharmacol. 2004;93(1):9-19.

26. Fu X, Li XC, Smillie TJ, Carvalho P, Mabusela W, Syce J, et al. Cycloartane glycosides from Sutherlandia frutescens. J Nat Prod. 2008;71(10):1749-53.

27. Avula B, Wang Y-H, Smillie TJ, Fu X, Li XC, Mabusela W, et al. Quantitative determination of flavonoids and cycloartanol glycosides from aerial parts of Sutherlandia frutescens (L.) R. BR. by using LC-UV/ELSD methods and 
confirmation by using LC-MS method. Journal of Pharmaceutical and Biomedical Analysis. 2010;52(2):173-80.

28. Fu X, Li XC, Wang YH, Avula B, Smillie TJ, Mabusela W, et al. Flavonol glycosides from the south African medicinal plant Sutherlandia frutescens. Planta medica. 2010;76(2):178-81.

29. Bates SH, Jones RB, Bailey CJ. Insulin-like effect of pinitol. Br J Pharmacol. 2000;130(8):1944-8.

30. Geethan PK, Prince PS. Antihyperlipidemic effect of D-pinitol on streptozotocin-induced diabetic Wistar rats. Journal of biochemical and molecular toxicology. 2008;22(4):220-4.

31. Tan MJ, Ye JM, Turner N, Hohnen-Behrens C, Ke CQ, Tang CP, et al. Antidiabetic activities of triterpenoids isolated from bitter melon associated with activation of the AMPK pathway. Chem Biol. 2008;15(3):263-73.

32. Yu Y, Wu Y, Szabo A, Wu Z, Wang H, Li D, et al. Teasaponin reduces inflammation and central leptin resistance in diet-induced obese male mice. Endocrinology. 2013;154(9):3130-40.

33. Kobori M, Masumoto S, Akimoto Y, Oike H. Chronic dietary intake of quercetin alleviates hepatic fat accumulation associated with consumption of a Western-style diet in C57/BL6J mice. Molecular nutrition \& food research. 2011;55(4):530-40.

34. Chang CJ, Tzeng TF, Liou SS, Chang YS, Liu IM. Kaempferol regulates the lipid-profile in high-fat diet-fed rats through an increase in hepatic PPARalpha levels. Planta medica. 2011;77(17):1876-82.

35. Williams S, Roux S, Koekemoer T, van de Venter M, Dealtry G.

Sutherlandia frutescens prevents changes in diabetes-related gene expression in a fructose-induced insulin resistant cell model. J Ethnopharmacol. 2013;146(2):482-9. 
36. Nguyen DM, El-Serag HB. The epidemiology of obesity. Gastroenterol Clin North Am. 2010;39(1):1-7.

37. (WHO) WHO. Obesity and overweight 2015 [Available from:

\section{http://www.who.int/mediacentre/factsheets/fs311/en/.}

38. Ogden CL, Carroll MD, Fryar CD, Flegal KM. Prevalence of Obesity Among Adults and Youth: United States, 2011-2014. NCHS data brief. 2015(219):1-8.

39. Puoane T, Steyn K, Bradshaw D, Laubscher R, Fourie J, Lambert V, et al. Obesity in South Africa: the South African demographic and health survey. Obes Res. 2002;10(10):1038-48.

40. Wellman NS, Friedberg B. Causes and consequences of adult obesity: health, social and economic impacts in the United States. Asia Pacific Journal of Clinical Nutrition. 2002;11(s8):S705-S9.

41. Angulo P. Obesity and nonalcoholic fatty liver disease. Nutrition reviews. 2007;65(6 Pt 2):S57-63.

42. Chalasani N, Younossi Z, Lavine JE, Diehl AM, Brunt EM, Cusi K, et al. The diagnosis and management of non-alcoholic fatty liver disease: practice guideline by the American Gastroenterological Association, American Association for the Study of Liver Diseases, and American College of Gastroenterology. Gastroenterology. 2012;142(7):1592-609.

43. Siddiqui MS, Charlton M. Liver Transplantation for Alcoholic and Nonalcoholic Fatty Liver Disease: Pretransplant Selection and Posttransplant Management. Gastroenterology. 2016;150(8):1849-62.

44. Cohen JC, Horton JD, Hobbs HH. Human fatty liver disease: old questions and new insights. Science. 2011;332(6037):1519-23. 
45. Nordlie RC, Foster JD, Lange AJ. Regulation of glucose production by the liver. Annu Rev Nutr. 1999;19:379-406.

46. Tortora GJ, Nielsen M. Principles of Human Anatomy. 13th ed: Wiley; 2013.

47. van den Berghe $\mathrm{G}$. The role of the liver in metabolic homeostasis: implications for inborn errors of metabolism. Journal of inherited metabolic disease. 1991;14(4):407-20.

48. Kuntz E, Kuntz HD. Hepatology: principles and practice. Heidelberg, Germany: Springer Medizin Verlag; 2006.

49. Iredale JP. Models of liver fibrosis: exploring the dynamic nature of inflammation and repair in a solid organ. J Clin Invest. 2007;117(3):539-48.

50. Gambino R, Musso G, Cassader M. Redox balance in the pathogenesis of nonalcoholic fatty liver disease: mechanisms and therapeutic opportunities. Antioxidants \& redox signaling. 2011;15(5):1325-65.

51. Meex RCR, Watt MJ. Hepatokines: linking nonalcoholic fatty liver disease and insulin resistance. Nat Rev Endocrinol. 2017;13(9):509-20.

52. Fabbrini E, Magkos F. Hepatic Steatosis as a Marker of Metabolic Dysfunction. Nutrients. 2015;7(6):4995-5019.

53. Adams LA, Lymp JF, St Sauver J, Sanderson SO, Lindor KD, Feldstein A, et al. The natural history of nonalcoholic fatty liver disease: a population-based cohort study. Gastroenterology. 2005;129(1):113-21.

54. Malhi H, Gores GJ. Molecular mechanisms of lipotoxicity in nonalcoholic fatty liver disease. Seminars in liver disease. 2008;28(4):360-9.

55. Haas JT, Francque S, Staels B. Pathophysiology and Mechanisms of Nonalcoholic Fatty Liver Disease. Annual review of physiology. 2016;78:181-205. 
56. Krishnan B, Babu S, Walker J, Walker AB, Pappachan JM.

Gastrointestinal complications of diabetes mellitus. World J Diabetes. 2013;4(3):51-63.

57. Cortez-Pinto H, de Moura MC, Day CP. Non-alcoholic steatohepatitis: from cell biology to clinical practice. Journal of hepatology. 2006;44(1):197-208.

58. Farrell GC, Larter CZ. Nonalcoholic fatty liver disease: from steatosis to cirrhosis. Hepatology. 2006;43(2 Suppl 1):S99-s112.

59. Bedossa P. Pathology of non-alcoholic fatty liver disease. Liver Int. 2017;37 Suppl 1:85-9.

60. Brunt EM. Nonalcoholic steatohepatitis: definition and pathology. Seminars in liver disease. 2001;21(1):3-16.

61. Matteoni CA, Younossi ZM, Gramlich T, Boparai N, Liu YC, McCullough AJ. Nonalcoholic fatty liver disease: a spectrum of clinical and pathological severity. Gastroenterology. 1999;116(6):1413-9.

62. Wieckowska A, Feldstein AE. Diagnosis of nonalcoholic fatty liver disease: invasive versus noninvasive. Seminars in liver disease. 2008;28(4):386-95.

63. Wieckowska A, McCullough AJ, Feldstein AE. Noninvasive diagnosis and monitoring of nonalcoholic steatohepatitis: present and future. Hepatology. 2007;46(2):582-9.

64. Nomura K, Yano E, Shinozaki T, Tagawa K. Efficacy and Effectiveness of Liver Screening Program to Detect Fatty Liver in the Periodic Health Check-Ups. Journal of Occupational Health. 2004;46(6):423-8.

65. Yano E, Tagawa K, Yamaoka K, Mori M. Test validity of periodic liver function tests in a population of Japanese male bank employees. Journal of clinical epidemiology. 2001;54(9):945-51. 
66. Targher G, Bertolini L, Padovani R, Rodella S, Tessari R, Zenari L, et al. Prevalence of nonalcoholic fatty liver disease and its association with cardiovascular disease among type 2 diabetic patients. Diabetes Care. 2007;30(5):1212-8.

67. Portillo-Sanchez P, Bril F, Maximos M, Lomonaco R, Biernacki D, Orsak $B$, et al. High Prevalence of Nonalcoholic Fatty Liver Disease in Patients With Type 2 Diabetes Mellitus and Normal Plasma Aminotransferase Levels. The Journal of clinical endocrinology and metabolism. 2015;100(6):2231-8.

68. Feldstein AE, Nobili V. Biomarkers in nonalcoholic fatty liver disease: a new era in diagnosis and staging of disease in children. Journal of pediatric gastroenterology and nutrition. 2010;51(4):378-9.

69. Fitzpatrick E, Dhawan A. Noninvasive biomarkers in non-alcoholic fatty liver disease: current status and a glimpse of the future. World journal of gastroenterology. 2014;20(31):10851-63.

70. Saadeh S, Younossi ZM, Remer EM, Gramlich T, Ong JP, Hurley M, et al. The utility of radiological imaging in nonalcoholic fatty liver disease. Gastroenterology. 2002;123(3):745-50.

71. Talwalkar JA, Yin M, Fidler JL, Sanderson SO, Kamath PS, Ehman RL. Magnetic resonance imaging of hepatic fibrosis: emerging clinical applications. Hepatology. 2008;47(1):332-42.

72. Yoneda M, Suzuki K, Kato S, Fujita K, Nozaki Y, Hosono K, et al. Nonalcoholic fatty liver disease: US-based acoustic radiation force impulse elastography. Radiology. 2010;256(2):640-7.

73. Gorden DL, Ivanova PT, Myers DS, McIntyre JO, VanSaun MN, Wright JK, et al. Increased diacylglycerols characterize hepatic lipid changes in progression of human nonalcoholic fatty liver disease; comparison to a murine model. PLoS One. 2011;6(8):e22775. 
74. Browning JD, Szczepaniak LS, Dobbins R, Nuremberg P, Horton JD, Cohen JC, et al. Prevalence of hepatic steatosis in an urban population in the United States: impact of ethnicity. Hepatology. 2004;40(6):1387-95.

75. Petersen KF, Dufour S, Feng J, Befroy D, Dziura J, Dalla Man C, et al. Increased prevalence of insulin resistance and nonalcoholic fatty liver disease in Asian-Indian men. Proceedings of the National Academy of Sciences of the United States of America. 2006;103(48):18273-7.

76. Vernon G, Baranova A, Younossi ZM. Systematic review: the epidemiology and natural history of non-alcoholic fatty liver disease and nonalcoholic steatohepatitis in adults. Aliment Pharmacol Ther. 2011;34(3):274-85.

77. Charlton MR, Burns JM, Pedersen RA, Watt KD, Heimbach JK, Dierkhising RA. Frequency and outcomes of liver transplantation for nonalcoholic steatohepatitis in the United States. Gastroenterology. 2011;141(4):1249-53.

78. Ruhl CE, Everhart JE. Determinants of the association of overweight with elevated serum alanine aminotransferase activity in the United States. Gastroenterology. 2003;124(1):71-9.

79. Tyler VE. Herbal medicine in America. Planta medica. 1987;53(1):1-4.

80. Vermani K, Garg S. Herbal medicines for sexually transmitted diseases and AIDS. J Ethnopharmacol. 2002;80(1):49-66.

81. Yeung KS, Gubili J, Cassileth B. Evidence-based botanical research: applications and challenges. Hematology/oncology clinics of North America. 2008;22(4):661-70, viii.

82. Rock CL. Multivitamin-multimineral supplements: who uses them? The American journal of clinical nutrition. 2007;85(1):277s-9s. 
83. van Breemen RB, Fong $\mathrm{HH}$, Farnsworth NR. Ensuring the safety of botanical dietary supplements. The American journal of clinical nutrition. 2008;87(2):509s-13s.

84. Brown L, Heyneke O, Brown D, van Wyk JP, Hamman JH. Impact of traditional medicinal plant extracts on antiretroviral drug absorption. J Ethnopharmacol. 2008;119(3):588-92.

85. Coates PM, Meyers CM. The National Institutes of Health investment in research on botanicals. Fitoterapia. 2011;82(1):11-3.

86. Fennell CW, Lindsey KL, McGaw LJ, Sparg SG, Stafford GI, Elgorashi EE, et al. Assessing African medicinal plants for efficacy and safety: pharmacological screening and toxicology. J Ethnopharmacol. 2004;94(2-3):205-17.

87. Jeong S, Chae K, Jung YS, Rho YH, Lee J, Ha J, et al. The Korean traditional medicine Gyeongshingangjeehwan inhibits obesity through the regulation of leptin and PPARalpha action in OLETF rats. J Ethnopharmacol. 2008;119(2):245-51.

88. Roh JS, Lee H, Woo S, Yoon M, Kim J, Park SD, et al. Herbal composition Gambigyeongsinhwan (4) from Curcuma longa, Alnus japonica, and Massa Medicata Fermentata inhibits lipid accumulation in 3T3-L1 cells and regulates obesity in Otsuka Long-Evans Tokushima Fatty rats. J Ethnopharmacol. 2015; 171:287-94.

89. Shin SS, Jung YS, Yoon KH, Choi S, Hong Y, Park D, et al. The Korean traditional medicine gyeongshingangjeehwan inhibits adipocyte hypertrophy and visceral adipose tissue accumulation by activating PPARalpha actions in rat white adipose tissues. J Ethnopharmacol. 2010;127(1):47-54.

90. Shin SS, Yoon M. The herbal composition GGEx18 from Laminaria japonica, Rheum palmatum, and Ephedra sinica inhibits high-fat diet-induced 
hepatic steatosis via hepatic PPARalpha activation. Pharmaceutical biology. 2012;50(10):1261-8.

91. Mosh D. A biosystematic study of the genus Sutherlandia R.Br. (Fabaceae, Galegeae): Johannesburg; 1998.

92. Diederichs N. Commercializing medicinal plants: A Southern African guide. SUN PRESS, Stellenbosch: African Sun Media; 2006.

93. Brownstein KJ, Rottinghaus GE, Knight M, Ito Y, Folk W. Isolation of Sutherlandioside B from by Spiral Countercurrent Chromatography. Journal of liquid chromatography \& related technologies. 2015;38(4):423-9.

94. Zhang B, Leung WK, Zou Y, Mabusela W, Johnson Q, Michaelsen TE, et al. Immunomodulating polysaccharides from Lessertia frutescens leaves: isolation, characterization and structure activity relationship. J Ethnopharmacol. 2014;152(2):340-8.

95. Shaik S, Singh N, Nicholas A. HPLC and GC analyses of in vitro-grown leaves of the cancer bush Lessertia (Sutherlandia) frutescens $L$. reveal higher yields of bioactive compounds. Plant Cell, Tissue and Organ Culture (PCTOC). 2010;105(3):431-8.

96. Singh RK, Pandey BL, Tripathi M, Pandey VB. Anti-inflammatory effect of (+)-pinitol. Fitoterapia. 2001;72(2):168-70.

97. Lortz S, Tiedge M, Nachtwey T, Karlsen AE, Nerup J, Lenzen S. Protection of insulin-producing RINm5F cells against cytokine-mediated toxicity through overexpression of antioxidant enzymes. Diabetes. 2000;49(7):1123-30.

98. Kaneto H, Fujii J, Myint T, Miyazawa N, Islam KN, Kawasaki Y, et al. Reducing sugars trigger oxidative modification and apoptosis in pancreatic betacells by provoking oxidative stress through the glycation reaction. The Biochemical journal. 1996;320 ( Pt 3):855-63. 
99. Ojewole JA. Anticonvulsant property of Sutherlandia frutescens R. BR. (variety Incana E. MEY.) [Fabaceae] shoot aqueous extract. Brain research bulletin. 2008;75(1):126-32.

100. Ortega A. A new role for GABA: inhibition of tumor cell migration. Trends in pharmacological sciences. 2003;24(4):151-4.

101. Cullinan WE, Ziegler DR, Herman JP. Functional role of local GABAergic influences on the HPA axis. Brain structure \& function. 2008;213(1-2):63-72.

102. Metzeler K, Agoston A, Gratzl M. An Intrinsic gamma-aminobutyric acid (GABA)ergic system in the adrenal cortex: findings from human and rat adrenal glands and the NCl-H295R cell line. Endocrinology. 2004;145(5):2402-11.

103. Hostettmann K, Marston, A. Saponins. Chemistry and pharmacology of natural products. Cambridge: Cambridge University Press; 2005.

104. Oleszek W, Bialy Z. Chromatographic determination of plant saponins--an update (2002-2005). Journal of chromatography A. 2006;1112(1-2):78-91.

105. Vincken JP, Heng L, de Groot A, Gruppen H. Saponins, classification and occurrence in the plant kingdom. Phytochemistry. 2007;68(3):275-97.

106. Lin H, Jackson GA, Lu Y, Drenkhahn SK, Brownstein KJ, Starkey NJ, et al. Inhibition of Gli/hedgehog signaling in prostate cancer cells by "cancer bush" Sutherlandia frutescens extract. Cell biology international. 2016;40(2):131-42.

107. Wu CR, Hseu YC, Lien JC, Lin LW, Lin YT, Ching H. Triterpenoid contents and anti-in $\mathrm{fl}$ ammatory properties of the methanol extracts of ligustrum species leaves. Molecules (Basel, Switzerland). 2010;16(1):1-15.

108. Choi K, Kim M, Ryu J, Choi C. Ginsenosides compound K and Rh(2) inhibit tumor necrosis factor-alpha-induced activation of the NF-kappaB and JNK pathways in human astroglial cells. Neuroscience letters. 2007;421(1):37-41. 
109. Bishayee A, Mandal A, Thoppil RJ, Darvesh AS, Bhatia D.

Chemopreventive effect of a novel oleanane triterpenoid in a chemically induced rodent model of breast cancer. International journal of cancer. 2013;133(5):105463.

110. Crozier A, Jaganath IB, Clifford MN. Dietary phenolics: chemistry, bioavailability and effects on health. Natural product reports. 2009;26(8):1001-43.

111. Funakoshi-Tago M, Ohsawa K, Ishikawa T, Nakamura F, Ueda F, Narukawa $Y$, et al. Inhibitory effects of flavonoids extracted from Nepalese propolis on the LPS signaling pathway. International immunopharmacology. 2016;40:550-60.

112. Shaik S, Singh N, Nicholas A. Comparison of the selected secondary metabolite content present in the cancer-bush Lessertia (Sutherlandia) frutescens L. Extracts. African journal of traditional, complementary, and alternative medicines : AJTCAM. 2011;8(4):429-34.

113. Lei W, Browning JD, Jr., Eichen PA, Brownstein KJ, Folk WR, Sun GY, et al. Unveiling the anti-inflammatory activity of Sutherlandia frutescens using murine macrophages. International immunopharmacology. 2015;29(2):254-62.

114. Masoko P, Mabusa IH, Howard RL. Isolation of alpha-linolenic acid from Sutherlandia frutescens and its inhibition of Mycobacterium tuberculosis' shikimate kinase enzyme. BMC complementary and alternative medicine. 2016;16:366.

115. Braga FC, Kreis W, Récio RA, de Oliveira AB. Variation of cardenolides with growth in a Digitalis lanata Brazilian cultivar. Phytochemistry. 1997;45(3):473-6.

116. Ojewole JA. Analgesic, antiinflammatory and hypoglycemic effects of Sutherlandia frutescens R. BR. (variety Incana E. MEY.) [Fabaceae] shoot aqueous extract. Methods Find Exp Clin Pharmacol. 2004;26(6):409-16. 
117. Lei W, Browning JD, Jr., Eichen PA, Folk WR, Sun GY, Lubahn DB, et al. An Investigation into the Immunomodulatory Activities of Sutherlandia frutescens in Healthy Mice. PLoS One. 2016;11(8):e0160994.

118. Tobwala S, Fan W, Hines CJ, Folk WR, Ercal N. Antioxidant potential of Sutherlandia frutescens and its protective effects against oxidative stress in various cell cultures. BMC complementary and alternative medicine. 2014;14:271.

119. Kundu JK, Mossanda KS, Na HK, Surh YJ. Inhibitory effects of the extracts of Sutherlandia frutescens (L.) R. Br. and Harpagophytum procumbens DC. on phorbol ester-induced COX-2 expression in mouse skin: AP-1 and CREB as potential upstream targets. Cancer letters. 2005;218(1):21-31.

120. Jiang J, Chuang DY, Zong Y, Patel J, Brownstein K, Lei W, et al.

Sutherlandia frutescens ethanol extracts inhibit oxidative stress and inflammatory responses in neurons and microglial cells. PLoS One. 2014;9(2):e89748.

121. Lei W, Browning JD, Jr., Eichen PA, Lu CH, Mossine VV, Rottinghaus GE, et al. Immuno-stimulatory activity of a polysaccharide-enriched fraction of Sutherlandia frutescens occurs by the toll-like receptor-4 signaling pathway. $J$ Ethnopharmacol. 2015;172:247-53.

122. Mills E, Foster BC, van Heeswijk R, Phillips E, Wilson K, Leonard B, et al. Impact of African herbal medicines on antiretroviral metabolism. AIDS (London, England). 2005;19(1):95-7.

123. Bessong PO, Obi CL, Andreola ML, Rojas LB, Pouysegu L, Igumbor E, et al. Evaluation of selected South African medicinal plants for inhibitory properties against human immunodeficiency virus type 1 reverse transcriptase and integrase. J Ethnopharmacol. 2005;99(1):83-91. 
124. Harnett SM, Oosthuizen V, van de Venter M. Anti-HIV activities of organic and aqueous extracts of Sutherlandia frutescens and Lobostemon trigonus. $J$ Ethnopharmacol. 2005;96(1-2):113-9.

125. Korb VC, Moodley D, Chuturgoon AA. Apoptosis-promoting effects of Sutherlandia frutescens extracts on normal human lymphocytes in vitro</i>. South African Journal of Science. 2010;106(1/2).

126. Folk WR, Smith A, Song H, Chuang D, Cheng J, Gu Z, et al. Does Concurrent Use of Some Botanicals Interfere with Treatment of Tuberculosis? Neuromolecular Med. 2016;18(3):483-6.

127. Katerere DR, Eloff JN. Antibacterial and antioxidant activity of Sutherlandia frutescens (Fabaceae), a reputed anti-HIV/AIDS phytomedicine. Phytother Res. 2005;19(9):779-81.

128. Gu Y, Reshetnikova L, Li Y, Wu Y, Yan H, Singh S, et al. Crystal structure of shikimate kinase from Mycobacterium tuberculosis reveals the dynamic role of the LID domain in catalysis. Journal of molecular biology. 2002;319(3):779-89.

129. Stander BA, Marais S, Steynberg TJ, Theron D, Joubert F, Albrecht C, et al. Influence of Sutherlandia frutescens extracts on cell numbers, morphology and gene expression in MCF-7 cells. J Ethnopharmacol. 2007;112(2):312-8.

130. Skerman NB, Joubert AM, Cronje MJ. The apoptosis inducing effects of Sutherlandia spp. extracts on an oesophageal cancer cell line. J Ethnopharmacol. 2011;137(3):1250-60.

131. Lu Y, Starkey N, Lei W, Li J, Cheng J, Folk WR, et al. Inhibition of Hedgehog-Signaling Driven Genes in Prostate Cancer Cells by Sutherlandia frutescens Extract. PLoS One. 2015;10(12):e0145507.

132. Prevoo D, Smith C, Swart P, Swart AC. The effect of Sutherlandia frutescens on steroidogenesis: confirming indigenous wisdom. Endocrine research. 2004;30(4):745-51. 
133. Prevoo $D$, Swart $P$, Swart $A C$. The influence of Sutherlandia frutescens on adrenal steroidogenic cytochrome P450 enzymes. J Ethnopharmacol. 2008;118(1):118-26.

134. Smith C, van Vuuren MJ. Central and peripheral effects of Sutherlandia frutescens on the response to acute psychological stress. Experimental biology and medicine (Maywood, NJ). 2014;239(1):123-8.

135. Sergeant CA, Africander D, Swart $P$, Swart AC. Sutherlandia frutescens modulates adrenal hormone biosynthesis, acts as a selective glucocorticoid receptor agonist (SEGRA) and displays anti-mineralocorticoid properties. J Ethnopharmacol. 2017;202:290-301.

136. Chuang DY, Cui J, Simonyi A, Engel VA, Chen S, Fritsche KL, et al. Dietary Sutherlandia and elderberry mitigate cerebral ischemia-induced neuronal damage and attenuate p47phox and phospho-ERK1/2 expression in microglial cells. ASN Neuro. 2014;6(6).

137. Johnson Q, Syce J, Nell H, Rudeen K, Folk WR. A randomized, doubleblind, placebo-controlled trial of Lessertia frutescens in healthy adults. PLoS Clin Trials. 2007;2(4):e16.

138. Wilson D, Goggin K, Williams K, Gerkovich MM, Gqaleni N, Syce J, et al. Consumption of Sutherlandia frutescens by HIV-Seropositive South African Adults: An Adaptive Double-Blind Randomized Placebo Controlled Trial. PLoS One. 2015;10(7):e0128522.

139. Seier JV, Mdhluli M, Dhansay MA, Loza J, Laubscher R. A toxicity study of Sutherlandia leafpowder (Sutherlandia microphylla) consumption. Medical Research Council of South Africa and National Research Foundation; 2002.

140. Lipinski CA. Lead- and drug-like compounds: the rule-of-five revolution. Drug discovery today Technologies. 2004;1(4):337-41. 
141. Thwaites DT, Basterfield L, McCleave PM, Carter SM, Simmons NL. Gamma-Aminobutyric acid (GABA) transport across human intestinal epithelial (Caco-2) cell monolayers. Br J Pharmacol. 2000;129(3):457-64.

142. Murata $Y$, Ogawa T, Suzuki YA, Yoshikawa S, Inui H, Sugiura M, et al. Digestion and absorption of Siraitia grosvenori triterpenoids in the rat. Bioscience, biotechnology, and biochemistry. 2010;74(3):673-6.

143. Christensen LP. Ginsenosides chemistry, biosynthesis, analysis, and potential health effects. Advances in food and nutrition research. 2009;55:1-99.

144. Gu Y, Wang GJ, Sun JG, Jia YW, Wang W, Xu MJ, et al. Pharmacokinetic characterization of ginsenoside $\mathrm{Rh} 2$, an anticancer nutrient from ginseng, in rats and dogs. Food Chem Toxicol. 2009;47(9):2257-68.

145. Tang Z, Li G, Yang J, Duan J, Qian D, Guo J, et al. Anemarrhena asphodeloides Non-Steroidal Saponin Components Alter the Pharmacokinetic Profile of Its Steroidal Saponins in Rat. Molecules (Basel, Switzerland). 2015;20(7):11777-92.

146. Krishnaiah YSR. Pharmaceutical Technologies for Enhancing Oral Bioavailability of Poorly Soluble Drugs. Journal of Bioequivalence \& Bioavailability. 2010;02(02).

147. Salmaso S, Bersani S, Elvassore N, Bertucco A, Caliceti P. Biopharmaceutical characterisation of insulin and recombinant human growth hormone loaded lipid submicron particles produced by supercritical gas microatomisation. Int J Pharm. 2009;379(1):51-8.

148. Keck CM, Muller RH. Drug nanocrystals of poorly soluble drugs produced by high pressure homogenisation. European journal of pharmaceutics and biopharmaceutics : official journal of Arbeitsgemeinschaft fur Pharmazeutische Verfahrenstechnik eV. 2006;62(1):3-16. 
149. Kesisoglou F, Panmai S, Wu Y. Nanosizing--oral formulation development and biopharmaceutical evaluation. Advanced drug delivery reviews. 2007;59(7):631-44.

150. Blagden N, de Matas M, Gavan PT, York P. Crystal engineering of active pharmaceutical ingredients to improve solubility and dissolution rates. Advanced drug delivery reviews. 2007;59(7):617-30.

151. Brewster ME, Loftsson T. Cyclodextrins as pharmaceutical solubilizers. Advanced drug delivery reviews. 2007;59(7):645-66.

152. Zatu MC, van Rooyen JM, Loots du T, Greeff M, Schutte AE. A comparison of the cardiometabolic profile of black South Africans with suspected non-alcoholic fatty liver disease (NAFLD) and excessive alcohol use. Alcohol. 2015;49(2):165-72.

153. Dowman JK, Tomlinson JW, Newsome PN. Pathogenesis of non-alcoholic fatty liver disease. QJM: An International Journal of Medicine. 2010;103(2):71-83.

154. Shay KP, Moreau RF, Smith EJ, Smith AR, Hagen TM. Alpha-lipoic acid as a dietary supplement: molecular mechanisms and therapeutic potential. Biochim Biophys Acta. 2009;1790(10):1149-60.

155. Smith AR, Shenvi SV, Widlansky M, Suh JH, Hagen TM. Lipoic acid as a potential therapy for chronic diseases associated with oxidative stress. Current medicinal chemistry. 2004;11(9):1135-46.

156. Scott BC, Aruoma OI, Evans PJ, O'Neill C, Van der Vliet A, Cross CE, et al. Lipoic and dihydrolipoic acids as antioxidants. A critical evaluation. Free radical research. 1994;20(2):119-33.

157. Sharp PE, LaRegina MC. The Laboratory Rat. : Boca Raton: CRC Press; 1998. 
158. Penney DP, Powers JM, Frank M, Willis C, Churukian C. Analysis and testing of biological stains--the Biological Stain Commission Procedures. Biotech Histochem. 2002;77(5-6):237-75.

159. Schindelin J, Arganda-Carreras I, Frise E, Kaynig V, Longair M, Pietzsch T, et al. Fiji: an open-source platform for biological-image analysis. Nature methods. 2012;9(7):676-82.

160. Ruifrok AC, Johnston DA. Quantification of histochemical staining by color deconvolution. Analytical and quantitative cytology and histology. $2001 ; 23(4): 291-9$.

161. Ismail TA, Soliman MM, Nassan MA. Molecular and immunohistochemical effects of metformin in a rat model of type 2 diabetes mellitus. Exp Ther Med. 2015;9(5):1921-30.

162. Kim SM, Lee B, An HJ, Kim DH, Park KC, Noh SG, et al. Novel PPARalpha agonist MHY553 alleviates hepatic steatosis by increasing fatty acid oxidation and decreasing inflammation during aging. Oncotarget. 2017;8(28):46273-85.

163. Vieira-Potter VJ, Padilla J, Park YM, Welly RJ, Scroggins RJ, Britton SL, et al. Female rats selectively bred for high intrinsic aerobic fitness are protected from ovariectomy-associated metabolic dysfunction. Am J Physiol Regul Integr Comp Physiol. 2015;308(6):R530-42.

164. Livak KJ, Schmittgen TD. Analysis of relative gene expression data using real-time quantitative PCR and the 2(-Delta Delta $C(T)$ ) Method. Methods. $2001 ; 25(4): 402-8$.

165. Wendel AA, Belury MA. Effects of conjugated linoleic acid and troglitazone on lipid accumulation and composition in lean and Zucker diabetic fatty (fa/fa) rats. Lipids. 2006;41(3):241-7. 
166. Stringer DM, Zahradka P, Declercq VC, Ryz NR, Diakiw R, Burr LL, et al. Modulation of lipid droplet size and lipid droplet proteins by trans-10,cis-12 conjugated linoleic acid parallels improvements in hepatic steatosis in obese, insulin-resistant rats. Biochim Biophys Acta. 2010;1801(12):1375-85.

167. Bertolotti M, Lonardo A, Mussi C, Baldelli E, Pellegrini E, Ballestri S, et al. Nonalcoholic fatty liver disease and aging: epidemiology to management. World journal of gastroenterology. 2014;20(39):14185-204.

168. Tarantino G, Savastano S, Colao A. Hepatic steatosis, low-grade chronic inflammation and hormone/growth factor/adipokine imbalance. World journal of gastroenterology. 2010;16(38):4773-83.

169. Angulo P. Nonalcoholic fatty liver disease. N Engl J Med. 2002;346(16):1221-31.

170. Marchesini G, Bugianesi E, Forlani G, Cerrelli F, Lenzi M, Manini R, et al. Nonalcoholic fatty liver, steatohepatitis, and the metabolic syndrome. Hepatology. 2003;37(4):917-23.

171. Walther TC, Farese RV, Jr. The life of lipid droplets. Biochim Biophys Acta. 2009;1791(6):459-66.

172. Brasaemle DL, Wolins NE. Packaging of fat: an evolving model of lipid droplet assembly and expansion. J Biol Chem. 2012;287(4):2273-9.

173. Pirola L, Johnston AM, Van Obberghen E. Modulation of insulin action. Diabetologia. 2004;47(2):170-84.

174. Kleinert M, Clemmensen C, Hofmann SM, Moore MC, Renner S, Woods SC, et al. Animal models of obesity and diabetes mellitus. Nat Rev Endocrinol. 2018;14(3):140-62. 
175. Yoon M. The role of PPARalpha in lipid metabolism and obesity: focusing on the effects of estrogen on PPARalpha actions. Pharmacol Res. 2009;60(3):151-9.

176. Yoon M. PPARalpha in Obesity: Sex Difference and Estrogen Involvement. PPAR Res. 2010;2010.

177. Rakhshandehroo M, Hooiveld G, Muller M, Kersten S. Comparative analysis of gene regulation by the transcription factor PPARalpha between mouse and human. PLoS One. 2009;4(8):e6796.

178. Rakhshandehroo M, Sanderson LM, Matilainen M, Stienstra R, Carlberg $\mathrm{C}$, de Groot PJ, et al. Comprehensive analysis of PPARalpha-dependent regulation of hepatic lipid metabolism by expression profiling. PPAR Res. 2007;2007:26839.

179. Hardwick JP. Cytochrome P450 omega hydroxylase (CYP4) function in fatty acid metabolism and metabolic diseases. Biochemical pharmacology. 2008;75(12):2263-75.

180. Simpson AE. The cytochrome P450 4 (CYP4) family. General pharmacology. 1997;28(3):351-9.

181. Aleksunes LM, Klaassen CD. Coordinated regulation of hepatic phase I and II drug-metabolizing genes and transporters using AhR-, CAR-, PXR-, PPARalpha-, and Nrf2-null mice. Drug metabolism and disposition: the biological fate of chemicals. 2012;40(7):1366-79.

182. Zhang $\mathrm{Y}$, Klaassen CD. Hormonal regulation of Cyp4a isoforms in mouse liver and kidney. Xenobiotica; the fate of foreign compounds in biological systems. 2013;43(12):1055-63.

183. Horton JD, Goldstein JL, Brown MS. SREBPs: activators of the complete program of cholesterol and fatty acid synthesis in the liver. $\mathrm{J}$ Clin Invest. 2002;109(9):1125-31. 
184. Ide T. Effect of dietary alpha-lipoic acid on the mRNA expression of genes involved in drug metabolism and antioxidation system in rat liver. $\mathrm{Br} \mathrm{J}$ Nutr. 2014;112(3):295-308.

185. Ide T, Azechi A, Suzuki N, Kunimatsu Y, Nakajima C, Kitade S. Effects of dietary a-lipoic acid enantiomers on hepatic fatty acid metabolism in rats. Journal of Functional Foods. 2013;5(1):71-9.

186. Song KH, Lee WJ, Koh JM, Kim HS, Youn JY, Park HS, et al. alpha-Lipoic acid prevents diabetes mellitus in diabetes-prone obese rats. Biochemical and biophysical research communications. 2005;326(1):197-202.

187. Yang Y, Li W, Liu Y, Sun Y, Li Y, Yao Q, et al. Alpha-lipoic acid improves high-fat diet-induced hepatic steatosis by modulating the transcription factors SREBP-1, FoxO1 and Nrf2 via the SIRT1/LKB1/AMPK pathway. J Nutr Biochem. 2014;25(11):1207-17.

188. Botezelli JD, Coope A, Ghezzi AC, Cambri LT, Moura LP, Scariot PP, et al. Strength Training Prevents Hyperinsulinemia, Insulin Resistance, and Inflammation Independent of Weight Loss in Fructose-Fed Animals. Sci Rep. 2016;6:31106.

189. de Moura LP, Sponton AC, de Araujo MB, Dalia RA, Pauli JR, Rostom de Mello MA. Moderate physical activity from childhood contributes to metabolic health and reduces hepatic fat accumulation in adult rats. Lipids in health and disease. 2013;12:29.

190. Keating SE, Hackett DA, Parker HM, O'Connor HT, Gerofi JA, Sainsbury $A$, et al. Effect of aerobic exercise training dose on liver fat and visceral adiposity. Journal of hepatology. 2015;63(1):174-82.

191. Linden MA, Sheldon RD, Meers GM, Ortinau LC, Morris EM, Booth FW, et al. Aerobic exercise training in the treatment of non-alcoholic fatty liver disease related fibrosis. The Journal of physiology. 2016;594(18):5271-84. 
192. Pereira RM, Botezelli JD, da Cruz Rodrigues KC, Mekary RA, Cintra DE, Pauli JR, et al. Fructose Consumption in the Development of Obesity and the Effects of Different Protocols of Physical Exercise on the Hepatic Metabolism. Nutrients. 2017;9(4). 


\section{VITA}

Nhu Nguyen was born in Ho Chi Minh City (HCMC, former name: Saigon), Vietnam on September $8^{\text {th }}, 1986$. After completing her senior high school in one of the top classes for the gifted in natural science, Nhu attended the International University (IU) - a member of the Vietnam National University in HCMC, Vietnam - to pursue a degree in Biotechnology with a focus on biomedical science and obtained her Bachelor's degree in 2010. IU was the first and only university in the southern of Vietnam to employ English as the main language of instruction at that time. Nhu had a precious opportunity to do her internship under supervision of Dr. Sarah Dunstan - group head in human genetics - at the Oxford University Clinical Research Unit (OUCRU) (based in the Hospital for Tropical Diseases in $\mathrm{HCMC}$ ) during the last six months of her undergraduate studies. After completing her Bachelor's, Nhu worked with Dr. Thuy Le - group leader in HIV research at the OUCRU-HCMC - and with Dr. Peter Horby - former Director of the OUCRUHanoi for about two years. Nhu has two peer-reviewed publications on the systematic review of the role of host genetics in susceptibility to influenza with Dr. Horby.

Although there were opportunities for Nhu to conduct doctoral research at the OUCRU, she decided to challenge herself to pursue her Ph.D. in complementary and alternative medicine using medicinal plants - a research area different from her previous training and background - in Dr. William Folk's biochemistry laboratory at the University of Missouri in Columbia, Missouri 
starting in August 2012. Part of her financial support for this Ph.D. training was from a two-year fellowship granted by the Vietnam Education Foundation - an independent U.S. Federal Government agency established in 2000 by the U.S. Congress to consolidate the bilateral relationship between the United States and Vietnam through educational exchange in the Science, Technology, Engineering, Mathematics, and Medicine disciplines. This fellowship program based on a national competition offered a unique and tremendous opportunity for young aspiring Vietnamese students to fulfill their academic career goals.

Nhu's initial project was about investigating the effects of Sutherlandia frutescens - a southern African herb - on neurocognitive dysfunction in HIV transgenic rats. At the end of 2015 , due to changes in funding and her growing interest in molecular nutrition and metabolism, she shifted her focus, with agreement from her Ph. D. adviser and Committee, to do research on the impact of Sutherlandia frutescens on fatty liver of high-fat fed rats. During her training at the University of Missouri, she presented multiple posters and received positive feedback at several local and international conferences. Nhu completed her doctoral training and earned her Ph.D. in July 2018. 